\title{
EXAMINING THE IMPACT OF MORAL IMAGINATION ON ORGANIZATIONAL DECISION-MAKING
}

\author{
by \\ LINDSEY NICOLE GODWIN \\ Submitted in partial fulfillment of the requirements \\ For the degree of Doctor of Philosophy \\ Dr. Ronald Fry, Chair \\ Dr. David Cooperrider \\ Dr. David Kolb \\ Dr. Peter Whitehouse \\ Department of Organizational Behavior \\ CASE WESTERN RESERVE UNIVERSITY
}

May, 2008 


\title{
SCHOOL OF GRADUATE STUDIES
}

We hereby approve the thesis/dissertation of

\author{
Lindsey Nicole Godwin
}

candidate for the Doctor of Philosophy degree *.

\author{
Dr. Ronald Fry \\ (chair of the committee) \\ Dr. David Cooperrider
}

Dr. David Kolb

Dr. Peter Whitehouse

March 31, 2008

*We also certify that written approval has been obtained for any proprietary material contained therein. 
Copyright (C 2008 by Lindsey Nicole Godwin All rights reserved 


\section{DEDICATION}

For Adam Paul whose youthful innocence and ever-unfolding potential reminds me that the world is still a beautiful place that is just waiting to be discovered anew everyday. For Matthew who gives me steadfast strength, unending love, and the encouragement to believe that one person can make a difference, but also shows me everyday what happens when you "multiple life by the power of two." 


\section{TABLE OF CONTENTS}

$\begin{array}{ll}\text { LIST OF TABLES } & 7\end{array}$

$\begin{array}{ll}\text { LIST OF FIGURES } & 9\end{array}$

$\begin{array}{ll}\text { PREFACE } & 10\end{array}$

$\begin{array}{ll}\text { ACKNOWLEDGEMENTS } & 12\end{array}$

$\begin{array}{ll}\text { DEFINITION OF TERMS } & 13\end{array}$

$\begin{array}{ll}\text { ABSTRACT } & 15\end{array}$

$\begin{array}{ll}\text { CHAPTER 1: INTRODUCTION } & 17\end{array}$

1.1 Research Opportunity and Purpose Statement 25

1.2 Organization of the Dissertation 27

CHAPTER 2: LITERATURE REVIEW AND HYPOTHESES 28

2.1: Mutually Beneficial Decision Making in Business 28

2.2: Defining Moral Imagination 33

2.3: Moral Awareness: The Ability to Discern Moral Issues 37

2.4: Creativity and Imagination: The Ability to Envision Possibilities 42

2.5: Moral Imagination: Greater than the Sum of it Parts 45

2.6: Factors Potentially Impacting Moral Imagination $\quad 46$

2.7: Hypotheses Summary and Model 58

CHAPTER 3: RESEARCH DESIGN AND METHODOLOGY 61

3.1: Procedures 61

3.2: Participants 65

3.3: Independent Variable: Assessing Moral Imagination 67

3.4: Dependent Variable: Assessing Decision-Making Outcomes 75

3.5: Assessment of Factors Impacting Moral Imagination 79

3.6: Validity and Reliability of Measures $\quad 82$

3.7: Social Desirability Check 94

CHAPTER 4: RESULTS 95

4.1 Review of Theoretical Model 95

4.2 Hypotheses Testing 96

4.3 Post-hoc Exploratory Analysis 104

CHAPTER 5: DISCUSSION AND CONCLUSIONS 120 
5.1 Discussion and Findings of Results $\quad 120$

$\begin{array}{ll}\text { 5.2 Limitations } & 130\end{array}$

5.3 Implications for Practice, Education and Future Research 133

$\begin{array}{ll}\text { APPENDIX A: SURVEY INSTRUMENT } & 142\end{array}$

APPENDIX B: MORAL AWARENESS SCORING RUBRIC 150

$\begin{array}{ll}\text { REFERENCES } & 151\end{array}$ 


\section{LIST OF TABLES}

Table 1: An Integrated Framework for Altruism and Self-Interest 32

Table 2: Moral Imagination Scoring Calculation Example 72

Table 3: Descriptive Statistics for Moral Imagination Dimensions 73

Table 4: Correlation Matrix for Issue Awareness, Impact Awareness, $\quad 74$ Fluency, Flexibility

Table 5: Frequencies of Moral Imagination Groupings 75

Table 6: Coding Rubric for Moral Imagination and Decision-Making Outcome 77

Table 7: Frequencies of Type of Decision-Making Outcome 79

Table 8: Inter-rater Reliability Coefficients by Scenario 83

Table 9: Mean differences for Fluency and Flexibility by Vignette 84

Table 10: Mean differences for Social Benefit by Vignette 84

Table 11: Descriptive Statistics for the Moral Awareness Measures 89

Table 12: Correlation Matrix for Moral Awareness and Discerning 91

Table 13: Correlation Matrix for Creativity, Developing, Fluency and Flexibility 93

Table 14: Discerning Averages by Type of Decision-Making Outcome 97

Table 15: Developing Averages by Type of Decision-Making Outcome 98

Table 16: Decision-making Outcome by Moral Imagination Group 100

Table 17: Gender by Type of Decision-Making Outcome 106

Table 18: Mean Discerning and Developing Scores by Gender 107

Table 19: Gender by Moral Imagination Group 108

Table 20: Age Group by Type of Decision-Making Outcome 109

Table 21: Mean Discerning and Developing Scores by Age Group 111

Table 22: Moral Imagination Group by Age Group 112 
Table 23: Mean years of work experience by type of decision-making outcome 114

Table 24: Years of Work Experience by Moral Imagination Group 114

Table 25: Correlations for Discerning, Developing and Yrs. Work Exp. 115

Table 26: Net Impact Member ship by Type of Decision-Making Outcome 116

Table 27: Moral Imagination group by Net Impact Membership 117

Table 28: Discerning and Developing Scores by Net Impact Membership 119

Table 29: An Expanded Framework for Moral Imagination 136 


\section{LIST OF FIGURES}

Figure 1: An Integrated conception of Altruism and Self-Interest

$22 ; 96$

Figure 2: Proposed Model for Moral Imagination and Mutually Beneficial

60

Decision-Making

Figure 3: Expanded Conceptual Model

Figure 4: Dimensions and Degrees of Mutual Benefit 


\section{PREFACE}

Before delving into my current study, it is first important to take a moment and trace the experiences and ideas that led me to even conduct this inquiry. The seeds of this dissertation were planted on June 24, 2004. While just days before I found myself sitting in a hospital room with my father who was recovering from a heart-attack, on the $24^{\text {th }}$ of June, I was sitting in the General Assembly Hall of the United Nations, listening to Kofi Annan declare with his distinct timbre, "Let us choose to unite the strengths of markets with the power of universal ideals, let us choose to reconcile the forces of private entrepreneurship with needs of the disadvantaged and the well-being of future generations." I was there as part of the team of students from Case Western Reserve University working with Dr. David Cooperrider to support his facilitation of the largest meeting ever held between the UN and leaders of business, non-profit and governmental agencies. This historic gathering of nearly 1000 organizational leaders was aimed at exploring the next phases of global corporate citizenship and offered a rare opportunity for CEOs of top companies like BP, Hewlett Packard, Nokia, Microsoft, to sit together and share as peers their successes and challenges with social responsibility efforts. Listening to the dialogues throughout the day, I realized that the conversations were not asking, "Should we be trying to create mutually beneficial outcomes through our business actions?" but rather were more focused on the question, "How can we create mutual benefit?"

This shift in conversation was particularly interesting to me and represented an important movement in the world of business practice toward an implicit acceptance of mutual benefit as the fundamental purpose of business. As a doctoral student who was 
studying social responsibility in business, I had been steeped in current academic theory and research on the subject, which had yet to resolve the question about the purpose of business. Yet sitting there among some of the business leaders in the world, I that they were not waiting for the academic world to settle the ongoing debate over the purpose of business, rather they were moving ahead at full speed with the intentions of creating benefit for both their company and wider society. They just wanted to find the best practices for doing such.

This realization became even more poignant in conjunction with my experiences just 72 hours prior, when I reminded once again of the fragility of life after my dad's survival of a potentially fatal heart blockage. I decided then and there that I while could use my energy as a scholar to engage in the ongoing argument on whether or not business should be engaged in social efforts and work to bring about positive social change, life was too short. Rather than spend a career trying to prove something that in my heart I already believed to be true, I decided to begin my inquiry building on the assumption that indeed businesses should be creating mutual benefit. This decision led me to a new stream of research that explores the nature of mutually beneficial decision-making in business, what impacts it, and how can we foster it? This dissertation represents my initial step toward trying to answer such questions. 


\section{ACKNOWLEDGEMENTS}

I would like to first acknowledge the great minds that inspired my current inquiry. Although we have not met, I would like to thank Patricia Werhane and Mark Johnson whose writings on moral imagination first sparked my own imagination. I would also like to acknowledge the inspiration I found in Jennifer Jordan's work on moral awareness, which helped provide a foundation for me to explore moral imagination. Also to the host of other scholars I site herein, I thank you for your contributions to the pool of knowledge in which I now enjoy swimming.

I would also like to thank all the special souls in my life who have made this dissertation possible. First, to Ron Fry I say thank you for always believing a gal from the hills can do good work, and making sure that I do! Your patience, humor, and guidance are the reason this work has progressed from an initial inkling to an actual dissertation. To David Kolb, thank you for your generous mind and kind heart that were always willing to engage so fully with my work. To Peter Whitehouse, thank you for your unending energy, curiosity and encouragement to get me to think like a mountain. To David Cooperrider, thank you for teaching me to see the world through appreciative eyes and to see the promise that lies not only in others, but within myself.

Special thanks to my parents whose unending query, "Is your paper done?" reminded me they were also passengers on my academic journey. Thanks also to my inlaws who were sure I would finish school, “one day....”! Special thanks to my dear friend MG who never stopped being my cheerleader, to GP and CB who provided the unconditional love for me to keep writing at 3 a.m., and the biggest thanks of all to my husband, Matt, who makes everything I do possible. It's your turn now. 


\section{DEFINITION OF TERMS}

The following definitions will be used for terms and concepts central to this thesis:

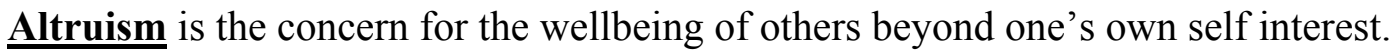

Developing is the ability to generate a range of alternative solutions to the situation from a moral perspective; synonymous with divergent/creative thinking.

Discerning is the ability to recognize the moral aspects within a situation; synonymous with moral awareness.

Divergent Thinking is one's ability to generate diverse and novel approaches to a situation; used as a proxy for creative thinking.

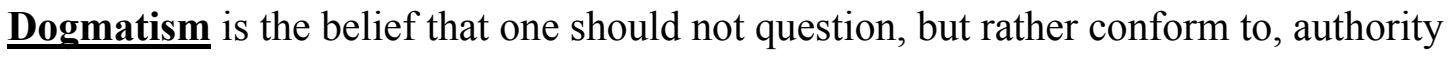
(be it religious, governmental, or another form of authority).

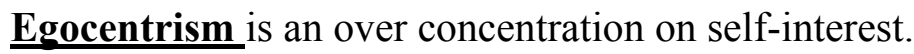

Empathy is the ability to imagine oneself in another person's situation.

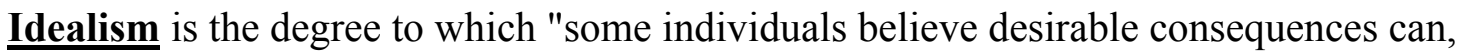
with the 'right' action, always be obtained" (Forsyth 1980 p. 176).

Imagination (or creativity) is an individual's ability to envision possibilities that do not currently exist.

Moral Awareness is "a person's recognition that his or her potential decisions or actions could affect the interests, welfare, or expectations of the self or others in a fashion that may conflict with one or more ethical standards" (Butterfield, Trevino, and Weaver, 2000, p. 982). 
Moral Imagination is the ability to discern the moral aspects embedded within a situation and develop a range of alternative solutions to the situation from a moral perspective.

Moral Development is the process through which individuals develop moral reasoning and morally based attitudes and behaviors toward others.

Mutual Benefit is where "business organizations are both profitable and functional for the common good - a position of integrated strategic focus on both organizational selfinterests and stakeholder interests" (Bright, Fry, and Cooperrider, 2006, p. 20).

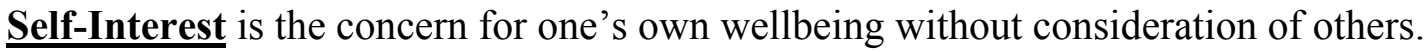
Stakeholders any entity beyond a business which is impacted by the actions of the business, can include individuals, groups, other organizations, communities and the natural environment.

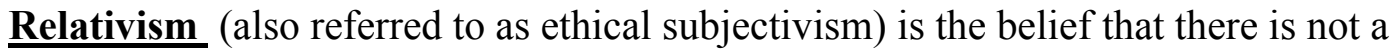
universal set of rules to guide moral behavior. 
Examining the Impact of Moral Imagination on Organizational Decision-Making

\author{
Abstract \\ by \\ LINDSEY NICOLE GODWIN
}

In the wake of the media attention given to recent tales of bad behavior within business, the dominant question asked seems to be, "Why do some business leaders make such bad moral decisions?" Yet there are many organizations where leaders act in moral and creative ways, making business decisions that lead to both increased profits and wider social benefit. While such examples are not apt to make headlines, they are reminders that in addition to understanding what goes wrong with some business leaders' decision making, it is just as important to ask: "Why do some business leaders make good moral decisions which result in mutual benefit to the company and wider society?" The overarching purpose of this dissertation is to explore that very question.

Building on the work of Werhane (1999, 1998), Johnson (1993), and others, I argue that one critical key to solving this question is a better understanding of moral imagination in organizational decision-making. Werhane defines moral imagination as, "the ability to understand a context or set of activities from a number of different perspectives, the actualizing of new possibilities that are not context-dependent, and the instigation of the process of evaluating those possibilities from a moral point of view" (1999, p. 5).

Using a new vignette-based cognitive measure for moral imagination, this dissertation provides one of the first empirical explorations of moral imagination as a 
theoretical construct and its relationship to mutually beneficial decision-making in business. Overall, findings from 180 respondents supported the hypothesis that individuals who exercise moral imagination, including the ability for discerning moral issues and developing a range of possible outcomes during the decision-making process, are indeed more likely to generate a mutually beneficial outcome for a situation compared to those who do not exercise moral imagination. 


\section{CHAPTER 1 \\ INTRODUCTION}

\section{We have always known that heedless self-interest was bad morals; we know now that it is also bad economics. \\ $\sim$ Franklin Delano Roosevelt}

Images flashing across the evening news of business executives led away in handcuffs offer real-life examples of the consequences of separating corporate and social values from each other. Over the past several years, a myriad of corporations have faced dramatic falls from the public grace with a number of executives found guilty of fraud and conspiracy. Enron, for example, was once touted as one of America's "most admired companies" 1 , but was forced to declare bankruptcy in 2001 following the revelation of fraudulent accounting practices that permeated the company (Pasha and Seid, 2006). Enron has since become an infamous character in the grand drama of business, emerging throughout the public zeitgeist as a symbol of problems with corporate greed and moral impropriety (CNN, 2006; ABC News, 2006). Unfortunately, Enron's story is only one example of recent corporate scandals that have ruptured not only public trust in corporations, but also the bank accounts of investors and employees alike (CBS News, 2002; PBS, 2002).

In the wake of the media attention given to these tales of bad behavior within the upper echelons of various companies, the dominant question asked seems to be, "Why do some business leaders make such bad moral decisions?" (e.g. Estes, 1996; Charan \& Colvin, 1999; Minkes, Small and Chatterjee, 1999; Kellerman, 2004; Jordan, 2005). In response, many have suggested that the "bad apples" within these companies, many who

\footnotetext{
${ }^{1}$ Enron was named No. 1 for "Innovativeness" and No. 2 for "quality of management" in Fortune Magazine's February 2001 ranking of America's most admired companies (ABC News, 2006).
} 
are now facing prison terms, are not morally bankrupt or ethically challenged individuals, but rather they became trapped by limited conceptual schema (Trevino \& Brown, 2004;

Jordan, 2005). Werhane (1999) elaborates on this theory:

What is evident, then in these cases [where business acted in a morally questionable manner] is not weak moral development, a failure of moral character, or lack of understanding what is right and wrong, but rather a setting aside of moral considerations in the pace of business activities... Most individual managers are not without moral sensibilities or values, nor are they motivated merely by greed or even self-interest, nor are most managers at a low level of moral development... Nevertheless in many situations managers have a narrow perspective on their situation and little in the way of moral imagination... or lack a sense of the variety of possibilities and moral consequences of their decisions, as well as the ability to imagine a wide range of possible issues, consequences and solutions. Some individuals and institutions are trapped in the framework of history, organization, corporate culture, and tradition that drives their decisionmaking to preclude taking into account moral concerns...” (p. 11)

Yet there are leaders who do not get caught in this faulty cognitive trap when making business decisions, whose vision for possibility is not narrow, and who are able to generate morally sound solutions that benefit both their company and other stakeholder groups. Take for instance companies like Seventh Generation ${ }^{2}$, Fuji Xerox ${ }^{3}$, or Green Mountain Coffee Roasters ${ }^{4}$. Although a scan of the headlines (or social consciousness) for companies like these are still likely to generate limited results, they are examples of organizations where leaders have acted in moral and creative ways, making business decisions that led to both increased profits and wider social benefit (World Inquiry,

\footnotetext{
${ }^{2}$ Seventh Generation is the leading brand of non-toxic household products whose company strategy is taken from the Native American saying, "in our every deliberation we must consider the impact of our decisions on the next seven generations."

${ }^{3}$ Fuji Xerox has a mission to become a 'zero footprint' company, meaning that they do not make any waste that will go to landfill. For example, their factories in China they have begun to recycle almost $100 \%$ of its resources.

${ }^{4}$ Green Mountain Coffee Roasters was ranked No. 1 on Business Ethics magazine's 2006 list of the "100 best Corporate Citizens'. They are one of the top producers of double certified - organic and fair trade - coffee. To better promote an understanding of interdependence within the supply chain, each year the company takes a group of employees, customers, and partners for a "trip to the origin" to engage with the actual coffee growers. These trips have helped create new mutually beneficial policies, methods, and approaches to coffee production.
} 
2006). Such examples are reminders that in addition to understanding what goes wrong with some business leaders' decision making, it is just as important to ask: "Why do some business leaders make good moral decisions which result in mutual benefit to the company and wider society?" The overarching purpose of this dissertation is to explore that very question.

Before I attempt to answer this question, though, I will first begin by providing a context for my inquiry by briefly reviewing the concept of mutual benefit in organizational decision-making as well as the growing demand for leaders who are able to create mutually beneficial organizational outcomes.

\section{The Call of the Times for Business: Creating Mutually Beneficial Outcomes}

As illustrated by the stark differences between some executives' actions at Enron, and those at say Green Mountain Coffee Roasters, it has been well established that leaders can run their organizations with differing levels of self-interest and consideration for the social consequences of their business decisions (Carroll, 1987). While negative social behaviors are more likely to generate headlines, there are a growing number of examples of the ways businesses are in fact acting as agents of "mutual benefit" in society, with both the business and wider society profiting from the businesses' activities (World Inquiry, 2006). Bright, Fry and Cooperrider (2006) define mutual benefit as actions "where business organizations are both profitable and functional for the common good - a position of integrated strategic focus on both organizational self-interests and stakeholder interests" (Bright, Fry, and Cooperrider, 2006, p. 20). 
The idea of creating mutual benefit is becoming a core part of many companies' business strategy. Take for example a recent survey of all U.S. Chamber of Commerce members, sponsored by the Boston Center for Corporate Citizenship (2005), which showed that of the 1200 responding top-level business leaders, $81 \%$ said that it was vitally important for business to address social issues, and $84 \%$ of large-business leaders saw social initiatives as helping profitability. Different analyses of business outcomes are also suggesting that those companies who "do good" (i.e. working to balance profits and social impact) are also doing well financially (Margolis and Walsh, 2001; Paine, 2003). Perhaps because of the recent corporate scandals, there is also mounting data suggesting that consumers and investors also increasingly expect companies to act in ways that are mutually beneficial to both the financial bottom line as well as a wider array of stakeholders beyond the business (Jackson and Nelson, 2004; Paine, 2003).

Despite the growing desire for - and evidence that - companies are acting as agents of mutual benefit, general public opinion seems to be that companies are greedy entities which make decisions only in their self interest, even at the cost of greater public welfare (i.e. Paul, 2002; Shannon \& Berl, 1997). In addition to the media sensationalism given to various $\mathrm{CEO}$ indictments, the discourse in management and social sciences may also be fueling this negative personification of business. As Ghoshal recently pointed out, although today's management theories are informed by a wide variety of disciplines, "they have increasingly converged on a pessimistic view of human nature, on the role of companies in society, and of the process of corporate adaptation and change" (2005, p. 82). Indeed, within the social science theories, selfishness and altruism are often depicted as polar opposites, suggesting that individuals (and by extension companies) 
must choose between self-interest and helping others (Hinman, 2005). Coupled with the tendency to portray altruism and selfishness as contradictory behaviors, research has also neglected to fully explore altruism. Instead, "science has largely focused on human deficits rather than on the positive side of our nature" (Post, 2003, p. xi). In his work on Unlimited Love, Post quotes Pitirim Sorokin, who sums up this reality by stating:

We have studied the negative types of human beings sufficiently - the criminal, the insane, the sinning, ... and the selfish. But we have neglected the investigation of positive types of Homo sapiens - the creative genius, the saint, the "good neighbor." We know a great deal about the general characteristics of the subsocial types. But we know precious little of the general or typical properties of creative persons. What, if any, are the typical characteristics of altruistic persons? $(2003$, p. $x)$

The dichotomous paradigm of altruism versus self-interest, and the myopic focus social science has on deficit-based theories has predominated the study and practice of business strategy for some time. Such thinking has reinforced the idea that if a company acts in societal interests it is acting against its own interests and vice versa, and (perhaps unknowingly) prevented us from exploring the nature of altruism in the business context. Yet, streams of emerging work are now suggesting that this may be a false dichotomy, opening the door to explore the nature of altruism in the business world (i.e. Rocha and Ghoshal, 2006; Paine 2003; Cameron, 2003: Margolis and Walsh, 2004). Instead of seeing the characteristics of self-interest and altruism as two anchors of a single scale, where movement toward one trait represents movement away from the other, these traits can be re-conceptualized as two independent, yet interactive, variables. As illustrated in Figure 1, a graphical representation of this interactivity results in a framework that suggests a much wider typology of possible behavioral outcomes than just altruism or 
self-interest (based on Hinnman, 2005). The resulting model has application at several levels of analysis, from an individual leader's behaviors to entire corporate strategies.

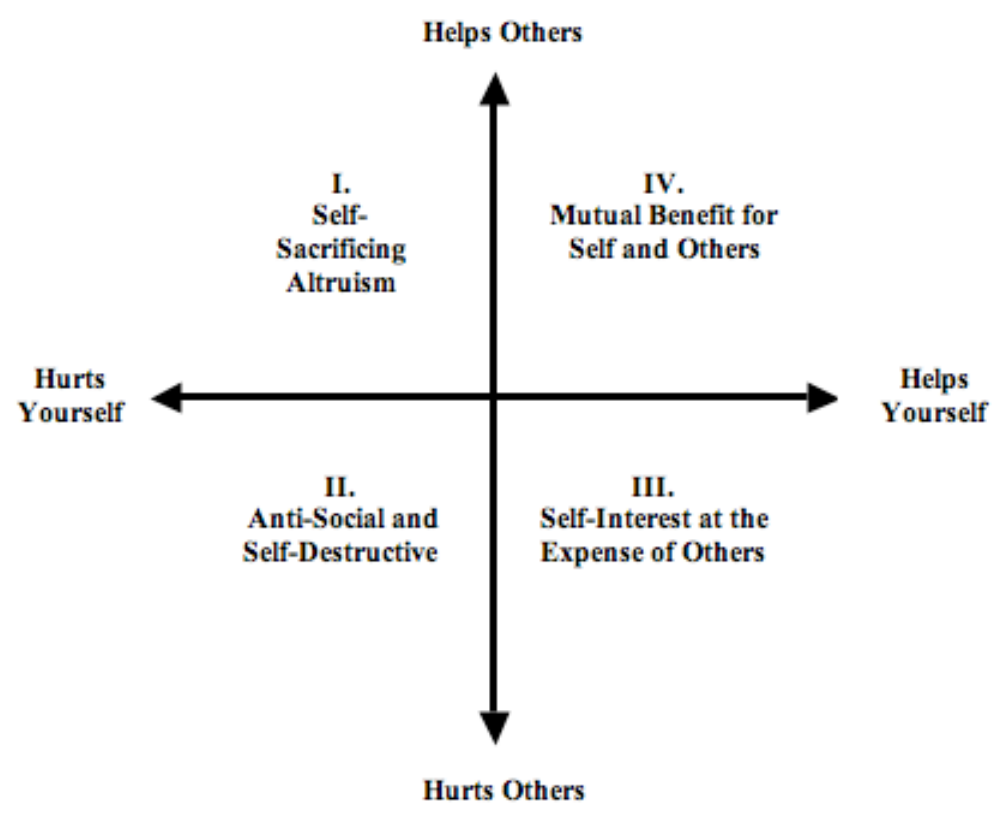

Figure 1: An integrated conception of altruism and self-interest (Modeled after Hinman, 2005)

Applying this model as a diagnostic to the business world, one can begin to map leaders according to where their actions fall on these two dimensions. For example, various decisions by executives at Enron to engage in fraudulent behavior could be categorized as Quadrant III behaviors. It could also be argued, however, that their actions were actually Quadrant II behaviors, given that we now know their behaviors were ultimately self-destructive and anti-social. Indeed, the label attributed to a particular behavior may not be fixed, but rather depend on an individual's perspective or relationship to the behavior. Perceptions about where a behavior falls may actually evolve as new information appears and society's historical sense-making perpetually unfolds; what is deemed Quadrant III today (i.e. self-serving), may turn out to be Quadrant II tomorrow (i.e. self-destructive). Similarly, what might be seen as Quadrant 
III behaviors at one point in time (i.e. self-serving at others' expense) may indeed be realized as Quadrant IV (i.e. mutually beneficial) if in the future the concept changes regarding what it means to be helpful to another.

Even with the potential fluidity of this typology, it does raise interesting questions regarding not only where individual leaders, but also where entire companies and even industries fall on this framework. One could ask: where would the tobacco industry fall? Phillip Morris as a company? The specific campaign by Philip Morris to prevent youth from smoking ${ }^{5}$ ? As this example illustrates, the line between self-interest and societal interests may not always be clear, and of course even within a single company there can be activities that fall in the different quadrants outlined above. For instance, there are undoubtedly activities going on in companies that are regularly applauded for their commitment to social responsibility, such Green Mountain Coffee Roasters, that are not Quadrant IV, but somewhere in the other three areas (Essex, 2005). Yet, regardless of this inherent ambiguity, researchers are beginning to suggest that a company's ability to sustain a competitive advantage in the future will rest upon their ability to move their overall business strategy into Quadrant IV (Hart 2005; Prahalad, 2004; Hart and Milstein, 2003; Paine, 2003). As Laszlo (2003) summarizes:

“....an integrated economic, social, and environmental approach leads to more enduring shareholder value than a short-term profit approach that transfers value from one or more stakeholders to the company's shareholders. It is a long-term strategy, uniquely relevant to the twenty-first century, in which responsible social change can become a source of innovation and profit rather than an added cost." (xxiii)

The question remains however: Who are the actors making decisions that result in mutual

\footnotetext{
${ }^{5}$ See: http://www.philipmorrisinternational.com/PMINTL/pages/eng/ysp/YSP.asp
} 
benefit and what is unique about them?

Moral Imagination: A Key to Creating Mutually Beneficial Outcomes

Building on the work of Werhane $(1999,1998)$, Johnson (1993), and others, I argue that one critical key to solving this question is a better understanding of moral imagination in organizational decision-making. Werhane defines moral imagination (MI) as "the ability to understand a context or set of activities from a number of different perspectives, the actualizing of new possibilities that are not context-dependent, and the instigation of the process of evaluating those possibilities from a moral point of view" (1999, p. 5). In other words, moral imagination encompasses the capability of not only being aware of the moral implications of one's actions in a situation, but also reframing a situation and creating moral alternatives to the situation at hand. As such, moral imagination encompasses abilities such as moral awareness, moral reasoning, and creativity.

I will elaborate on the definition further in Chapter 2, but for purposes of this dissertation, I am defining moral imagination as: the ability to discern the moral aspects embedded within a situation and develop a range of alternative solutions to the situation from a moral perspective.

Based on a variety of philosophical thought including Smith and Kant, Werhane argues that moral imagination is a "necessary condition for creative moral managerial decision-making," and suggests that moral imagination coupled with a developed sense of moral reasoning "provides concrete managerial decision-making skills with which to avoid questionable activities, prevent unseemly consequences, and enable a manager or a company to create decision models that contribute positively to corporate and social well 
being" (1999, p. 13-14). Extending this argument, I reason that an active moral imagination may be one important ability that differentiates those leaders who make decisions in Quadrant IV, where they are creating mutually beneficial solutions that tap into what Himman (2005) refers to as a moral "sweet spot" - or the point at which altruism and self-interest coincide.

\subsection{Research Opportunity \& Purpose Statement}

Although work by Johnson (1993), Werhane $(1999,1998)$, and others present well developed theoretical definitions and arguments as to why moral imagination is an important construct to consider when trying to understand moral decision-making, empirical investigations of moral imagination as a holistic construct remain abstract within the literature. The only empirical investigation of moral imagination I have found to date is qualitative in nature, and applies the construct post hoc to the data (see Drumwright and Murphy, 2004). The purpose of this dissertation, therefore, was to begin to fill this literature gap by providing one of the first empirical explorations of the theory of moral imagination. Specifically, I examined if individuals who exercised moral imagination during a decision-making process were more likely to generate mutually beneficial outcomes - outcomes that have benefit to both the company and also to wider society - than individuals who did not exercise moral imagination. I also explored other factors, including moral development and demographic characteristics, which may impact an individual's demonstration of moral imagination. 


\section{Significance and Implications}

Developing a better understanding for moral imagination and its relationship to mutually beneficial decision-making in business has implications for both management education and future research in business ethics. Each year hundreds of thousands of individuals step across the graduation stage of their management education programs and into the leadership ranks of organizations across the globe. These are the same individuals who enter the ranks of organizations across the globe and make the millions of daily decisions that impact not only their organization, but wider society as well. Recently, however, management education has been under attack for not adequately preparing students to appreciate or deal with the moral challenges and responsibilities that they will face in the business world (e.g. Adler, 2002; Emiliani, 2004; Grey, 2004; Mitroff and Swanson, 2004; Giacalone, 2004; Waddock, 2003; Ghoshal, 2005; Bennis and O'Toole, 2005). In light of growing critiques, there are increasing conversations around the need to re-evaluate business schools' curriculum and create pedagogical experiences that prepare students to be socially responsible citizens capable of balancing complex moral issues with the strategic needs of business (e.g. Aspen TIP, 2006; BAWB Summit, 2005; BAWB Global Forum, 2006). If moral imagination is found to be a factor in creating mutually beneficial business decisions, then focusing on developing students' capacity for moral imagination will be an important component for future management education pedagogy. Through a better understanding of moral imagination, management educators will be able to more effectively foster its development during the management education experience and thus better prepare future business leaders to more effectively deal with the moral challenges inherent in today's business landscape. 
This research can also be beneficial to business as organizations continue to develop ethical training programs for their employees. Again, with a better understanding of moral imagination, organizations can not only create training to foster it, but also develop organizational cultures which allow it to flourish.

\subsection{Organization of the Dissertation}

The following chapters detail the research undertaken to explore the impact of moral imagination on organizational decision-making. First, in Chapter 2, I explore the current literature on and related to mutually beneficial decision-making and moral imagination. Building from theory, I propose thirteen hypotheses that I aim to test through the dissertation, and conclude the chapter with a new hypothetical model of moral imagination that summarizes the hypothetical relationships being proposed. In Chapter 3, I then empirically test this theoretical model to determine if an individual who demonstrates higher moral imagination when presented with a business dilemma does in fact also exhibit an ability to craft a "mutually beneficial" solution that creates both company and social benefit, as the current theory would predict. I also explore other factors which I hypothesized may impact an individual's demonstration of moral imagination. Chapter 4 provides an overview of the results from my investigation, including which hypotheses were supported and which were refuted. Finally, Chapter 5 includes a discussion of the implications of the empirical findings, provides an overview of the limitations of this research and concludes with a call for future research on moral imagination and decision-making in organizations. 


\section{CHAPTER 2}

\section{LITERATURE REVIEW AND HYPOTHESES}

Profit and morality are a hard combination to beat. $\sim$ Hubert H. Humphrey

This chapter reviews literature relevant to moral imagination and its relationship to mutually beneficial decision-making. I begin by reviewing the idea of mutually beneficial decision-making in organizations, which was briefly outlined in Chapter 1. After reviewing the existent definitions of moral imagination, I propose a new working definition for the construct. Specifically, I will detail how a person's ability to recognize moral issues within a situation and generate a range of possible alternatives comprises their ability for moral imagination. I then detail how moral imagination has been theoretically linked to an individual's ability for creating mutually beneficial decisions when faced with a business dilemma. Next, I theorize how traits such as empathy, egotism, dogmatism, relativism, and idealism, which reflect an individual's level of moral development, may impact their ability for moral imagination and thus their ability for creating mutually beneficial decisions. The chapter concludes with a model for moral imagination and mutually beneficial decision making that summarizes the hypotheses that I will be testing in this dissertation.

\subsection{Mutually Beneficial Decision-Making in Business}

Today, the global footprint of business extends to global economies, societies, and the natural environment in increasingly complex ways (Margolis and Walsh, 2003; Jackson and Nelson, 2004; Paine, 2003). With the world's five largest corporations' 
sales revenues overshadowing the GDP of over 180 of the world's nation states and the existence of over 60,000 trans-national corporations which transcend the governance of any one country (Jackson and Nelson, 2004), one could argue that business has become the stage upon which many of today's global events play out. Yet, while the scope of business seems to be ever increasing, the very purpose of business remains a source of great dispute. Recent tales of greed and corruption within the upper echelons of various corporations have rejuvenated decades-old debates regarding the raison d'etre of the corporation (e.g. Friedman, 1970; Davis, 1973; Freeman, 1994; Sundram \& Inkpen, 2004; Giacalone, 2004). On the one hand, many still support the classic stockholder profit maximization argument that argues the "social responsibility of business is to create profits" (Friedman, 1970). On the other hand, the stakeholder view of the firm is growing in popularity with its suggestion that a businesses are most successful when they not only consider stockholder interests in making business decisions, but also other stakeholder needs and concerns as well (Freeman, 1994).

While the academic debate over the purpose of business will inevitably continue, there is growing evidence to suggest that consumers and investors alike want companies to create mutual benefit, that is, to make decisions in such a way that both the business and wider society gain from the business's activities. Take for example a Business Week/Harris Poll conducted in 2000 which found that only 4\% of those (Americans) surveyed believe that companies should have the sole purpose of making profit for shareholders, with 95\% agreeing that corporations should have more than one purpose and that they owe something to their workers and to the communities in which they operate (as sited by Jackson and Nelson, 2004, p. 15). Research is also demonstrating 
that those companies who "do good" (i.e. working to create mutual benefit by balancing profits and social impact) are also doing well financially (Margolis and Walsh, 2001). A recent study of the 500 largest U.S. companies appearing on the Business Week 1000 list found that those with a defined commitment to ethical principles out-performed their peers (as sited by Paine, 2003 p. 53). Other theorists have begun to suggest that a company's maintenance of a competitive advantage will rest upon its ability to move their business strategy into realm of mutual benefit, where both the company and wider society benefit at the same time (Hart \& Milstein, 2003; Laszlo, 2003; Prahalad, 2004).

As stated in Chapter 1, for purposes of this dissertation, I will be adopting the definition of mutual benefit proposed by Bright, Fry, and Cooperrider (2006). They state that, "mutual benefit exists where business organizations are both profitable and functional for the common good - a position of integrated strategic focus on both organizational self-interests and stakeholder interests" (ibid, p. 20). Building on the work of Jackson and Nelson (2004), Bright, Fry, and Cooperrider further expand on the notion of "mutuality" which is an important element in the concept of "mutual benefit" by explaining what it means for business and society to both benefit from businesses decisions. They state:

First, benefit to business is the economic profitability of an organization, where the focus is to maximize returns for shareholding owners. A concern for the economic self-interests is a constant strategic imperative: Unprofitable free-market businesses generally do not long survive, and therefore, benefit to business is usually seen as a priority. It is a necessary condition for sustainable mutual benefit. In contrast, benefit to society is the extent to which business activity has an impact on nonshareholding stakeholders, including organization members and employees, local and global community constituents, industry partners, regulatory bodies, among others (Jackson \& Nelson, 2004, Freeman, 1984; Freeman \& Philips, 2002). Essentially, this is a concern for stakeholders who are external to the organization (Freeman, 1984). The scale of benefit to society is intrinsically tied to the extent an organization incorporates concerns for social and environmental issues as an 
integral part of its strategic operations and value-structure. Together with the necessary condition of profitability, benefit to society is a sufficient condition for mutual benefit. (Bright, Fry, and Cooperrider, 2006, p. 20)

The idea of mutual benefit in organizational decision-making suggests that businesses can "do well" for themselves while also 'doing well' for others beyond the business, and that such outcomes are more desirable than if one acted only in their own self-interest or only in the interest of others. Thus, the "best" outcome from this perspective comes when both the needs of self and others are acknowledged, managed, and fulfilled. I acknowledge that this perspective assumes a utilitarian view of ethics, in that an action is presumed to be 'better' or more desirable when it benefits more people (i.e. stockholders and other stakeholders in society). For purposes of this dissertation, I will be adopting such a utilitarian view.

Much of the social science literature, and especially economic and strategic theory, has painted a "unidimensional continuum (of) self-interest vs. unselfishness" (Rocha and Ghoshal, 2006, p. 587). Some have traced the separation of these two ideas back to Adam Smith who wrote, "It is not from the benevolence of the butcher, the brewer, or the baker, that we can expect our dinner, but from their regard to their own interest" (1776). While not all agree that it was Smith's intention to propagate a theory that divorces morality and economics, many do acknowledge that his work has been used (and perhaps misused) as the rationale for putting self-interest at the heart of our modern capitalist economic model while leaving altruism in the shadows. For example, in his book, Adam Smith's Mistake: How a Moral Philosopher Invented Economics and Ended Morality, Kenneth Lux (1990) suggests that Smith mistakenly left out the word "only"

\footnotetext{
${ }^{6}$ I am using "unselfishness" and "altruism" and "benevolence" as interchangeable terms.
} 
from this now-famous passage (as in "It is not only from the benevolence....), which would have indicated that Smith thought benevolence and self-interest could both be factors in a successful economic model.

Regardless of Smith's intentions or the misinterpretations thereof, the concept of "mutual benefit" that is emerging in the literature challenges the separation of altruism and self-interest. The idea of mutual benefit posits that success in the economic and social spheres are not separate, but can be intertwined. According to the idea of mutual benefit, advantageous outcomes can simultaneously occur for both business and wider society - one does not need to suffer at the other's expense. As illustrated in Figure 1 in the previous chapter, instead of seeing the characteristics of self-interest and altruism as two anchors of a single scale, where movement toward one trait represents movement away from the other, these concepts can be re-conceptualized as two independent, yet interactive, variables (Himman, 2005). Thus, assuming that a person (or company) can demonstrate either higher or lower degrees of aptness for both altruism and self-interest, the resultant typology that emerges from this interactivity includes four possible behavioral outcomes, summarized again in Table 1.

\begin{tabular}{cc|c|c|}
\multicolumn{2}{c}{} & \multicolumn{2}{c}{ SELF-INTEREST } \\
\cline { 3 - 4 } & \multirow{2}{*}{ Higher } & Self-sacrificing altruism & $\begin{array}{c}\text { Mutual Benefit for self } \\
\text { and others }\end{array}$ \\
\cline { 3 - 4 } & Lower & $\begin{array}{c}\text { Anti-social, self- } \\
\text { destructiveness }\end{array}$ & $\begin{array}{c}\text { Self-interest at other's } \\
\text { expense }\end{array}$ \\
\cline { 2 - 3 } & &
\end{tabular}

Table 1: An Integrated Framework for Self-Interest and Altruism 
The question that remains open in the literature is: what factors impact an individual's ability to make decisions that are mutually beneficial? Working from the assumption that mutually beneficial decisions are the best possible decisions because they create the greatest good for the greatest number of people, the answer to this question is an important one. While there are potentially an infinite number of factors that can be explored in relation to mutually beneficial decision-making in organizations, a provocative theory has emerged in the literature with one proposed answer to this query. That is the theory of moral imagination. As stated in Chapter 1, Werhane (1999) argues that an active moral imagination "enables a manager or a company to create decision models that contribute positively to corporate and social well being" (p. 14). It is to this theory that we will now turn to further explore how moral imagination may facilitate mutually beneficial decision-making in organizations.

\subsection{Defining Moral Imagination}

The concept of moral imagination is not new and often appears in literary theory. The specific definition of the term, however, remains elusive as various authors have each described the concept slightly differently (Werhane, 1999). For example, according to Powers and Vogel (1980), it is "the ability to perceive that a web of competing economic relationships is, at the same time, a web of moral or ethical relationships" (p. 40). Larmore (1981) defines moral imagination as, "our ability to elaborate and appraise different courses of action which are only partially determined by the given content of moral rules, in order to learn what in a particular situation is the morally best thing to do" 
(p. 284). Jacobs (1991) describes it as, "articulating and examining alternatives, weighing them and their probable implications, considering their effects on one's other plans and interests, and considering their possible effects on the interests and feelings of others" (p. 25). Johnson (1993) defines moral imagination as "an ability to imaginatively discern various possibilities for acting in a given situation and to envision the potential help and harm that are likely to result from a given action" (p. 202).

In her conceptualization of the moral imagination, Werhane (1998) echoes the two-fold nature of the construct described by Johnson. Specifically, she describes it as both the creative ability to "disengage us from the perspective with which we are dealing with a situation so that we will be able to consider new possibilities" as well as a sense of moral awareness where one can then "evaluate these possibilities in terms of their moral worth" (p. 9). Based on this dual process conceptualization of moral imagination, it can be argued that although creativity and moral awareness are necessary antecedents to one's capacity for moral imagination, each alone is not sufficient. Rather, it is the coupling of these two distinct abilities that makes moral imagination a unique construct.

\section{Trait Versus Ability}

Going beyond simply defining moral imagination as an innate ability one has or does not have, Werhane and Johnson have specifically discussed it as being a unique cognitive process that an individual does (or does not) apply when making a decision. Specifically, Werhane (1998) builds upon Kant to propose that there are actually three cognitive steps an individual employs when they enact their moral imagination (p. 9-10):

(1) Reproductive imagination:

(a) an awareness of one's context and (b) an awareness of the "script" or 
schema functioning in that context, and awareness of possible moral conflicts or dilemmas that might arise in that context, that is, dilemmas created at least in part by the dominating script

\section{(2) Productive imagination:}

revamping one's schema to take into account new possibilities within the scope of one's situation and/or within one's role

\section{(3) Creative imagination or free reflection:}

(a) the ability to envision and actualize possibilities that are not contextdependent but encouraged by or project a fresh schema and/or (b) the ability to envision possibilities that other reasonable persons could envision. Morally imaginative free play also includes (c) evaluation: (i) envisioning how morally to justify actualizing these possibilities and/or (ii) how to evaluate both the status quo and these newly formulated possible outcomes.

Rather than portraying moral imagination as a personal trait that is present or absent within an individual, this cognitive framing of moral imagination allows for the possibility that moral imagination can be exercised and further developed by individuals with every decision they face. Therefore, for purposes of this dissertation, I will be assuming that moral imagination is an ability that can be exercised or not by an individual faced with a decision, rather than a trait one does or does not have.

\section{Cognition Versus Action}

It is important to note that while specific language may differ across definitions, most authors to date have constrained conceptualizing moral imagination as a reflective, cognitive process. Action may be implied, but following the specific letter of these definitions, action is not a requisite for an individual to engage in the moral imagination process. The embedded assumption (and perhaps hope) in the literature is that an individual who is able to exercise their moral imagination and create mutually beneficial alternatives will indeed take action by committing to a mutually beneficial solution they 
have generated and following it through. Yet, an individual may be able to generate and determine a mutually beneficial solution to a situation, but not necessarily translated it into action, instead taking an alternative, less moral path in any specific situation. For purposes of this dissertation, however, I will hold the assumption that an individual who is able to cognitively arrive at mutually beneficial solution is more likely to translate that solution into actual mutually beneficial behaviors.

There is research to support the argument that cognition is indeed linked to behaviors. For example, if we take attitudes as a proxy measure for the cognitive process, several studies have shown that changes in attitudes are precursors to changes in behavioral actions (Basadur et al, 1982; Basadur, Graen, \& Scandura, 1986; Kraut, 1972). I will return to this assumption in my discussion section, as I see many future research possibilities to explore the accuracy of this supposition.

For now, though, I will follow the pattern of existing moral imagination definitions and also bound my definition of the concept to specifically being a cognitive, or reflective, process. Thus, I build upon prior definitions and conceptualize moral imagination as a two-fold reflective process that incorporates moral awareness and imagination. As outlined in Chapter 1, for purposes of this dissertation, I am defining moral imagination as: the ability to discern the aspects embedded within a situation and develop a range of alternative solutions to the situation from a moral perspective.

Dissecting my definition results in two distinct processes that one must engage in to demonstrate moral imagination. Similar to the two-fold process proposed above by Johnson (1993) and Werhane (1998), I argue that to exercise moral imagination, an individual must first "discern the moral aspects embedded within a situation." I will refer 
to this recognition process as "discerning". Then, they must also "develop a range of alternative solutions to the situation from a moral perspective." I will refer to this creative, idea generation process as "developing". Detailed further below, I argue that both of these processes are needed for an individual to arrive at mutually beneficial solution when faced with a decision.

\section{Examining the Pieces to Understand the Whole}

While the concept of moral imagination is arguably greater than the sum of its two parts, looking at these parts may help us understand the whole. Reviewing the various definitions above, including my own, moral imagination incorporates both the recognition of moral issues (i.e. moral awareness) as well as the ability to generate new ideas (i.e. creativity). Taking each of these abilities in turn, I will explore how moral imagination both depends upon and extends these various constructs.

\subsection{Moral Awareness: The Ability to Discern Moral Issues}

As discussed above, I propose that exercising one's moral imagination involves an initial step I refer to as Discerning. This is the ability to recognize the complexities of a situation, including the possible moral dilemmas and opportunities embedded therein. Such awareness also involves recognizing the potential impact one's actions may have on others. Discernment by definition means "to see something that is not clear or obvious; to be able to understand something that is not immediately obvious; or to tell the difference between two or more things" (Encarta, 1999). This label is inspired specifically by Johnson's (1993) work on moral imagination where he likens morality to an artistic activity. He suggests that just as we value artists' ability to "notice what we do 
not see, to imagine possibilities we have not imagined and to feel in ways we might, but are not now feeling," likewise the work of our morality is "done not in the grasping of moral laws or principles, but in discerning what is going on in the situations we face: who we are and what we desire, what others want and need, how we relate to them, what possible forms our action could take and what is likely to result from various envisioned courses of action" (p. 210). What Johnson (1993) terms the "subtle discernment and discrimination of what is important in the situation" (p. 210), and I refer to as "discerning" others have referred to as "moral awareness".

While the concept has been of interest to scholars for decades, the definition of moral awareness continues to evolve in the literature. According to Rest (1986), moral awareness involves interpreting a "particular situation in terms of what actions [are] possible, who (including oneself) would be affected by each course of action, and how the interested parties would regard such effects on their welfare" (p. 3). Rest's (1979; 1986) seminal works provided the argument that moral awareness is a necessary first step in the ethical decision making process. Rest's four-component model of ethical decision-making suggests that an individual must begin with moral awareness (Step 1) before they are able to make a moral judgment (Step 2). Only then, are they able to establish a moral intention - or the determination to put moral concerns as an important element in the decision-making process (Step 3) and ultimately engage in a moral action (Step 4) (Jones 1991). Since Rest, others have built upon and expanded his definition of moral awareness. For example, Butterfield, Trevino, and Weaver (2000) define moral

\footnotetext{
${ }^{7}$ For the remainder of the paper I will treat the terms "discerning" and "moral awareness" as interchangeable, referring to an individual's ability to recognize the moral dilemmas and opportunities embedded within a situation. This term has also been referred to as "ethical sensitivity" and "ethical perception".
} 
awareness as "a person's recognition that his or her potential decisions or actions could affect the interests, welfare, or expectations of the self or others in a fashion that may conflict with one or more ethical standards" (p. 982). For purposes of this dissertation, I will be using this later definition for moral awareness.

Research on moral awareness has been mainly rooted in theories of social cognition (Reynolds 2006; Butterfield, Trevino, and Weaver, 2000). Originating out of work on Social Learning Theory and grounded in the work of Bandura $(1977 ; 1986)$, Social Cognitive Theory (SCT) poses that human behavior is determined by the interaction of individual cognition, actual behaviors, and the environment. While not discounting the traditional behaviorist idea that behavior is a response to stimuli within the environment, SCT suggests that behavior is also filtered and controlled largely through a cognitive process. Introducing individual cognition into the behavioral equation opens the argument that behavior is more than a simple reflex to the environment, but that the, "reality to which we respond is the reality created by our cognitive construction ... Our environment can no longer be seen as simply a set of raw stimuli. Rather, it is a context of information created by the activity of our mind" (Jones, 1989, p. 25).

While there may be an endless multitude of factors that impact cognitive processing, from one's present mood to past experiences, Mischel (1973) suggests five specific cognitive variables that "mediate the manner in which new experiences affect" an individual's processing of external stimuli (p. 265). These cognitive mediators include: 1) an individual's cognitive and behavioral construction competencies; 2) encoding strategies and personal constructs; 3) personal expectancies; 4) the subjective 
value an individual places on the stimulus; and 5) one's self-regulatory systems and plans (Mischel, 1973). Of specific relevance to the discussion of moral awareness is the second cognitive mediator: encoding strategies. "Encoding strategies refer primarily to the selectivity which the cognitive processing system exerts on incoming stimuli" (Jones, 1989, p. 25). In their work on SCT, Fiske and Taylor (1990) suggest that when a person is making a decision, they begin by encoding (i.e. processing and taking into their cognition) pieces of information from the environment, but they do so on a selective basis. In other words, not all aspects of the environmental stimuli are taken in and processed when someone is making a decision, but rather certain elements are ignored and others are focused on because of their saliency, vividness, and accessibility (Fiske and Taylor, 1990).

Examining moral issues specifically as a unique type of environmental stimuli, Jones (1991) developed an issue-contingent model of ethical decision-making where he suggested that the characteristics of a moral issue can vary with regard to saliency and vividness, thus impacting an individual's ability to pay attention to (or encode) elements of the issue into their cognition. Similar to Rest's model, Jones argues that the first step toward ethical decision-making is recognizing that a moral issue exists, but he goes on to suggest that recognition will be different across individuals depending on the perceived "moral intensity" of the issue. Extending this argument, "moral awareness can be conceptualized as a special kind of encoding process in which the individual pays attention to incoming information and categorizes it as a moral issue" (Butterfield, Trevino, and Weaver, 2000, p. 984).

While research is just beginning to explore the antecedents of moral awareness 
(Butterfield, Trevino, and Weaver, 2000), many studies have suggested that individuals can vary across their ability to recognize moral issues (Shaub et al, 1993; Butterfield, Trevino, and Weaver, 2000; Cohen, Pant and Sharp, 2004; Reynolds, 2006). Thus, while "moral awareness is a critical first step in an unfolding ethical decision making process because issue interpretation is likely to set the premises within which subsequent thought processes take place” (Butterfield, Trevino, and Weaver, 2000, p. 983-4), everyone does not necessarily perceive moral issues in the same manner. Where one person may determine that a situation involves a moral issue, another individual may not even recognize the existence of a moral issue within those exact same circumstances. This is of particular relevance in the context of business because, as Jordan (2005) argues, "many difficult decision-making situations are morally ambiguous, meaning that they can be viewed from a strategic perspective, a moral perspective, or a perspective that involves a combination of both" (p. 13). As such, moral awareness is arguably necessary if an individual is to recognize the moral elements of a decision, including the possible moral implications of their actions.

Building on these arguments, I reason that having moral awareness - or what I refer to as the ability to "discern" the moral dilemmas and opportunities embedded within a situation - is a critical prerequisite for an individual to create mutually beneficial solutions in a given situation. An individual must first be able to perceive or distinguish the moral issues in a situation, which include their impact on others beyond themselves, before they can make a decision that will benefit others as well as themselves. If they are not "encoding", or becoming aware of, the moral issues in a situation, they will not be able to act beyond their own self-interest. Extending this logic, I believe that having the 
ability to discern moral aspects of a situation will be one factor that differentiates

individuals who are able create mutually beneficial outcomes for a situation compared to those who do not. Therefore, the first hypothesis that this dissertation will explore is:

(H1) Individuals who demonstrate a greater ability to discern the moral aspects of a situation will have a greater likelihood of arriving at a mutually beneficial outcome for that situation compared to those who demonstrate lower levels of discerning.

Moral awareness, or the ability to discern moral issues, is not synonymous with moral imagination. Rather, I argue that moral imagination extends beyond moral awareness alone. While a certain level of moral awareness may be necessary for an individual to act in a morally imaginative manner, simply being able to discern the moral issues in a situation does not explain why some people are able to develop creative alternatives to a morally challenging situation, which I have defined as another critical component for moral imagination. Thus, to be morally imaginative, one cannot stop merely at the recognition of moral issues within a situation, but rather the individual must engage in additional thinking processes that I have referred to as "developing," or creating alternative solutions to a situation.

\subsection{Creativity \& Imagination: The Ability to Envision Possibilities}

Just as the term "moral imagination" requires the exploration of moral awareness, it also begs examination of imagination as a construct. While it has not been traditionally linked with moral awareness, some have suggested that imagination is critical to any examination of morality. As Johnson (1993) states:

Something crucial is missing in this widely held conception of morality. What is missing is any recognition of the fundamental role of imagination in our moral 
reasoning. We human beings are imaginative creatures, from our most mundane, automatic acts of perception all the way to our most abstract conceptualization and reasoning. Consequently, our moral understanding depends in large measure on various structures of imagination, such as images, image schemas, metaphors, narratives and so forth. Moral reasoning is thus basically an imaginative activity, because it uses imaginatively structures concepts and requires imagination to discern what is morally relevant in situations, to understand empathetically how others experience things, and to envision the full range of possibilities open to us in a particular case. (p. $i x-x)$

According to the dictionary, imagination is defined as "the act or power of forming mental images of what is not actually present" (Encarta, 1999). Similarly, creativity is defined as "the ability to use the imagination to develop new and original ideas or things" (Encarta, 1999). Given the narrow semantic distinction between the two, I will use both "creativity" and "imagination" interchangeably to refer to an individual's ability to envision possibilities that do not currently exist.

Interestingly, although research suggests that creativity is an important factor in the creation of effective organizations and managers (Mott, 1972; Scratchley \& Hakstain, 2001) and even a healthy society (Mumford \& Gustafson, 1988), the construct of creativity remains an elusive construct with no single definition or measurement (Besemer \& O’Quin, 1993; Basadur \& Hausdorf, 1996). Within the plethora of definitions that exist for what constitutes creativity, most refer to an individual's ability to generate something (including ideas) that are both novel and useful (Smith, Hill and Barber, 1989; Unsworth, 2001).

While the framing of creativity as a mental ability favors a cognitive conceptualization of the construct, I do want to recognize that others have advocated creativity be approached as a personality variable (i.e. Cattell, 1971). From the framework of personality, for example, higher levels of creative ability have been 
associated with a person who is "more adventurous, industrious, intuitive, nonconforming, versatile, curious, self confident, imaginative, and willing to take risks" (Halpin, Halpin and Torrence, 1974, p. 80). Although research on personality (and even intelligence) once predominated the creativity literature, the current trend in creativity research, however, gives less attention to "the creative personality" and focuses on other influences to creativity including an "individual's potentials, dispositions, abilities and capacities," as well as "the environment and social context" (Runco, 2004, p. 660).

Within the cognitive approach, the concept of divergent thinking has dominated the conceptualization of creativity (Scratchley and Hakstain, 2001). Introduced by Guilford (1950), divergent thinking, or the ability to generate diverse and novel approaches to a situation, has become all but synonymous with creativity in much research (Scratchley and Hakstain, 2001). Studies have found that divergent thinking measures predict performance on creative problem solving tasks (i.e. Plucker \& Renzulli, 1999), as well as creative achievement (Mumford, Marks, Connelly, Zaccarro \& Johnson, 1998). In looking specifically at the creative performance of managers, Scratchley and Hakstain (2001) found a significant positive correlation between divergent thinking and creative management measures. Thus, given both the conceptual and empirical interconnectedness of divergent thinking to creativity, I propose using divergent thinking as a proxy for creativity.

Divergent thinking comes into play during the "Developing" step of moral imagination, where an individual is actively creating new possibilities for a given situation in their mind. I argue that this ability to reframe a situation and come up with a range of options from which one could act is another critical prerequisite for an 
individual to create mutually beneficial solutions in a given situation. The more possibilities one can imagine when faced with a business dilemma, the more likely that one of those possibilities will result in mutual benefit for the company and wider society. Therefore, the next hypothesis I will test is:

(H2) Individuals who demonstrate a greater ability to develop a range of alternative solutions for a situation will have a greater likelihood of arriving at a mutually beneficial outcome for that situation compared to those who demonstrate lower levels of developing.

\subsection{Moral Imagination: Greater than the Sum of its Parts}

While both the ability to discern moral issues and develop creative alternatives may impact one's ability to create mutually beneficial solutions for a situation, it is my contention that neither of these abilities exercised in isolation are enough to be morally imaginative as I am defining it. Rather, it is the unique convergence of these abilities that results in moral imagination. Without imagination, moral awareness and moral principles "become trivial, impossible to apply, and even a hindrance to morally constructive action (Johnson, 1993, p. x). On the other hand, imagination without moral awareness or a grounding in moral principles, "is arbitrary, irresponsible, and harmful" (ibid). Similarly, Werhane (1999) echoes the idea that moral reasoning and awareness coupled with imagination are needed to exercise moral imagination, stating that without imagination "one might remain mired in a particular situation," but without moral reasoning and awareness, "one could slip into moral fantasy" (p. 111).

Building on these ideas, I argue that moral imagination is greater than the sum of its parts. While looking at an individual's ability to discern moral issues and develop creative alternatives in isolation helps us begin to understand mutually beneficial 
decision-making, it is these two abilities in combination that I predict will provide the most powerful predictor for an individual's ability to create mutually beneficial solutions for a situation. Thus individuals who demonstrate only a singular ability to discern moral issues or develop creative alternatives - or who show neither ability - will be less likely to generate mutually beneficial solutions compared to individuals who demonstrate both of these abilities together. This assumption will be the third hypothesis I test:

(H3) Individuals who demonstrate both the ability to discern moral aspects and develop creative alternatives for a situation will have a greater likelihood of arriving at a mutually beneficial outcome compared to those who demonstrate either ability in isolation or not at all.

\subsection{Factors Potentially Impacting Moral Imagination}

An individual's ability to discern moral issues and develop a range of alternatives to a situation will be impacted by a number of factors. While trying to identify every such factor is beyond the scope of this dissertation (and represents hopefully a career-long investigation), it is important to at least begin to explore at least some factors that may impact moral imagination. Specifically, I will focus on the literature on moral development to begin hypothesizing what some of these factors may be.

Inextricably interwoven with discussions of moral awareness is the concept of moral development, which may impact - if not determine - an individuals' capability for discerning the moral issues within a situation. Rest's (and others') work on moral awareness is actually grounded in the earlier work of psychologists such as Piaget (1932) and Kolberg (1969) who explored the developmental stages individuals go through that allows them to perceive and deal with moral issues differently. Paralleling cognitive development models, Kolberg's moral development model is one of the most widely 
referenced in psychological literature. His theorized stages of moral development include 1) Pre-Conventional, 2) Conventional, and 3) Post-Conventional, with each of these stages sub-divided into more subtle developmental distinctions. He argued that as children, in the pre-conventional stages, we begin with an egocentric focus where behaviors (and assessment of situations) are guided primarily by a desire to avoid punishment and meet personal needs. As we mature, ${ }^{8}$ we then move into a more conformist mode of behavior, where we depend upon peer groups and social norms to set the boundaries of acceptable behaviors. In this stage, adhering to the set rules and laws guides our behavior. Some individuals then progress to an even higher-level of moral development where we are able to identify and apply more universal moral values regardless of current rules and laws.

There has been a tremendous amount of critique of Kolberg's theory including the potential for an inherent age bias in his stages, as well as the challenge of its generalizability across the genders (i.e. Gilligan, 1982). The concept of stages, however, remains prominent in the moral development literature. For instance, building on Kolberg's work, Perry (1970) offered an alternative stage analysis of intellectual and ethical development. Based on longitudinal interviews with undergraduates at Harvard University, Perry proposed four stages, sub-divided into nine levels, of cognitive development that impacted knowledge acquisition and ethical decision-making. The first stage is "dualism" (which includes two sub-positions of basic duality and full dualism), where individuals have an unquestioned view of authority, and all questions are believed to have specific right or wrong answers. In the second stage, "multiplicity" (which

\footnotetext{
${ }^{8}$ Kolberg and others have done studies showing that not everyone progresses through these stages, suggesting for example, that criminals may remain at a pre-conventional level of development.
} 
includes the sub-positions of early and late multiplicity), individuals begin to recognize that the answer to some questions may not be known. Progressing through this stage, individuals begin to realize that some things may never be known or agreed upon and therefore external authorities are not the best sources of knowledge. Rather, they feel it is better to trust their own ideas and opinions, creating an "anything goes" mentality. The third stage, "contextual relativism" (which includes contextual relativism and precommitment), represents a shift away from a dualistic perspective toward a more relativistic, context-bound sense of the world where one recognizes that there are multiple ways of looking at a situation. Finally, in stage four, "commitment within relativism" (which is subdivided into commitment, challenges to commitment, and postcommitment), individuals realize that there are a number of correct possibilities to any situation. They must decide from the alternatives what is the most well reasoned and best possible course of action for the given context and then "commit" to that idea or action.

Trying to measure moral development poses a variety of challenges. First, simply trying to determine which theoretical schema to use is difficult, as each theory presents its own series of developmental stages. Even if one does settle on a particular theory, the existent measures to assess moral development are fraught with validity and reliability issues (Villegas, 2005). While the specific stages, reasons for movement among them, and measurement of them may remain in debate, we still can apply insights from the research on moral development to the concept of moral imagination. As Werhane (1999) comments, "from their [Kolberg, Gilligan, and others] studies, one can conclude that people deal with moral issues differently, some of us more naively than others, some of us primarily from self-interest, some of us depending on law, convention, and social 
relationships, and others seeking more ideal or universal principles through which to ground and evaluate moral decisions" (p. 22). Thus, cognitive and moral development theories help to explain why we are likely to see individual differences in an individual's ability for discerning the moral dilemmas and opportunities embedded within a situation.

Rather than constrain my theorizing to one particular theory of moral

development, I will instead explore how the general characteristics of individuals within different levels of development proposed by theorists such as Perry and Kolberg may relate to an individual's ability to be morally imaginative. For example, we see that Perry and Kolberg both suggest that individuals with "lower" levels of moral development have a focus on their own personal needs and conformity to authority. Kolberg's theory, specifically, suggests that higher levels of egocentrism, or a concentration on selfinterest, characterize individuals in early moral development. Piaget (1932), whose work Kolberg's is based upon, also theorized that children are immature in their moral judgment because of their egocentric preoccupation. Since then, other research has also suggested that egocentrism prevents the individual (i.e. child) from taking another's point of view into account during communications (Rubin, 1973) as well as when trying to resolve moral conflicts (Lee, 1971). Based on such findings, I reason that an individual who remains focused on their egocentric needs is likely to be blind to the moral complexities of certain situations because they can not see implications of the situation on others beyond themselves. This creates a myopia for moral awareness (discerning) because they simply do not encode incoming information as impacting others beyond themselves. Because their ability for discerning moral issues - which I have already argued above is an important factor in creating mutually beneficial decisions - is 
diminished, an egocentric person will have a diminished capacity for moral imagination compared to a non-egocentric person. This relationship will be tested via the following hypothesis:

(H4) There is a significant negative relationship between an individual's level of egocentrism and their ability for discerning the moral aspects within a situation.

Somewhat different from egotism, Perry suggests that in early stages of development individuals may also have blind acceptance of authority (or conformity) and a belief that there is a set of rules defining right and wrong. Kolberg also refers to conformity, but suggests that it comes after the egocentric phase. Regardless of when it comes in the stages of development, a person who has an unquestioning conformity to authority (be it religious, governmental, or another form of authority), has what is also referred to as a dogmatic mindset. Based on Rokeach's work, Davis et al (2001) define dogmatism as the "tendency of some individuals to maintain a relatively closed central core of beliefs and disbeliefs about reality, organized around some strong convictions about absolute authority that provide a framework for patterns of intolerance and qualified tolerance toward others" (p. 39). Research has shown that dogmatism is negatively correlated with moral development (Alker and Poppen, 1973) and measures of ethical behavior (Black et al, 1980). Because they are more set in their views on what constitutes right and wrong, a highly dogmatic individual may be less likely to approach a situation with an open mind and less perceptive of moral issues that fall outside of their pre-defined notions of what issues are important to consider. Although there is little direct research exploring the impact of dogmatism on moral awareness, I reason that an 
individual with a high level of dogmatism will be less able to discern the moral dilemmas and opportunities embedded within a situation, as captured in the following hypothesis:

(H5) There is a significant negative relationship between an individual's level of dogmatism and their ability to discern the moral aspects of a situation.

Perry suggests that as people "progress" ${ }^{\text {" }}$ through moral development, they move away from a dogmatic view of the world and toward a more relativistic view. Relativism has since become a concept commonly explored in the ethical development literature. Moral relativism (also referred to as ethical subjectivism) is the belief that there is not a universal set of rules to guide moral behavior. "Relativists generally feel that moral actions depend upon the nature of the situation and the individuals involved, and when judging others they weigh the circumstances more than the ethical principal that was violated" (Forsyth, 1992). Research has suggested, however, that although relativists may not focus on their own egocentric needs or conformity, they may still not be fully morally aware. For example, finding a negative relationship between relativism and ethical sensitivity (i.e. moral awareness), Shuab (1989) theorized that relativists may be less likely to perceive violations of ethical codes because they do not recognize the existence of moral absolutes and reject the use of ethical codes to guide behavior. Similarly, research by Singhapakdi et al (1995) found support for a negative relationship between an individual's level of relativism and their perception of the importance of ethics. Building on such findings, Sparks and Hunt (1998) specifically explored marketing researchers' ethical sensitivity and also found that relativism was negatively related to ethical sensitivity. Based on these studies and Shuab's logic, I propose that

\footnotetext{
${ }^{9}$ I recognize that this term suggests a normative advancement, where the later stages are preferred to the earlier, but for purposes of this discussion I am taking a normative stance.
} 
moral relativism will have a negative impact on an individual's ability for discerning the moral dilemmas and opportunities embedded within a situation.

(H6) There is a significant negative relationship between an individual's level of moral relativism and their ability to discern the moral aspects of a situation.

In the "upper" stages of development, Kolberg theorized that individuals apply more universal moral values regardless of the current laws or rules. This kind of approach has also been referred to as "idealistic". Along with relativism, idealism has been shown to be an important aspect in ethical judgments and behaviors in the business context (Park, 2005). Idealism has been defined as the degree to which individuals "assume that desirable consequences can, with the right action, always be obtained" (Forsyth, 1992, p. 175) and that "harming others is always avoidable" (ibid, p. 462). Idealists are concerned with the welfare of others, and rather than embracing moral absolutes, they value altruism and approach moral issues with a sense of optimism that there is always the possibility of creating beneficial solutions for everyone (Singhapakdi et al., 1999). Idealism then, may be a factor associated with one's ability to create mutually beneficial solutions to situations, a key component to moral imagination.

Forsyth (1992) suggests that idealism and relativism are not innately conflicting traits, rather they are actually independent dimensions of one's moral philosophy along which an individual can be high or low on either quality. As such, a person could potentially reflect both high levels of relativism and high levels of idealism. Parks (2005) summarizes these two orientations: "idealism focuses on 'unselfish' concern for others, where relativism focuses on the best alternatives" to the situation (p. 84). Yet, despite Forsyth's theoretical conceptualization of these two orientations as being separate, research has suggested that they may indeed be conflicting constructs, as "idealism has 
been found to positively and relativism has been found to negatively influence the degree of deontological norms and ethical judgment, perceived importance of ethics and social responsibility, and ethical judgment and behavioral intention” (Park, 2005, p. 84). Thus, where relativism may represent an obstacle to an individual's ability to discern moral issues and act upon them, it can be argued based on this research, that idealism is an aid in moral awareness and thus is a positive impact on moral imagination. To explore the impact of idealism, the following hypothesis will be tested:

(H7) There is a significant positive relationship between an individual's level of moral idealism and their ability to discern the moral aspects of a situation.

These various moral development characteristics may not only impact an individual's ability for discerning moral issues, but also their ability to develop creative alternatives to a situation. For instance, dogmatic thinking may actually pose a particular challenge to moral imagination by also impacting one's level of creativity, in addition to their moral awareness. A critical component of moral imagination involves "questioning prevailing organizational problem solving scripts" which are the "cognitive frameworks for understanding events that provide guidance for appropriate behavior in certain situations" (Vidaver-Cohen, 1997, p. 2). An individual with dogmatic thinking may not be able to challenge the framing of the situation, and thus may be unable to create or even consider new possibilities, which as discussed above, is a key to moral imagination (Werhane, 1994). Rather, they will take the situation as is presented to them by their boss or another authority (who may paint the situation as being black and white where they need to make a decision to act a certain way or not) and not even realize that they can reframe and expand the possible list of solutions to the situation. As such, they will not demonstrate the ability to develop alternatives to a situation, which is the next hypothesis I will test: 
(H8) There is a significant negative relationship between an individual's level of dogmatism and their ability to develop a range of alternative solutions to the situation.

On the other hand, relativism may have a positive impact on an individual's creativity, and thus their ability to develop alternatives in a situation. As referenced above, relativists do not accept a universal approach to any situation, but rather believe that actions should depend upon the circumstances at hand. Thus, relativists may be better able to challenge the dominant script of a given situation and generate a variety of alternative solutions to a problem, which is my next hypothesis:

(H9) There is a significant positive relationship between an individual's level of relativism and their ability to develop a range of alternative solutions to the situation.

\section{Creativity, Morality, and Empathy}

It is important to note that creativity is not intrinsically moral or amoral (Werhane, 1999). Seabright and Schminke (2002) remind us with their discussion of immoral imagination that creativity can also be applied to unethical acts. To exercise moral imagination then, creativity needs to be coupled with moral reasoning and moral awareness such that the possibilities one creates are anchored in a moral schema. In other words, a person must not only be able to generate new alternatives, but they must also be able to imagine the potential moral implications of those alternatives - or the harm and benefit that could result from each option.

While connecting imagination and morality is arguably necessary for moral imagination, the idea that these two concepts are interrelated is not a new. For instance, looking at "creative morality", Gruber (1993) suggested that moral leaders are often very 
creative. Rest (1994) also claims that "imaginatively constructing possible scenarios" for a given situation is an aspect of having moral sensitivity (i.e. awareness), which I have already discussed above as a critical element of the Discerning stage of moral imagination (p. 23). Therefore, when an individual is discerning the possible moral dilemmas embedded within a situation and then deciding which course of actions to take, they need to be able to imagine the impact of the situation and its outcomes on individuals other than themselves. This is a specific type of imagination that Johnson (1993) refers to as empathetic imagination. As Johnson (1993) states:

Traditional moral theories have almost entirely ignored one of our most important moral capacities - the capacity for empathy...[imaginative empathetic projection] requires the ability to imagine ourselves in different situations and conditions at past and future times. Unless we can put ourselves in the place of another, unless we can enlarge our own perspective through an imaginative encounter with the experience of others, unless we can let our own values and ideals be called into question from various points of view, we can not be morally sensitive." (p. 19)

Empathy has been long been a subject of inquiry in social science research.

Webster's (2002) defines empathy as:

the action of understanding, being aware of, being sensitive to, and vicariously experiencing the feelings, thoughts, and experience of another of either the past or present without having the feelings, thoughts, and experience fully communicated in an objectively explicit manner.

Empathy has come to be viewed as a multi-dimensional construct in the literature, encapsulating both cognitive and affective processes (Davis, 1980). According to Duan and Hill (1996) there are three main theoretical approaches that have been applied to the exploration of empathetic perspective taking. These include: 1) a "dispositional approach" where empathy is treated as an innate ability; 2) a "cognitive-affective experience" where empathy is explored as cognitive response to a situation; and 3) a 
"multiphase experiential process" where empathy is looked at as an "in the moment" experience (Parker and Axtell, 2001, p. 1086). Scanning the literature as a whole, Parker and Axtell (2001) note that the terms "perspective taking" and "empathy" are often used interchangeably, yet as they articulate, "perspective taking is a cognitive or intellectual process that results in the affective response of empathy" (p. 1087). Duan and Hill (1996) specifically differentiate between the cognitive ability to engage in perspective taking - or "intellectual empathy" and an affective state of empathy -- or "empathetic emotions" (p. 263).

While I recognize the importance of exploring the affective conceptualization of empathy, for this dissertation I am particularly interested the early conceptualization of empathy proposed by Piaget (1932) that characterizes empathy as a cognitive ability where an individual can take the perspective of another. Similarly, Kohlberg (1976), Selman (1971), and others recognized the importance of cognitive empathetic perspective taking and moral reasoning discussed above. Exploring both the perspective taking (i.e. the cognitive aspect of empathy) and the emotional contagion (i.e. the affective aspect of empathy) elements of empathy, Sparks and Hunt (1998) found only the cognitive dimension to be positively related to ethical sensitivity (i.e. moral awareness). From such findings, I argue that empathy, defined specifically as the cognitive ability to imagine oneself in another person's situation, is an essential type of imagination necessary for moral imagination, specifically for the ability to discern the moral dilemmas and opportunities embedded within a situation. This relationship is the next hypothesis I will test:

(H10) There is a significant positive relationship between an individual's level of empathy and ability for discerning the moral aspects of a situation. 
Conceptualizing empathy as a related - yet separate - construct from imagination opens the possibility to theorize (and empirically explore) the relationship between empathy and creativity. Past research has also explored the connection between these two concepts. For example, Alligood (1991) found evidence to support a positive correlation between creativity and empathy. In another study, McConnell and LeCapitaine (1985) found that creativity training had a significant impact on increasing teachers' empathy toward their students. Based on such findings, I propose that empathetic perspective taking has a positive correlation with one's ability to creatively develop alternatives in a situation, as captured in the following hypothesis:

(H11) There is a significant positive relationship between an individual's level of empathy and their ability to develop a range of alternative solutions to the situation.

Empathy may also be impacted by various characteristics discussed above with regards to moral development. Findings from Bowman and Reeves (1987) empirically support the argument that moral development is related to empathy, as they found that empathy correlated significantly with individual's moral development scores. Specifically, the construct of egotism may have a negative correlation with empathy. As discussed above, egocentrism is a concentration on self-interest that characterizes individuals in early moral development. Rubin's (1973) work suggests that egocentrism prevents and individual from taking another's point of view - thus limiting their capacity for empathy. This relationship will be explored through the following hypothesis:

(H12) There is a significant negative relationship between an individual's level of egocentrism and empathy. 
Additionally, dogmatism may also have a negative impact on an individual's ability for empathy. As discussed above, dogmatism is characterized not only by strong convictions about absolute authority, it also is marked by a pattern of intolerance toward certain others. The highly dogmatic person is likely to not be able to take another person's viewpoint because they have a rigid framework guiding their perceptions of whose viewpoints are important to consider (i.e. specific authority figures).

\section{(H13) There is a significant negative relationship between an individual's level of dogmatism and empathy.}

\subsection{Hypotheses Summary and Model}

In summary, one's ability to exercise moral imagination involves both the ability to discern moral issues and develop a range of alternatives. I predict that these abilities exercised in unison will lead to a greater likelihood of an individual creating a mutually beneficial solution to a situation than someone who demonstrates either ability in isolation (or not at all). An individual's ability to discern moral issues and develop creative alternatives to a situation is potentially impacted by factors such as moral development characteristics such as their level of egotism, relativism, idealism, dogmatism, and empathy. While these constructs are not meant to represent an exhaustive list of all possible factors impacting moral imagination, they do represent at least an initial set of possible factors to explore.

The specific hypotheses I will explore include:

1. Individuals who demonstrate a greater ability to discern the moral aspects of a situation will have a greater likelihood of arriving at a mutually beneficial outcome for that situation compared to those who demonstrate lower levels of discerning.

2. Individuals who demonstrate a greater ability to develop a range of alternative solutions for a situation will have a greater likelihood of 
arriving at a mutually beneficial outcome for that situation compared to those who demonstrate lower levels of developing.

3. Individuals who demonstrate both the ability to discern moral aspects and develop creative alternatives for a situation will have a greater likelihood of arriving at a mutually beneficial outcome compared to those who demonstrate either ability in isolation or not at all.

4. There is a significant negative relationship between an individual's level of egocentrism and their ability for discerning the moral aspects of a situation.

5. There is a significant negative relationship between an individual's level of dogmatism and their ability to discern the moral aspects of a situation.

6. There is a significant negative relationship between an individual's level of moral relativism and their ability to discern the moral aspects of a situation.

7. There is a significant positive relationship between an individual's level of moral idealism and their ability to discern the moral aspects of a situation.

8. There is a significant negative relationship between an individual's level of dogmatism and their ability to develop a range of alternative solutions to the situation.

9. There is a significant positive relationship between an individual's level of relativism and their ability to develop a range of alternative solutions to the situation.

10. There is a significant positive relationship between an individual's level of empathy and ability for discerning the moral dilemmas and opportunities embedded within a situation.

11. There is a significant positive relationship between an individual's level of empathy and their ability to develop a range of alternative solutions to the situation.

12. There is a significant negative relationship between an individual's levels of egocentrism and empathy.

13. There is a significant negative relationship between an individual's levels of dogmatism and empathy.

Looking collectively at the relationships suggested by these hypotheses, we can

begin to create a theoretical model of moral imagination, factors impacting moral

imagination, and its relationship to mutually beneficial decision-making (Figure 2). The

relationships illustrated in this model represent the various hypotheses that I will test through this dissertation. 


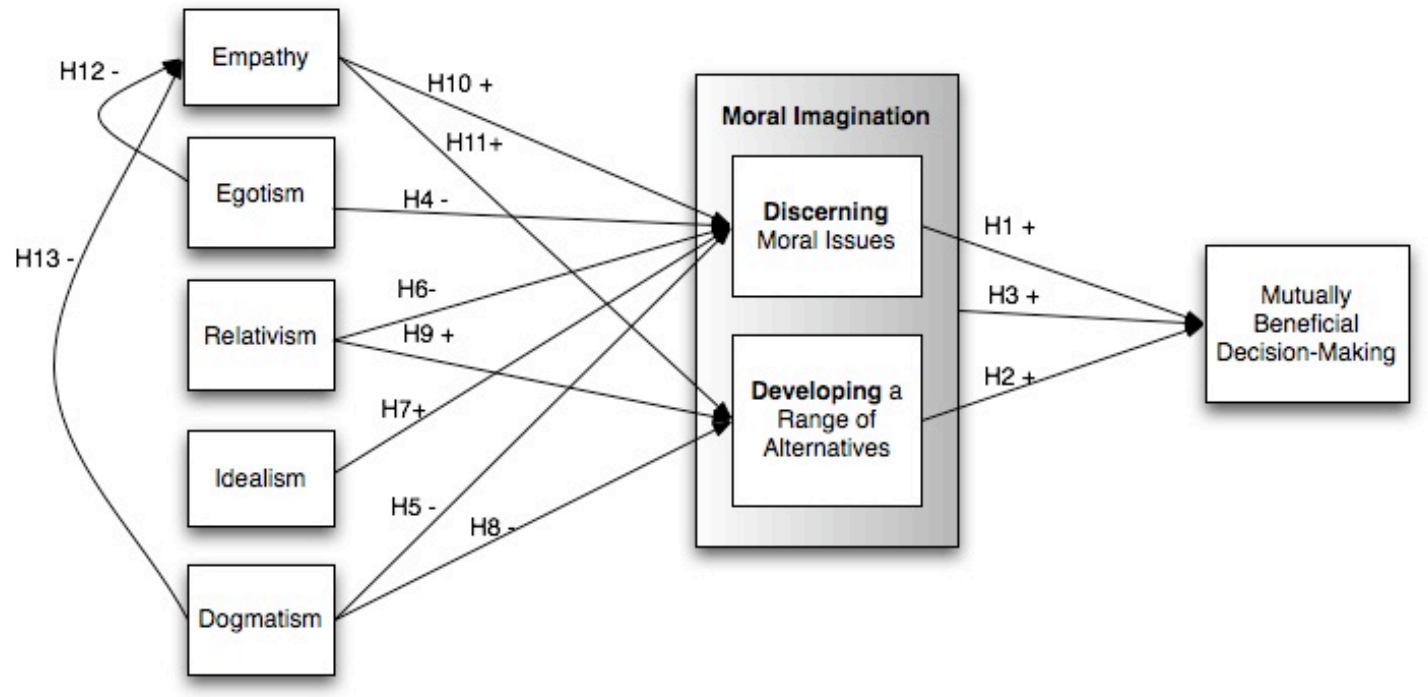

Figure 2: Proposed model for moral imagination and mutually beneficial decisionmaking 


\section{CHAPTER 3}

\section{RESEARCH DESIGN AND METHODOLOGY}

This chapter details the data collection procedure and analysis used in this study to test the theoretical model and hypotheses outlined in Chapter 2. I detail the procedures used to collect the data, including pilot testing that was done prior to the main study. Participant demographics are summarized and an overview is given of the various scales and measures used for each construct being tested in the study. The chapter concludes with details about the validity and reliability checks that were completed to assess the data prior to further analysis.

\subsection{Procedures}

MBA students were chosen as the target sample because they not only represent the diverse variety of individuals currently working in organizations, but they also represent the future of management. To recruit the majority of participants, MBA professors and program directors at universities across the United States were contacted. The general purpose of the study was explained via e-mail, with faculty and administrators then asked to forward on an e-mail, containing a link to the study's website, to their MBA students. The e-mail explained to students that their participation was completely voluntary and unpaid, however, participants were informed that upon completion of the survey, they could volunteer to be entered into a raffle to win an iPod Shuffle as an incentive for them 
to participate. Additional participants were recruited via the StudyResponse project which is hosted by the School of Information Studies at Syracuse University ${ }^{10}$.

An online survey was created and all data collection was done via the Internet. Upon accessing the survey's website, participants first read a brief overview of the study. Because of the potential to influence responses in a socially desirable manner, the description of the study did not specifically indicate that the topic being examined was 'moral imagination' or linked to moral awareness and reasoning. Rather, the study was framed as a general exploration of organizational decision-making. Additionally, participants were informed that their responses would be kept confidential and not shared with their university (and thus could not impact their grade or standing in their classes). Given an estimated time to complete the survey of thirty minutes, participants were also asked to fill out the survey at their convenience, but informed that they needed to fill it out in one session (i.e. partial submissions were not able to be saved and retrieved later). This overview concluded with providing the contact information for the researchers conducting the study should they have any questions or concerns about the study.

\section{Demographics Questionnaire}

After reading this overview, participants were first asked for their basic demographic information including: age, race, nationality, years in their MBA program, their focus of study, and their membership affiliation (or not) with Net Impact, an “international nonprofit organization whose mission is to make a positive impact on society by growing and strengthening a community of new leaders who use business to

\footnotetext{
${ }^{10} \mathrm{http}: / /$ studyresponse.syr.edu/studyresponse/index.htm
} 
improve the word." 11 Additionally, they were asked questions about their work experience, including their current employment status, the number of years of business experience they had, and the type of organization for which they work.

Once they completed the demographic questions, participants were asked to read three business vignettes and respond to a series of questions afterward. Answers to these questions were coded and used to establish participants' scores for: moral imagination (both discerning and developing), their ability for creating mutually beneficial decisions, and their level of moral awareness. Following these open-ended response questions, participants then proceeded to fill in various Likert-scale items that represented validated instruments to measure their: 1) moral development characteristics, including their level of egotism, dogmatism, relativism, idealism; 2) creativity; and 3) empathy. Additionally, a measure of social desirability was also included to use as a validity check for the data collected (see Appendix A for a copy of the complete questionnaire). After detailing the pilot testing, I will further explain each of these measures in turn.

\section{Pilot Testing}

Before the survey was distributed widely, a pilot test was first conducted. This process was designed to: 1) assess the face validity of my moral imagination measure; 2) determine how long it takes to complete the questionnaire; 3 ) resolve any ambiguous or off-putting language within the questionnaire; 4) ensure that the directions for each section of the questionnaire are easily decipherable; 5) gain a better understanding of participants' overall experience in filling out the questionnaire.

\footnotetext{
11 From Net Impact: http://www.netimpact.org
} 
For this phase, 13 individuals ( 5 female, 8 male) from a single management school completed a pilot version of the questionnaire online. Once these individuals completed the questionnaire, they were asked the following questions:

- How long did it take you to complete the survey?

- Were there any sections of the survey where you had questions or where the directions were unclear?

- How easy was it to access the survey site and fill in your responses online?

- What was it like to read the vignettes and answer the questions asked? (i.e difficult, easy, confusing, etc.)

- What was your overall experience completing the survey? (i.e. bored, frustrated, curious, interested, engaged, etc.)

- What suggestions do you have to make the survey easier to complete?

- Would you rather fill out personal information at the outset or at the end of the survey?

Responses to this process indicated that no major overhaul of the questionnaire was needed, though a few minor changes were made. Based on responses to the pilot 'exit survey', the longest time to complete the survey was reported to be 45 minutes and the shortest was 20 , with an average time being 33 minutes. It was suggested that participants be told up front how long they should expect the survey to take, as well as shortening the overall survey if possible. Both of these suggestions were employed for the experimental version. At the outset, participants were told on average the survey took 30 minutes to complete. To help shorten the survey, a few of the demographic questions were dropped including religious and political affiliation, as these were not tied 
specifically to any a priori hypotheses. Also, to further curtail the length, participants were asked to respond to only two instead of three vignettes for the moral imagination measure. Thus, only the two vignettes with the highest response rate (i.e. most issues listed, most different issues listed, etc.) from the pilot were used for the experimental version. The overwhelming majority of pilot responses indicated that accessing the website and filling out the survey online posed no difficulty. Also, pilot respondents reported overall that the directions and language throughout the survey were clear, and thus no clarifying changes were deemed necessary.

\subsection{Participants}

Respondents for the main study included 265 individuals. After removing responses from participants who did not have some graduate level work in management ${ }^{12}$ (72 responses, mostly from undergraduate students), and those individuals who rated high on the social desirability measure (14 participants), the total usable " $n$ " for subsequent analysis became 179 . Of the 179 "usable" respondents, 53\% (95) were female and $47 \%$ (84) were male, providing a relatively equal gender representation for the analysis. Approximately 78\% (139) identified themselves as Caucasian, 7\% (12) identified themselves as African-American, 8\% (15) identified as Asian-Pacific Islander; 4\% (7) identified as Latino or Hispanic, and 5\% (9) identified themselves as "other." 13

A majority of respondents, 37\% (67) were full-time MBA students, 15\% (27) were part-time MBA students, and 12\% (22) were graduates of MBA or other graduate

\footnotetext{
12 Graduate level work was determined a necessary prerequisite to be included in the main study, as it was deemed as a threshold experience separating people who had been trained in "business" from those who had not.

13 The percentage of responses exceeds $100 \%$ because respondents were allowed to select more than one ethic category.
} 
management programs. Of the remaining participants who indicated their educational status, $17 \%$ (19) identified themselves as executive education students or "other," including those participants who identified themselves as MBA/JD or participants in a similar joint management graduate program. Those who were current students represented 44 different institutions.

In addition to educational status, information regarding participants' current employment status and type of work was also collected. Full-time employees comprised $49.2 \%$ (88) of the participants, $21.2 \%$ (38) were part-time workers, and $29.6 \%$ (53) were not currently employed. Of participants who were currently employed, 11.7\% (21) were employed in a public organization, $43.6 \%$ (78) were in a private enterprise, $10.6 \%$ (19) worked for a non-profit entity, and 1.1\% (7) identified "other" for their type of work, including higher education and self-employment. Overall, their average years of work experience were $13.3($ minimum $=0 ;$ maximum $=54 ; \mathrm{SD}=11.37)$.

Age was collected as a categorical variable, as such 4.5\% (8) were 18-20, 11.7\% (21) were $21-24,25.1 \%(45)$ were $25-29,16.2 \%$ (29) were $30-34,15.1 \%$ (27) were 35 $39,7.3 \%$ (13) were $40-44,8.4 \%$ (15) were 45-49, and $11.7 \%$ (21) were 50 and older. Thus, while there was a somewhat heavier representation of participants under 30, in general, all target age groups were represented.

Participants were also asked to identify their membership of Net Impact. Of the 173 participants who responded to this question, $26.3 \%$ (47) were members of Net Impact, and 70.4\% (126) were not. Affiliation with this organization was expected to potentially correlate to positively skewed responses to the ethical measures, which will be explored further below in connection with the post-hoc analyses performed. 


\subsection{Independent Variable: Assessing Moral Imagination}

The main independent variable for this study was a participant's score on the moral imagination measure. Specifically, this included their scores for the two components of moral imagination - discerning and developing - as well as their overall score for moral imagination, which was determined through a combination of both their discerning and developing scores.

Because there currently exists no developed measure of moral imagination -nor of decision-making in the context of mutual benefit - one major contribution of the current study was to create a measurement for each of these constructs. Again, the goal of the study was to explore the decision-making process individuals used when faced with a business dilemma in order to determine if individuals who exercise moral imagination are more likely to generate mutually beneficial solutions compared with those who do not exercise moral imagination. Thus, I needed a measure that would help expose the cognitive process individual's engage in when making a decision. A vignette based measure was determined to be the best approach for trying to reveal this cognitive process because vignettes put respondents in a situation where they are not "thinking in the abstract" but are provided "a context from which they can base their decisions" and they help provide researchers with insight into the respondent's decision making process (Morrison, Stettle, and Anderson, 2004, p. 319). Vignettes are brief narratives that describe situations and actions a researcher is interested in exploring followed by specific questions for respondents to answer (Gerber, Wellens and Keeley, 1996). As Morrison, Stettle, and Anderson (2004) state, "vignettes have become a generally accepted cognitive technique" for surveying, mostly because "they attempt to make the decision- 
making process seem more real, they lend insight into the response, judgment, and communication processes, and they allow for analysis of respondents' judgments by varying the situations" (p. 319).

The vignettes used to analyze respondent's moral imagination and ability to generate a mutually beneficial decision were adapted from the vignettes created by Jordan (2005) for her study on moral awareness, which were originally adapted from Butterfield et al. (2000). The vignettes used were shortened versions of the ones Jordan used, and were selected because of their general business application (i.e. they were not tailored to marketing or accounting per se) and their content had been pre-tested by Jordan (2005) to verify that they did contain situations with both moral and strategic components to them, thus there was not a "right" or a "wrong" solution to the situation.

Participants were asked to read two vignettes that described a specific business dilemma (see Appendix A for copy of vignettes). Then, after being directed to envision that they were in a position to make a decision on the situation, they were asked to respond to four questions:

1) Briefly list as many ways as you can think of to take action on this situation.

2) Briefly list the underlying issues that are important to consider when deciding on which of the above actions to take in this situation.

3) Of the possible actions you generated, indicate which is best and briefly explain WHY this choice/option is better than the others you thought of. ${ }^{14}$

4) Briefly list who you think will be impacted by your decision and how they will be impacted.

These questions were designed to evaluate a respondent's abilities related to the moral imagination process, as well as their ability to generate mutually beneficial solutions to a situation, which I will elaborate upon below in relation to the coding process.

\footnotetext{
14 This question was used for assessment of the DV and will be discussed separately below
} 


\section{Coding the Moral Imagination}

Given that vignette-based measures result in open-ended responses, coding was necessary to transform the qualitative data generated into scores that could be used for subsequent statistical analysis. Two coders were used to score responses. Coders read participants' responses to the above four questions and rated responses on a 4-point Likert scale (detailed below in Table 2) across six dimensions - two dimensions for both discerning and developing, and two dimensions for decision-making (which is discussed below in relation to the DV). As referred to above, and detailed further below, “discerning” consisted of issue awareness (ISA) and impact awareness (IMA); “developing" included fluency (FLU) and flexibility (FLX); and "mutual beneficial decision-making" included scores for company benefit (CB) and social benefit (SB) (these last two dimensions will be discussed below in relation to the type of decisionmaking outcome variable).

Developing involves the ability to generate a variety of alternative responses to a situation; in essence, this component is trying to capture their creativity, or more specifically, their ability for divergent thinking. Based on this premise, participants' scores for Developing were assessed across two dimensions: fluency (FLU) and flexibility (FLX). Both of these dimensions come from established divergent thinking measures, such as the Torrence Test of Creative Thinking, where fluency refers to the volume of ideas generated and flexibility refers to the amount of different ideas generated (i.e. different categories of ideas). Thus, looking specifically at responses given to question 1 (i.e. list as many ways...), answers were coded for fluency and flexibility 
based on the number of different ideas they listed and the different categories of ideas they listed, respectively.

Discerning involves recognizing the embedded moral aspects within a situation. This component, therefore, aims at tracking the particpants' moral awareness for the given situation. As Rest (1986), Jordan (2005), and others have explored, moral awareness itself may have different components. These components can be extracted from the definition I am using for moral awareness, which is "a person's recognition that his or her potential decisions or actions could affect the interests, welfare, or expectations of the self or others in a fashion that may conflict with one or more ethical standards" (Butterfield, Trevino, and Weaver, 2000, p. 982). Dissecting this definition, moral awareness involves both an awareness of "ethical standards" or moral issues, as well as an awareness of how one's actions impact others. Based on these two aspects of moral awareness, Discerning was coded along two dimensions: issue awareness (ISA), or how much they were aware of moral issues within the situation, and impact awareness (IMA), or how much they were aware of who else would be affected by their actions. Issue awareness was coded specifically by using responses to question 2 (i.e. list the underlying issues...), where higher scores indicated an awareness of more moral issues within the situation. ${ }^{15}$ Responses to question 4 (i.e. who you think will be impacted...) were used to determine impact awareness, where higher scores indicated a greater awareness for different stakeholder groups who would be impacted by the decision being made.

\section{Calculation of Moral Imagination Scores}

\footnotetext{
15 For coding purposes, I am used Jordan's (2005) definition of moral components to include how much the issue raised relates to: 1) well being of the people in power, 2) well-being of non-powerful people, 3) well-being of the community or society affected by the decision, and 4) ethical and moral responsibility of the corporation.
} 
Scores were calculated for discerning, developing, and overall moral imagination based on the coding described above. To calculate the discerning score, first average scores were calculated along the two dimensions along which it was coded (i.e. issue awareness and impact awareness) by summing the scores for each of these dimensions for vignette \#1 and vignette \#2 and then dividing by two (i.e. (issue awareness for vignette $1+$ issue awareness for vignette 2 )/2 = average issue awareness score). Then an overall composite score for discerning was created by summing the averages for issue awareness and impact awareness (Discerning average = ISAavg + IMAavg).

To calculate the score for developing, the process above was mimicked. First, average scores were calculated along the two dimensions along which it was coded (i.e. fluency and flexibility) by summing the scores for each of these dimensions for vignette \#1 and vignette \#2 and then dividing by two (i.e. (fluency for vignette $1+$ fluency for vignette 2$) / 2$ = average fluency score). Then an overall composite score for developing was created by summing the averages for fluency and flexibility (Developing average $=$ FLUavg + FLXavg). Table 2 illustrates how the raw scores were converted to the composite scores for both discerning and developing. 


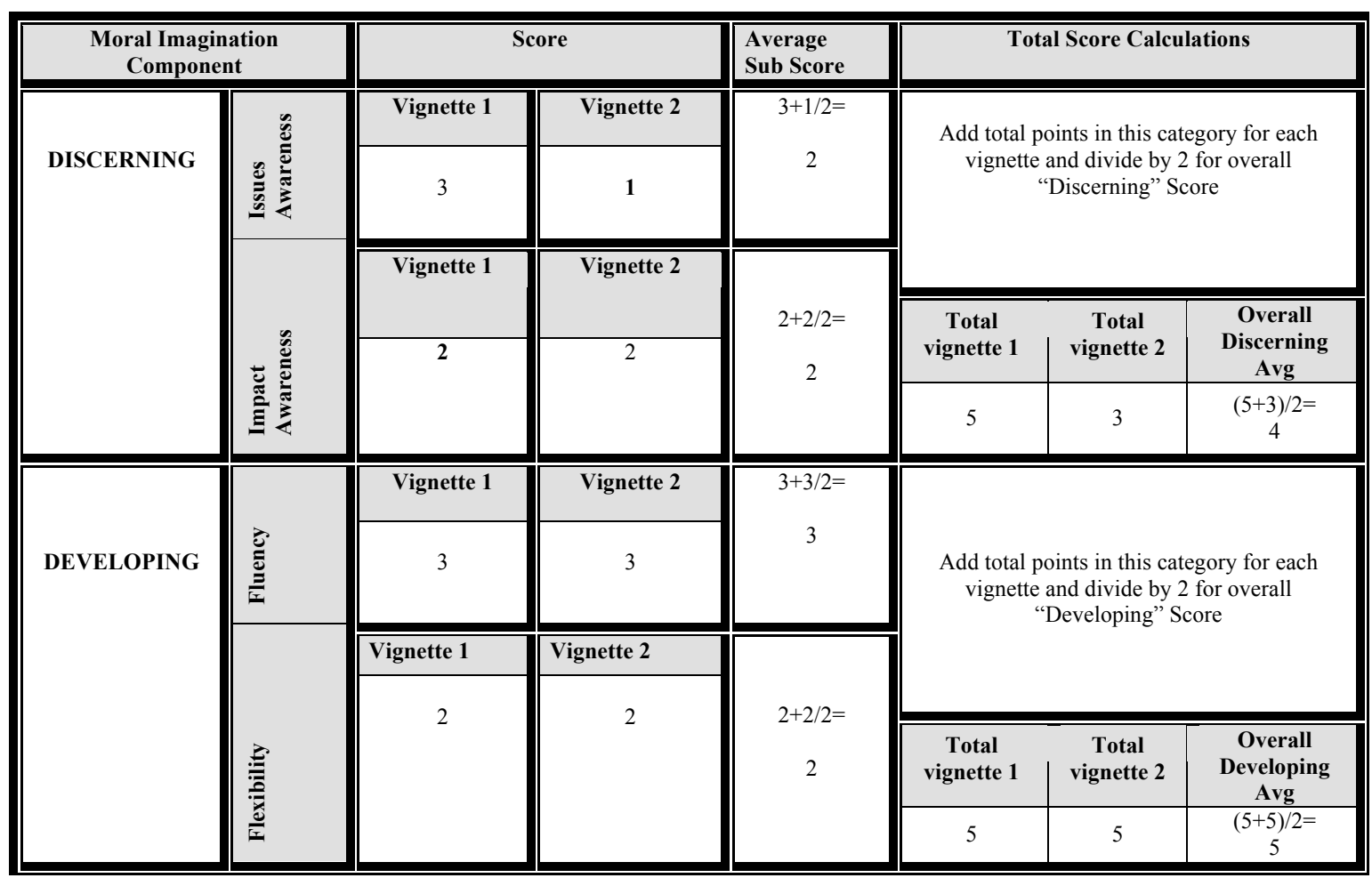

Table 2: Moral Imagination Scoring Calculation Example

Descriptive statistics for participants' results on the discerning and developing dimensions of moral imagination are found in Table 3, as well as the descriptive statistics for the four sub-dimensions along which these two skills were coded. 


\begin{tabular}{|c|c|c|c|c|}
\hline & Mean & Min & Max & SD \\
\hline \multicolumn{5}{|c|}{ Dimensions Average Across both Scenarios } \\
\hline Discerning Average & 2.19 & 0.00 & 6.00 & 1.24 \\
\hline Developing Average & 3.89 & 0.50 & 6.00 & 1.34 \\
\hline \multicolumn{5}{|l|}{ Average Scores for Scenario \#1 } \\
\hline Average Discerning for Scenario 1 & 2.22 & 0.00 & 6.00 & 1.47 \\
\hline Average Developing for Scenario 1 & 4.20 & 0.00 & 6.00 & 1.53 \\
\hline \multicolumn{5}{|l|}{ Average Scores for Scenario \#2 } \\
\hline Average Discerning for Scenario 2 & 2.17 & 0.00 & 6.00 & 1.43 \\
\hline Average Developing for Scenario 2 & 3.57 & 0.00 & 6.00 & 1.65 \\
\hline \multicolumn{5}{|c|}{ Coded Sub-dimensions for Discerning and Developing } \\
\hline Issue Awareness Average & 0.85 & 0.00 & 3.00 & 0.60 \\
\hline Impact Awareness Average & 1.34 & 0.00 & 3.00 & 0.91 \\
\hline Fluency Average & 1.91 & 0.00 & 3.00 & 0.81 \\
\hline Flexibility Average & 1.97 & 0.50 & 3.00 & 0.65 \\
\hline
\end{tabular}

Table 3: Descriptive Statistics for Moral Imagination Dimensions ( $=179)$

Applying bi-variate correlations to the four coded sub-dimensions showed significant correlations between each of the dimensions. These correlations are found in the correlation matrix shown in Table 4. 


\begin{tabular}{|l|r|r|r|r|}
\hline & $\begin{array}{c}\text { Issue } \\
\text { Awareness }\end{array}$ & $\begin{array}{c}\text { Impact } \\
\text { Awareness }\end{array}$ & Fluency & Flexibility \\
\hline $\begin{array}{l}\text { Issue } \\
\text { Awareness }\end{array}$ & 1.000 & $.322^{* *}$ & $.463^{* *}$ & $.437^{* *}$ \\
\hline $\begin{array}{l}\text { Impact } \\
\text { Awareness }\end{array}$ & & 1.000 & $.378^{* *}$ & $.214^{* *}$ \\
\hline Fluency & & & 1.000 & $.684^{* *}$ \\
\hline Flexibility & & & & 1.000 \\
\hline \\
**. Correlation is significant at the 0.01 level (2-tailed). \\
*. Correlation is significant at the 0.05 level (2-tailed). \\
\hline
\end{tabular}

Table 4: Correlations for Issue Awareness, Impact Awareness, Fluency, Flexibility

Finally, respondents were then grouped into one of two groups: those who demonstrated moral imagination and those who did not. As detailed in Chapter 2, I argue that the two abilities of discerning and developing in combination are what constitutes moral imagination and thus provide the most powerful predictor for an individual's ability to create mutually beneficial solutions for a situation. Thus, per my definition, to be deemed "morally imaginative" a respondent needed to demonstrate both discerning and developing ${ }^{16}$. As such, individuals who were determined to have low scores for either discerning or developing (or both) were grouped into the "non moral imagination" group, and those determined to have high scores on both these abilities were grouped into the "moral imagination" group. A respondent was considered to have a "low" score for discerning or developing if their average score for either of these dimensions was less than 4. This was determined as the cut point because it indicated their responses had been

\footnotetext{
${ }^{16}$ A simple summation of these two dimensions would not have accurately indicated that they were demonstrating both discerning and developing abilities. A summation could result in an individual with a high discerning score, but a low developing score being treated the same as an individual with moderate scores on both developing and discerning. Rather, I am interested in looking at those respondents who demonstrated a higher level on both dimensions, and thus determined I needed to consider each dimension as a separate variable into the overall categorization as someone being "morally imaginative" or not.
} 
coded consistently in the bottom half of possible responses on the coding rubric. Scores equal to or greater than 4 on either dimension were considered "high," as they illustrated a consistent rating in the top half of possible responses per the coding rubric.

Summarized in Table 5 below, of the usable respondents, 20 (10.9\%) were found to be in the morally imaginative group, meaning that they had higher scores for both discerning and developing. The majority of respondents, $154(88.6 \%)$, however, were in the non-moral imagination group, indicating that they had a lower score on either discerning or developing, or both.

\begin{tabular}{|l|r|r|r|r|}
\hline \multicolumn{1}{|c|}{$\begin{array}{c}\text { Moral Imagination } \\
\text { Grouping }\end{array}$} & Frequency & Percent & $\begin{array}{c}\text { Valid } \\
\text { Percent }\end{array}$ & $\begin{array}{c}\text { Cumulative } \\
\text { Percent }\end{array}$ \\
\hline Morally Imaginative & 20 & 10.9 & 10.9 & 10.9 \\
\hline Non-Morally Imaginative & 154 & 88.6 & 89.1 & 100.0 \\
System Missing & 1 & .6 & & \\
Total & 175 & 100.0 & & \\
\hline
\end{tabular}

Table 5: Frequencies of Moral Imagination Groupings

\subsection{Dependent Variable: Assessing Decision-Making Outcomes}

The dependent measure for the study was the type of decision-making outcome a respondent gave in response to a business dilemma. Of particular interest were the decisions deemed to be "mutually beneficial," in that they both benefitted the company as well as wider society. As referenced earlier, there currently exists no measure of moral imagination and its impact on decision-making. Therefore, I developed the vignettebased measure detailed above to assess both as respondent's moral imagination and their final decision-making outcome. While there are limitations for using the same instrument to collect both the DV and IV measures (which will be discussed in Chapter 
5), the benefits in this instance were seen as outweighing the limitations. In order to determine if participants were exercising moral imagination during a decision-making process, both the process they used to arrive at a solution, as well a the outcomes they generated, became inextricably linked. Collection of the IV and DV at the same time, therefore, became not only appropriate, but also fundamentally necessary.

\section{Coding the Decision-Making Outcomes}

Assessing the decision-making outcomes generated by respondents to determine their degree of mutual benefit involved coding responses to question 3 (i.e. indicate which is best and briefly explain why this choice is the best...) following each of the two vignettes described above. Operationalizing the typology of possible decision-making outcomes posed in Chapter 1 and 2, responses to this question were coded along two dimensions: company benefit (CB), or how much the selected solution positively impacted the needs of the organization, and social benefit (SB), or how much the selected solution positively impacted the needs of wider society. For purposes of this study, company benefit was assumed to be a proxy with self-interest because the respondent was directed through the vignette to assume they are in a position of authority within the company, and thus protecting the company interests are in their self-interests.

Furthermore, social benefit was assumed to be a proxy for altruism in that it involved creating an outcome that showed concern for the well-being of others beyond the company, which is one conception of altruism.

The specific rubric used for coding of both the moral imagination measures, as well as the decision-making outcome is detailed below in Table 6 . 


\begin{tabular}{|c|c|c|c|c|c|}
\hline \multicolumn{2}{|c|}{ Moral Imagination Component } & \multirow{2}{*}{$\begin{array}{c}0 \text { points } \\
\text { Moral implications } \\
\text { are given no } \\
\text { consideration and/or } \\
\text { only strategic issues } \\
\text { are listed }\end{array}$} & \multirow{2}{*}{ 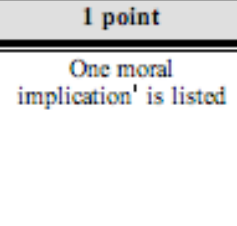 } & \multirow{2}{*}{ 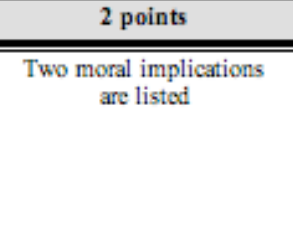 } & \multirow{2}{*}{$\begin{array}{c}3 \text { points } \\
\text { Three or more moral } \\
\text { implications are listed }\end{array}$} \\
\hline $\begin{array}{l}\text { Discerning the } \\
\text { cmbedded moral } \\
\text { dilemmas and moral } \\
\text { opportunities within a }\end{array}$ & 氖产 & & & & \\
\hline & 总 & $\begin{array}{l}\text { Lists } 0-1 \\
\text { stakeholder groups }{ }^{2} \\
\text { as being impacted }\end{array}$ & $\begin{array}{l}\text { Lists two different } \\
\text { stakeholder groups } \\
\text { are listed as being } \\
\text { impacted }\end{array}$ & $\begin{array}{l}\text { Three different stakeholder } \\
\text { groups are listed as being } \\
\text { impacted }\end{array}$ & $\begin{array}{c}\text { Four or more different } \\
\text { stakeholder groups are } \\
\text { listed as being } \\
\text { impacted }\end{array}$ \\
\hline \multirow[t]{2}{*}{$\begin{array}{l}\text { Developing a variety of } \\
\text { alternative possibilities } \\
\text { for the situation }\end{array}$} & 逆 & $\begin{array}{l}\text { Lists 0-1 possible } \\
\text { solutions }\end{array}$ & $\begin{array}{l}\text { Lists two different } \\
\text { possible solutions }\end{array}$ & $\begin{array}{l}\text { Lists three different } \\
\text { solutions }\end{array}$ & $\begin{array}{l}\text { Lists four or more } \\
\text { different possible } \\
\text { solutions }\end{array}$ \\
\hline & 氙 & $\begin{array}{l}\text { No responses are } \\
\text { listed }\end{array}$ & $\begin{array}{l}\text { Only one category of } \\
\text { responses are listed } \\
\text { (i.e. only doing } \\
\text { various extemal PR, } \\
\text { or only doing various } \\
\text { internal } \\
\text { investigations) }\end{array}$ & $\begin{array}{l}\text { Two different categories of } \\
\text { responses are listed (i.e. } \\
\text { doing both internal } \\
\text { investigation and external } \\
\text { PR) }\end{array}$ & $\begin{array}{l}\text { Three or more } \\
\text { different categories of } \\
\text { responses are listed }\end{array}$ \\
\hline \multirow{2}{*}{$\begin{array}{l}\text { Determining a mutually } \\
\text { beneficial course of } \\
\text { action based on moral } \\
\text { and strategic evaluation } \\
\text { of the solutions } \\
\text { generated }\end{array}$} & 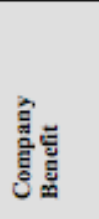 & $\begin{array}{l}\text { Solution only has a } \\
\text { negative impact on } \\
\text { the company }\end{array}$ & $\begin{array}{l}\text { Solution has no } \\
\text { benefit to the } \\
\text { company, but does } \\
\text { not have negative } \\
\text { impact (neutral } \\
\text { impact to company) }\end{array}$ & $\begin{array}{l}\text { Solution provides benefit } \\
\text { to the company by } \\
\text { addressing the immediate } \\
\text { strategic concems of the } \\
\text { company }\end{array}$ & $\begin{array}{l}\text { Solution provides } \\
\text { benefit to the company } \\
\text { by addressing both the } \\
\text { immediate and long } \\
\text { term strategic needs of } \\
\text { the company }\end{array}$ \\
\hline & 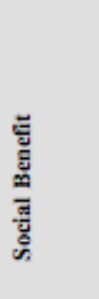 & $\begin{array}{l}\text { Solution has } \\
\text { negative impact on } \\
\text { wider society }\end{array}$ & $\begin{array}{l}\text { Solution has no } \\
\text { benefit to wider } \\
\text { society, but does not } \\
\text { have negative impact } \\
\text { (neutral impact to } \\
\text { society) }\end{array}$ & $\begin{array}{l}\text { Solution provides benefit } \\
\text { to society by offering } \\
\text { disclosure or minimum } \\
\text { action on the moral issue at } \\
\text { hand }\end{array}$ & $\begin{array}{l}\text { Solution provides } \\
\text { bencfit to society by } \\
\text { offering support and/or } \\
\text { resources to multiple } \\
\text { stakeholder groups } \\
\text { (including } \\
\text { stakeholders beyond } \\
\text { the company) } \\
\text { regarding the moral } \\
\text { issue(s) at hand }\end{array}$ \\
\hline
\end{tabular}

Table 6: Coding Rubric for Moral Imagination and Decision-Making Outcome

\section{Calculation of Decision-making Scores}

Similar to the process used to calculate the moral imaginations scores, first average scores were calculated for the two dimensions along which decision-making was coded (i.e. company benefit and social benefit) by summing the scores for each of these dimensions for vignette \#1 and vignette \#2 and then dividing by two (i.e. (company 
benefit for vignette $1+$ company benefit for vignette 2$) / 2$ = average company benefit score). Based on the assumption that an individual can act with a high or low level of self-interest (i.e. company benefit), as well as a high or low level of altruism (i.e. social benefit), the overall average scores for company and social benefit were used to group respondents into 1 of 4 possible groups per the typology of possible decision-making outcomes posed in Chapter 1 and 2. Overall, average scores of 2 and above were deemed to be "high" for average company benefit and social benefit because such scores reflected participants' decisions had being consistently rated in top $50 \%$ of possible responses on the coding rubric. ${ }^{17}$ Using this approach for the cut-offs for "high" and "low" for both social benefit and company benefit, the four groups were determined as follows:

1) Self-Sacrificing Altruism - low overall average company benefit and high overall average social benefit

2) Anti-Social/Self-Destructiveness - low overall average company benefit and low overall average social benefit

3) Self-Interest at other's expense - high overall average company benefit and low overall average social benefit

4) Mutual Benefit - high overall average company benefit and high overall average social benefit

Summarized in Table 7 below, of the usable respondents, 6 (3.6\%) were grouped in the "self-sacrificing" category based on their decision-making outcome; 18 (10.7\%)

${ }^{17}$ Refer back to the coding rubric to see that a score of "2" on company benefit indicated that the, "solution provides benefit to the company by addressing the immediate strategic concerns of the company" and a score of " 2 " on social benefit indicated that the "solution provides benefit to society by offering disclosure or minimum action on the moral issue at hand". For either dimension, a score lower than 2 indicated that the solution did not show any benefit to the company or to society. As such, an average score of "2" or higher was determined to be the appropriate cut-off to indicate those who showed benefit to the business or society in their responses. 
were grouped in the "anti-social" category; 84 (50\%) were grouped in the "selfinterested" category; and 60 (35.7\%) were grouped in the "mutually beneficial" category.

\begin{tabular}{|l|r|r|r|r|}
\hline $\begin{array}{c}\text { Type of Decision-Making } \\
\text { Outcome }\end{array}$ & Frequency & Percent & Valid Percent & $\begin{array}{c}\text { Cumulative } \\
\text { Percent }\end{array}$ \\
\hline Mutually Beneficial & 60 & 34.3 & 35.7 & 100.0 \\
Self-sacrificing & 6 & 3.4 & 3.6 & 3.6 \\
Self-interested & 84 & 48.0 & 50.0 & 64.3 \\
Anti-social & 18 & 10.3 & 10.7 & 14.3 \\
\hline System missing & 7 & 4.0 & & \\
Total & 175 & 100.0 & & \\
\hline
\end{tabular}

Table 7: Frequencies of Type of Decision-Making Outcome

\subsection{Assessment of Factors Impacting Moral Imagination}

In addition to the main IV of moral imagination described above, there were other variables theorized in Chapter 2 to have an impact on Moral Imagination and thus which also needed measured. Specifically, these variables included different characteristics reflecting an individual's level of moral development and their level of empathy.

Various approaches for measuring moral development have existed for decades.

For example, Kolberg developed the Moral Judgment Interview (MJI), which includes a semi-structured interview with subjects responding to a series of moral dilemmas (1973). Since then, Rest (1986) created the Defining Issues Test (DIT), which, although it has undergone revisions, has become a popular assessment because it is self-administered. Similar to the MJI, the DIT presents participants with short vignette-based dilemmas and asks them to select their response on a multiple-choice basis. Perry's schema has also spurred measurements such as Erwin's (1983) Scale of Intellectual Development (SID). 
As I discussed earlier, however, I am not interested in labeling individuals as being within a particular stage of moral development. Rather I am interested in looking at various characteristics I described above as being indicators of different levels of moral development. Specifically, I sought to measure individuals' level of egotism, dogmatism, moral relativism, and idealism per my hypotheses described in Chapter 2.

\section{Egotism}

Egotism was assessed using Jordan's (2005) egotism scale. This measure was a subscale of an instrument she created to measure Sternberg's (2002) five fallacies of thinking, of which one is egotism. The scale consists of 7 items on 8 point Likert scale (1=agree strongly, $8=$ disagree strongly).

\section{Dogmatism}

Dogmatism was measured using Schulze's (1962) shortened version (10 items) of the Rokeach Dogmatism Scale. Also known as the D-10 Scale, this shortened scale has been shown to correlate $(0.76)$ with the full Rokeach Dogmatism Scale and the coefficient of reproducibility has been shown to be 0.83 (Schulze, 1962).

\section{Relativism and Idealism}

To measure both moral relativism and idealism, I used the Ethics Position Questionnaire (EPQ) developed by Forsyth (1980). The EPQ is a 20-item instrument that measures two dimensions of moral thought: idealism and relativism. Items are rated on a 9-point Likert scale (1=completely disagree, 9=completely agree). Reliability coefficients 
for Idealism and Relativism are .80 and .73 respectively. Test-retest reliability figures are .67 and .66 respectively.

\section{Empathy}

Just like moral development, there are a plethora of measures that have been designed to assess empathy. These measures have varied according to the different definitions of empathy, with some aimed at assessing empathy as a cognitive ability or taking the perspective of others (based on Hogan 1969). Others have attempted to measure empathy as an emotional response or the ability to become aroused or sympathetic to feelings of others (based on Mehrabian and Epstein, 1972). Still others have suggested integrative approaches to both the definition and measure of empathy in terms of its cognitive and emotional components (i.e. Davis, 1983).

Davis $(1980,1983)$ created the Interpersonal Reactivity Index (IRI), which measures both cognitive and affective components of empathy. I, however, propose using only one of the subscales from this Index, specifically the seven-item perspective taking subscale. Although theoretically I agree with the multi-factor approach to empathy as a construct, as I discussed above, for purposes of this investigation, I am particularly interested in the cognitive conceptualization of empathy originally proposed by Piaget (1932), as the ability to take the perspective of another. The perspective taking sub-scale aims to specifically measure an individual's tendency to embrace the psychological point of view of another. Items are scored on a 5-point Likert scale (from $0=$ does not describe me well, to $5=$ describes me very well). Davis (1980) reported the standardized reliability coefficient for this dimension as alpha $=.79$. 


\subsection{Validity and Reliability of Measures}

Given the range of measures, including newly developed measures, used for this study, the validity and reliability of these measures was explored to test various assumptions about the data for analysis.

\section{Inter-rater reliability}

First, because the responses to the moral imagination measure and the decisionmaking outcome involved coding open-ended responses by two coders, inter-rater reliability needed to be established. Prior to complete coding of all the responses to the moral imagination and decision-making measure, a sub-sample of 25 cases were used to establish inter-rater reliability between the two coders. To provide an accurate representation of the complete data set, the sub-sample was selected to mirror the major demographic characteristics of the entire group, specifically around gender, Net Impact membership, race, and type of student. Results indicated an acceptable level of interrater reliability on the coding of the sub-sample of 25 cases scored by the two coders. Overall, inter-rater reliability was $\alpha=0.882$ using Cronbach's alpha as a test. Looking at the specific correlations between the two coders' ratings on the six dimensions for each scenario ranged from $r=.996$ to $r=.846$, as detailed in Table 8 below. Given the strength of the correlations between the two raters' codings, it was determined that using multiple coders was appropriate for subsequent analysis and would not produce significant different coding results between the two coders. 


\begin{tabular}{|c|c|c|}
\hline Coding Dimension & Scenario \#1 & Scenario \#2 \\
\hline Issue Awareness & $r=.867$ & $r=.987$ \\
\hline Impact Awareness & $r=.938$ & $r=.938$ \\
\hline Fluency & $r=.938$ & $r=.938$ \\
\hline Flexibility & $r=.872$ & $r=.960$ \\
\hline Company Benefit & $r=.846$ & $r=.991$ \\
\hline Social Benefit & $r=.914$ & $r=.985$ \\
\hline
\end{tabular}

Table 8: Inter-rater Reliability Coefficients by Scenario

Vignette Impact

Before using the scores generated as overall averages for the two vignettes, the assumption first needed to be tested that the responses across the two vignettes did not differ significantly, and thus the average of the two was an accurate estimate of their responses. A series of paired t-tests was run to examine if the means of the four coded sub-dimensions of the moral awareness measure (i.e. impact awareness, issue awareness, fluency, and flexibility) and the two dimensions of the decision-making outcome variable (i.e. social benefit and company benefit) differed significantly by vignette.

Looking at the two sub-dimensions for "discerning" first, there were no significant differences found across the two vignettes for either impact awareness $(t(174)$ $=1.455, p=0.147)$ or issue awareness $(t(174)=1.270, p=0.206)$. Examining the subdimensions for "developing" however did reveal significant differences across the two vignettes, with t-scores for fluency and flexibility respectively: $(t(174)=3.652, p=$ $0.000)$ and $(t(174)=5.095, p=0.000)$. Summarized in Table 9, the means for each of 
these variables was higher for vignette 1 than for vignette 2 , meaning participants demonstrated higher levels of fluency, flexibility, and social benefit in their responses to the first vignette compared to the second.

\begin{tabular}{|l|l|l|l|}
\hline & \multicolumn{1}{|c|}{ Vignette 1 } & \multicolumn{1}{c|}{ Vignette 2 } & \multicolumn{1}{c|}{$\begin{array}{c}\text { Paired Sample t } \\
\text { scores }\end{array}$} \\
\hline Fluency & Mean $=2.06, \mathrm{SD}=0.92$ & Mean $=1.75, \mathrm{SD}=1.05$ & $\begin{array}{l}t(174)=3.65, p= \\
0.00\end{array}$ \\
\hline Flexibility & Mean $=2.13, \mathrm{SD}=0.77$ & Mean $=1.81, \mathrm{SD}=0.77$ & $\begin{array}{l}t(174)=5.10, p= \\
0.00\end{array}$ \\
\hline
\end{tabular}

Table 9: Mean differences for Fluency and Flexibility by Vignette

Next, looking at the two sub-dimensions for the dependent measure of type of decision-making outcome (social benefit and company benefit), more interesting differences were revealed. First, there were no significant differences found across the two vignettes for company benefit $(t(174)=0.00, p=1.00)$. A significant difference was found, however, for social benefit across the two vignettes, $(t(174)=2.716, p=$ 0.007). Summarized in Table 10, the means for social benefit was higher for vignette 1 than for vignette 2 , meaning that participants' decision-making outcomes for vignette 1 demonstrated higher levels of social benefit.

\begin{tabular}{|l|l|l|c|}
\hline & \multicolumn{1}{|c|}{ Vignette 1 } & \multicolumn{1}{c|}{ Vignette 2 } & Paired Sample t scores \\
\hline $\begin{array}{l}\text { Social } \\
\text { Benefit }\end{array}$ & $\begin{array}{l}\text { Mean }=1.61, \mathrm{SD}= \\
0.575\end{array}$ & Mean $=1.43, \mathrm{SD}=0.754$ & $t(174)=2.716, p=0.007$ \\
\hline
\end{tabular}

Table 10: Mean differences for Social Benefit by Vignette

Returning for a moment to the content of these two scenarios (Vignette 1 referred to the possible food poisoning by the natural foods company and Vignette 2 referred to the change in accounting and subsequent retirement benefit impacts), we might be able to better understand the differences appearing between the means for these various measures. For instance, it could be argued that because scenario one deals with an issue that has immediate implication both within and outside the company, it was easier for 
participants to create more and a wider variety of possible ways to take action, thus giving them higher fluency and flexibility scores on this scenario. Similarly, because scenario one dealt with a possible public health concern, actions to address the wider society's concerns may also have been more apparent than in scenario two which focused more on an internal company issue, thus resulting in higher social benefit scores.

Regardless of the post hoc rationale applied to these found differences, the entire purpose of having two scenarios to measure moral imagination was to help account for the fact that participants may likely respond more favorably on some dimensions for one scenario versus another. Thus, rather than reconfigure the calculation of the overall moral awareness score or the sub components, it was determined that using the average score across both scenarios would indeed serve as an appropriate representation for each of these measures. The differences across the two scenarios would thus be muted by averaging them together to get a better representative score of their ability to respond in fluent, flexible, and socially beneficial ways across different scenarios. I will return to this issue again, however, in Chapter 5 during the discussion of the limitations to the study.

\section{Criterion Related Validity of the Moral Imagination Measure}

Noted above, an important part of this research was to begin developing a measure for moral imagination as a holistic construct, as no such instrument yet existed at the time of this study. Given this aim, establishing criterion related validity was important to assess whether my vignette-based measure provided accurate measurements for the constructs it was designed to measure (Huck, 2004). As detailed earlier, my moral 
imagination instrument was designed with the intention of evaluating respondents' abilities for discerning moral aspects of a situation and developing a range of alternatives for the situation. To assess the validity of the instrument's measures for these abilities, I needed to be able to compare scores from my moral imagination measure with relevant criterion variables from other previously established measures. Specifically, I need to compare scores from respondents on my measure with validated measures for moral awareness (to validate my discerning measure) and creativity (to validate my developing measure). Additional measures for moral awareness and creativity were therefore administered concurrently with the survey, which are detailed below.

\section{Moral Awareness Measure as a Check for Discerning}

Just as with moral development, there are many different approaches for trying to assess moral awareness. Given the cognitive nature of moral awareness, I again wanted to used a vignette-based approach rather than a close-ended survey to assess this process. I decided to use part of Jordan's (2005) business vignette measure, which is derived from a measure used by Butterfield, et al. (2000). The measure presents participants with a corporate dilemma about developing a drug for a developing country, after which they are asked to imagine themselves as a member of a committee within the company that is meeting to discuss the presented dilemma (their specific position remains ambiguous). They are then asked to indicate: (1) three to five issues they would bring up to the committee (not the course of action that should be taken); (2) why they believe each issue is important to consider; and (3) rank the importance of each issue they raised (Jordan, 2005 , p. 57). The measure is actually similar to the 'ethical sensitivity' measure 
developed by Whittmer (2000). Unlike Whittmer's measure, however, which presents a defined list of factors to consider after reading a short vignette, Jordan's measure leaves the possible issues that participants see impacting their decision open-ended, and thus I felt it was a more accurate representation of their awareness of what the issues may have even included.

Using Jordan's (2005) rating rubric to score this measure (see Appendix B), a coder read the various issues the participant listed they would bring up to the committee. Each issue was rated on an 8 -point Likert scale $\left(8=\right.$ almost entirely and $1=$ not at all $\left.{ }^{18}\right)$ across eight dimensions. Four dimensions were related to strategic components, including: financial profitability (FP), viability or competitive stance (VL), legal culpability (LC), industry image or public reputation (PR). The other four dimensions were related to moral components, including: well-being of the powerful (WBP), wellbeing of the non-powerful (WBN), well-being of the community (WBC), and ethical or moral responsibility $(\mathrm{EM})$.

Following Jordan's analysis plan as a guide, an overall moral and strategic average were each calculated by first summing the coded scores of each item listed across the eight dimensions (i.e. FPsum, VLsum, LCsum, PRsum, WBPsum, WBNsum, WBCsum, EMsum). Then these sums were then averaged to create composite moral and strategic awareness scores, such that: moral awareness average $=(($ WBPsum + WBNsum + WBCsum + EMsum $) / 4)$; and strategic awareness average $=(($ FPsum + VLsum + LCsum + PRsum)/4). Finally, as she did for her analysis, using these two averages, a difference score between the moral and strategic components were

\footnotetext{
18 This was reverse scored compared to Jordan's original rubric (which had $8=$ not at all and $1=$ almost entirely), so that higher scores would indicate higher association with that dimension
} 
calculated $^{19}$. The difference score involved dividing the moral average by the strategic average such that a score close to 1 indicated an equal emphasis placed on strategic and moral issues, a number less than one indicated an emphasis on strategic issues over moral, and a number greater than one indicated an emphasis on moral over strategic issues. As Jordan notes, using this difference score allow for further interpretation of how much emphasis the participant placed on moral issues versus strategic issues (Jordan, 2005).

First, looking at the descriptive statistics for Jordan's moral awareness measure, participants listed an average of 3.49 issues $($ minimum $=1$; maximum $=5 ; \mathrm{SD}=1.26)$ for this measure. Because only one coder was used for scoring this measure, establishing inter-rater reliability was not needed. Table 11 provides the descriptive statistics for participants' moral and strategic awareness averages, as well as difference scores between these two, and the eight dimension sums that were detailed in Chapter 3.

\footnotetext{
${ }^{19}$ She also calculated a ratio score for comparison, but I will only be using the difference score for my current analysis.
} 


\begin{tabular}{|c|c|c|c|c|}
\hline & & & & \\
\hline & Mean & Min & Max & S.D. \\
\hline \multicolumn{5}{|l|}{ Total Awareness Scores } \\
\hline Moral Awareness Average & 5.57 & 2.00 & 13.50 & 1.91 \\
\hline Strategic Awareness Average & 8.76 & 1.00 & 15.75 & 2.65 \\
\hline Moral and Strategic Difference & -3.18 & -10.75 & 7.25 & 2.93 \\
\hline \multicolumn{5}{|l|}{ Dimension Sum Scores } \\
\hline Financial Profitability (FP) & 12.98 & 1.0 & 28 & 5.47 \\
\hline Viability or competitive stance (VL) & 12.40 & 1.0 & 38 & 6.02 \\
\hline Legal Culpability (LC) & 5.17 & 1.0 & 12 & 2.79 \\
\hline Industry image or public reputation (PR) & 5.64 & 1.0 & 19 & 3.39 \\
\hline Well-being on the powerful (WBP) & 4.07 & 1.0 & 13 & 1.60 \\
\hline Well-being of the non-powerful (WBN) & 7.44 & 1.0 & 24 & 4.26 \\
\hline Well-being of the community (WBC) & 5.09 & 1.0 & 25 & 3.16 \\
\hline Ethical or moral responsibility (EM) & 5.64 & 1.0 & 24 & 3.52 \\
\hline
\end{tabular}

Table 11: Descriptive Statistics for the Moral Awareness Measures $(\mathrm{N}=171)$

Again, theoretically I expected scores on my measure for discerning (including specifically scores for issue awareness (ISA) and impact awareness (IMA)) to correlate with their scores on Jordan's (2005) measure of moral awareness. As anticipated, results from bi-variate correlations showed that participants discerning score, and sub-scores, were correlated to scores on Jordan's moral awareness measure. Specifically, the overall discerning average score correlated with the strategic awareness average $(r=0.153, p=$ $0.046)$, the moral awareness average $(r=0.192, p=0.012)$. While it was not significantly correlated with the strategic/moral awareness difference score $(r=-0.13, p$ 
$=0.870)$, the overall discerning score was also correlated with some of the specific moral awareness sub-dimensions established in Jordan's measure as well, including “well-being of people in power" $(r=0.195, p=0.011)$ and "well-being of the community" $(r=0.162$, $p=0.034$ ). Discerning was not, however, correlated with any of the specific strategic awareness sub-dimensions in Jordan's measure.

Looking deeper into the data, it was also found that as would be expected, specific sub-components of discerning (impact awareness and issue awareness) also correlated with various scores from Jordan's measure of moral awareness as well. Issue awareness, for example, was found to be significantly correlated with the moral awareness average $(r$ $=.229, p=0.003$ ), as well as the moral awareness sub-component, "well-being of people in power" $(r=0.168, p=0.028)$. Impact awareness, while not significantly correlated to the overall moral awareness average, was also found to be significantly correlated with the moral awareness sub-component, "well-being of people in power" $(r=0.155, p=$ 0.043). Table 12 summarizes these findings in a correlation matrix. These various correlations between participants' ratings for discerning on the new moral awareness measure and the criterion-related measure, lend support to the assumption that the new moral imagination instrument, specifically the discerning sub-element, was reflective of participants' ability to recognize the moral aspects of a situation. 


\begin{tabular}{|c|c|c|c|c|c|c|c|c|c|c|}
\hline & $\begin{array}{r}\text { Discerning } \\
\text { Average }\end{array}$ & $\begin{array}{r}\text { Issue } \\
\text { Aware }\end{array}$ & $\begin{array}{l}\text { Impact } \\
\text { Aware }\end{array}$ & $\begin{array}{l}\text { Strat } \\
\text { Avg }\end{array}$ & $\begin{array}{r}\text { Moral } \\
\text { Avg }\end{array}$ & WBP & WBN & WBC & $\mathrm{EM}$ & $\begin{array}{r}\text { Moral } \\
\text { Aware } \\
\text { Dif }\end{array}$ \\
\hline $\begin{array}{l}\text { Discerning } \\
\text { average }\end{array}$ & 1.000 & $.719^{* *}$ & $.889^{* *}$ & $.153^{*}$ & $.192^{*}$ & $.195^{*}$ & .017 & $.162^{*}$ & .146 & -.013 \\
\hline Issue Aware & & 1.000 & $.322^{* *}$ & .104 & $.229^{* *}$ & $.168^{*}$ & .110 & .145 & .141 & .056 \\
\hline Impact Aware & & & 1.000 & |.139 & .111 & $.155^{*}$ & -.049 & .125 & .106 & -.053 \\
\hline Strat. Avg & & & & 1.000 & $.207^{* *}$ & $.428^{* *}$ & -.052 & $.223^{* *}$ & .116 & $-.769^{* *}$ \\
\hline Moral Avg & & & & & 1.000 & $.599^{* *}$ & $.674^{* *}$ & $.638^{* *}$ & $.514^{* *}$ & $.466^{* *}$ \\
\hline WBP & & & & & & 1.000 & $.252^{* *}$ & $.421^{* *}$ & $.154^{*}$ & .004 \\
\hline WBN & & & & & & & 1.000 & $.180^{*}$ & -.012 & $.487^{* *}$ \\
\hline WBC & & & & & & & & 1.000 & .093 & $.214^{* *}$ \\
\hline EM & & & & & & & & & 1.000 & $.230^{* *}$ \\
\hline $\begin{array}{l}\text { Moral Aware } \\
\text { Dif }\end{array}$ & & & & & & & & & & 1.000 \\
\hline $\begin{array}{l}* * \text { Correlation } \\
{ }^{*} \text { Correlation } \\
\mathrm{N}=171\end{array}$ & $\begin{array}{l}\text { is significa } \\
\text { s significan }\end{array}$ & $\begin{array}{l}\text { at the } 0 \\
\text { it the } 0 .(\end{array}$ & $\begin{array}{l}1 \text { level } \\
\text { level }(2\end{array}$ & $\begin{array}{l}\text { 2-tailed } \\
\text {-tailed) }\end{array}$ & & & & & & \\
\hline
\end{tabular}

Table 12: Correlation Matrix for Moral Awareness and Discerning

\section{Creativity Measure as a Check for Developing}

The second proposed dimension of the moral imagination measure, developing, was designed to assess a participant's ability to create a variety of possible solutions to a situation. This element included scores for fluency (FLU), or how many solutions were generated, as well as flexibility (FLX), or how many different types of solutions were generated. As such, it was expected that scores on these measures would correlate with scores on other established creativity measures.

Typical of most psychological constructs, there are a multitude of measures designed to assess creativity. Almost twenty years ago, Hovevar \& Bachelor (1989) classified what was then 100 measurements of creativity into eight categories such as 
'tests of divergent thinking," "judgment of creative products" and "ratings by others". As I discussed above, I am interested in conceptualizing and measuring creativity as the ability to engage in divergent thinking, which is what my coding of fluency and flexibility for the developing component of moral imagination is trying to assess. As such, for the criterion related validity check of this measure, I used a subscale from an instrument created by Basadur and Hausdorf (1996) based on the measures originally created by Basadur and Finkbeiner (1983). This subscale measures two attitudinal factors indicated by previous research to be related to divergent thinking: valuing new ideas and a preference of ideation (or divergent thinking) (Basadur and Hausdorf, 1996). The subscale includes 13 items and uses a Likert-style 5-point scale format ranging from 5 (strongly agree) to 1 (strongly disagree).

Summing the responses to the items, a creativity score was calculated for each respondent, with higher scores indicating higher levels of creativity. The average score was $23.70($ minimum $=13 ;$ maximum $=39 ; \mathrm{SD}=4.797) . \quad$ The overall average developing score was just shy of being significantly correlated with the Basadur and Hausdorf creativity measure $(r=0.143, p=0.063)$. In looking at the sub-components of developing, the only significant correlation with the creativity measure was found with the flexibility sub-score, $(r=0.165, p=0.032)$. Table 13 summarizes these findings in a correlation matrix. 


\begin{tabular}{|l|r|r|r|r|}
\hline & Fluency & Flexibility & $\begin{array}{c}\text { Developing } \\
\text { average }\end{array}$ & Creativity \\
\hline Fluency & 1.000 & $.684^{* *}$ & $.936^{* *}$ & .104 \\
\hline Flexibility & & 1.000 & $.897^{* *}$ & $.165^{*}$ \\
\hline $\begin{array}{l}\text { Developing } \\
\text { average }\end{array}$ & & & 1.000 & .143 \\
\hline Creativity & & & & 1.000 \\
\hline
\end{tabular}

Table 13: Correlation Matrix for Creativity, Developing, Fluency and Flexibility

While these findings may at first seem to provide mixed support to the assumption that the developing measure within the moral imagination instrument reflected participants' divergent thinking abilities, overall they are encouraging. Specifically promising is the fact that the Flexibility score was correlated with the creativity scores. As I will discuss in the limitations to this study in Chapter 5, the specific creativity instrument that was used for this criterion-related check may be the underlying reason that more significant relationships were not found. Basadur and Hausdorf's creativity measure was a self-report survey, and thus relied on participants, in a sense, to recognize their own ability to think divergently.

While further testing is needed to better establish the reliability and validity of the new moral imagination measure, these current findings provided enough evidence for criterion related validity to proceed with other analyses using the scores from the new moral imagination measure. 


\subsection{Social Desirability Check}

When answering questions about morality and other potentially personal perceptions, individuals may answer in a manner they see as socially acceptable, or in a manner that projects a favorable description of themselves. To account for this tendency, I included a short version of the Social Desirability Scale (SDS) as outlined by Ray (1984). This version consists of eight questions from the original 33-item scale created by Crowne \& Marlowe (1960) which asks participants yes-no questions about their tendency to behave in certain ways with the idea of detecting individuals who present themselves in a socially-desirable, but inaccurate, manner. This short version has been shown to have an alpha of .74 .

Scores on this measure were used only as a control, with individuals who rated particularly high (meaning that they are perhaps answering only in a socially desirable manner and thus biasing the results towards inflated ethical sensitivity) excluded from further analysis. Using the same threshold as Yetmar and Eastman (2000), if the subject, gave a socially desirable answer to more than $50 \%$ of the questions, their responses were discounted from further analysis. Based on this criterion, 14 subjects were removed from subsequent analysis. 


\section{CHAPTER 4}

\section{RESULTS}

This chapter details the analyses performed to test the theoretical model and hypotheses outlined in Chapter 2. After reviewing the hypotheses and theoretical model being tested, I detail which hypotheses were supported and which ones were refuted. I conclude the chapter with a description of the post-hoc exploratory analyses performed.

\subsection{Review of Theoretical Model}

As detailed in Chapter 2, I have suggested that individuals who can discern moral issues and develop a range of alternatives to a situation have a greater likelihood of creating mutually beneficial outcomes than those who do not demonstrate these abilities. Furthermore, I hypothesize that these two abilities exercised in unison will be the best predictor of identifying who creates mutually beneficial solutions to a situation. I also predicted that an individual's ability to discern moral issues and develop creative alternatives to a situation is potentially impacted by factors such as moral development characteristics such as their level of egotism, relativism, idealism, dogmatism, and empathy. The model that illustrates the specific hypotheses I will be testing is pictured again below. 


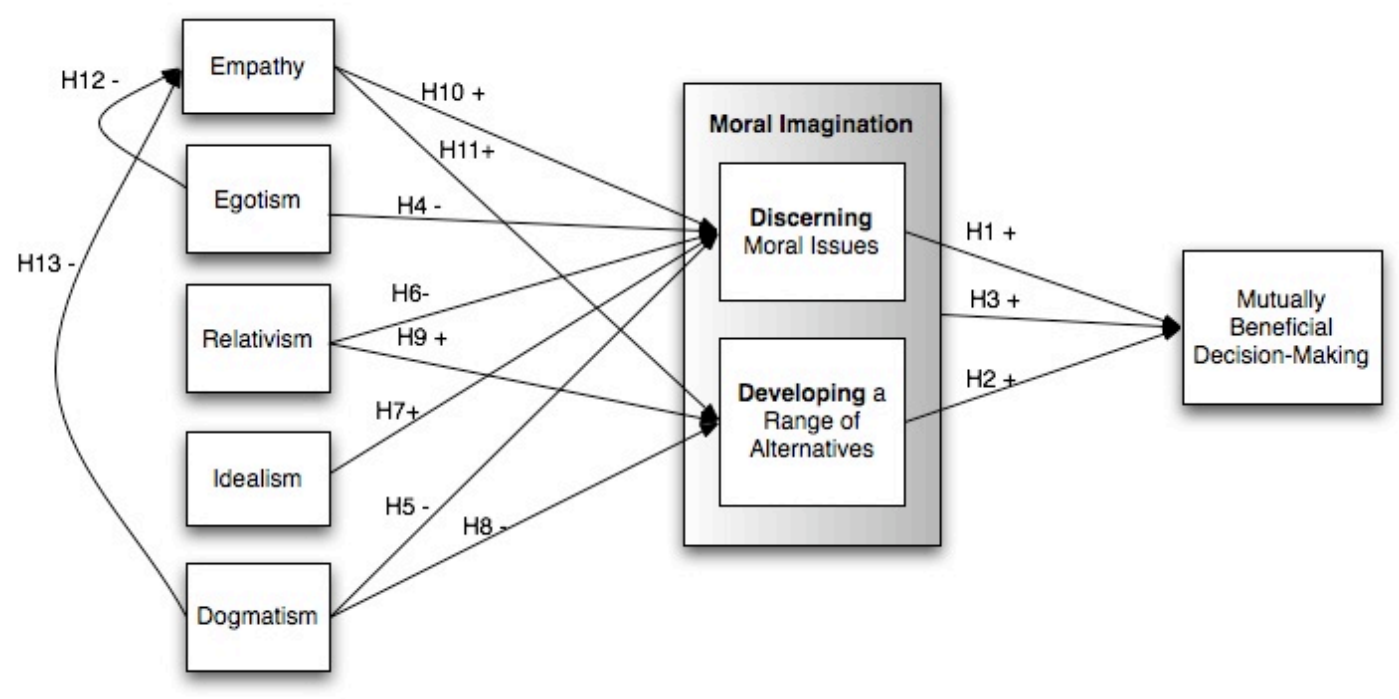

Figure 2: Proposed model for moral imagination and mutually beneficial decisionmaking

\subsection{Hypotheses Testing}

The first hypothesis aimed at exploring if there was a correlation between an individual's ability to discern moral aspects of a situation and their ability to create mutually beneficial solutions for that situation. It was hypothesized that there would indeed be a positive relationship between these two variables, with individuals who generate mutually beneficial solutions demonstrating a greater ability for discerning compared to those who demonstrate do not generate mutually beneficial outcomes. A one-way ANOVA was run to examine the differences in demonstrated ability for discerning moral issues by type of decision-making outcome. Supporting Hypothesis 1, a significant difference was found in demonstrated abilities for discerning by type of decision-making outcome, $(F(3,167)=6.162 ; p=0.001)$. As predicted, individuals who generated mutually beneficial outcomes did in fact have the highest mean discerning average, $2.62(\mathrm{SD}=1.34)$, compared to all the other types of outcomes generated. 
Summarized in Table 14, individuals who demonstrated other types of decision-making outcomes had lower discerning averages: the self-sacrificing group had a mean of 2.25 $(\mathrm{SD}=1.54)$; the self-interest group had a mean of $2.05(\mathrm{SD}=1.13)$; and the anti-social group had a mean of $1.31(\mathrm{SD}=0.89)$.

\begin{tabular}{|l|r|r|r|r|r|r|}
\hline \multicolumn{1}{|c|}{ Type of Decision } & $\mathrm{N}$ & \multicolumn{1}{c|}{ Mean } & Std. Deviation & Std. Error & Minimum & Maximum \\
\hline Mutually beneficial & 60 & 2.6167 & 1.34154 & .17319 & .00 & 6.00 \\
Self-sacrificing & 6 & 2.2500 & 1.54110 & .62915 & .00 & 4.00 \\
Self-interest & 84 & 2.0476 & 1.12641 & .12290 & .00 & 4.50 \\
Anti-social & 18 & 1.3056 & .89342 & .21058 & .00 & 3.00 \\
\hline Total & 168 & 2.1786 & 1.25646 & .09694 & .00 & 6.00 \\
\hline
\end{tabular}

Table 14: Discerning Averages by Type of Decision-Making Outcome

The second hypothesis aimed at exploring if there was a correlation between an individual's ability to develop a range of possible solutions for a situation and their ability to create mutually beneficial solutions for that situation. It was hypothesized that there would indeed be a positive relationship between these two variables, with individuals who generate mutually beneficial solutions demonstrating a greater ability for developing a range of possible solutions for the situation compared to those who demonstrate do not generate mutually beneficial outcomes. Another one-way ANOVA was run to examining the differences in demonstrated ability for developing a range of alternative solutions for a situation by type of decision-making outcome. Supporting Hypothesis 2, a significant difference was found in demonstrated abilities for developing by type of decision-making outcome, $(F(3,167)=5.425 ; p=0.001)$. However, somewhat different than predicted, individuals who generated mutually beneficial outcomes had the second highest mean developing average $4.13(\mathrm{SD}=1.35)$. The highest developing mean 
score was actually found in the self-sacrificing group, with a mean of $4.67(\mathrm{SD}=0.88)$.

Summarized in Table 15, individuals who demonstrated other types of decision-making outcomes had lower developing averages, with the self-interest group demonstrating a mean of $3.82(\mathrm{SD}=1.29)$; and the anti-social group had a mean of $2.83(\mathrm{SD}=1.21)$.

\begin{tabular}{|l|r|r|r|r|r|r|}
\hline \multicolumn{1}{|c|}{ Type of Decision } & $\mathrm{N}$ & \multicolumn{1}{c|}{ Mean } & Std. Deviation & Std. Error & Minimum & Maximum \\
\hline Mutually beneficial & 60 & 4.1250 & 1.34550 & .17370 & .50 & 6.00 \\
Self-sacrificing & 6 & 4.6667 & .87560 & .35746 & 3.50 & 6.00 \\
Self-interested & 84 & 3.8155 & 1.29359 & .14114 & 1.00 & 6.00 \\
Anti-social & 18 & 2.8333 & 1.21268 & .28583 & 1.00 & 5.50 \\
\hline Total & 168 & 3.8512 & 1.34427 & .10371 & .50 & 6.00 \\
\hline
\end{tabular}

Table 15: Developing Averages by Type of Decision-Making Outcome

The third hypothesis was designed to investigate if the simultaneous demonstration of both discerning and developing abilities in a situation would result in the greater likelihood of arriving at a mutually beneficial decision compared to those who demonstrate either ability in isolation or not at all. Given that both the variables for moral imagination and decision-making outcomes are categorical, a cross-tabulation was run to explore the relationship between these two variables. A significant Chi-square test allows for the rejection of the null hypothesis that there is no relationship between the moral imagination group and decision-making outcome (or that the differences seen are due to chance), thus lending support to the argument that these variables are related, $\left(x^{2}\right.$ $(3 \mathrm{df})=1.114, \mathrm{p}<0.011)$. Hypothesis 3 is further supported through examination of the expected and observed counts in each for the moral imagination group by type of decision-making outcome (see Table 16). As predicted by Hypotheses 3, the distribution of scores indicates that respondents in the morally imaginative group were more likely to 
be in the mutual beneficial decision-making group as well, with the majority of the participants in the morally imaginative group (68.4\%) also found to be in the group that created the most mutually beneficial solutions to the situations ${ }^{20}$. This is compared to the $31.8 \%$ of those in the non-morally imaginative group who created mutually beneficial solutions. The majority of the non-morally imaginative group, on the other hand, was found to generate solutions to the business dilemma that were in their own self-interest $(52.7 \%)$, compared to the only $26.3 \%$ of the morally imaginative individuals who were also found to generate self-interested focused solutions. Also interesting is the fact that no one in the morally imaginative group was found to generate responses that were considered anti-social/self-destructive, whereas $12.2 \%$ of those in the non-morally imaginative group were also found in this category. Other interpretations and implications of these findings will be addressed in Chapter 5.

\footnotetext{
${ }^{20}$ Examination of the positive residual in the mutually beneficial cell also shows that if the two variables were not related, then we would expect to see only 7 of the morally imaginative respondents in that group, but the observed count of 14 was double that expectation.
} 


\begin{tabular}{|c|c|c|c|c|}
\hline \multirow{2}{*}{\multicolumn{2}{|c|}{ Type of Decision-Making Outcome }} & \multicolumn{3}{|c|}{ Moral Imagination Grouping } \\
\hline & & \multirow{2}{*}{$\begin{array}{c}\begin{array}{c}\text { Morally } \\
\text { Imaginative }\end{array} \\
14\end{array}$} & \multirow{2}{*}{$\begin{array}{r}\begin{array}{l}\text { Non-Morally } \\
\text { Imaginative }\end{array} \\
47\end{array}$} & \multirow{2}{*}{$\frac{\text { Total }}{60}$} \\
\hline \multirow[t]{4}{*}{ Mutually Beneficial } & Observed & & & \\
\hline & Expected & 6.8 & 53.2 & 60.0 \\
\hline & $\%$ & $68.4 \%$ & $31.8 \%$ & $35.9 \%$ \\
\hline & Std. Residual & 2.4 & -.8 & \\
\hline \multirow[t]{4}{*}{ Self- sacrificing } & Observed & 1 & 5 & 6 \\
\hline & Expected & .7 & 5.3 & 6.0 \\
\hline & $\%$ & $5.3 \%$ & $3.4 \%$ & $3.6 \%$ \\
\hline & Std. Residual & .4 & -.1 & \\
\hline \multirow[t]{4}{*}{ Self-interested } & Observed & 5 & 78 & 83 \\
\hline & Expected & 9.4 & 73.6 & 83.0 \\
\hline & $\%$ & $26.3 \%$ & $52.7 \%$ & $49.7 \%$ \\
\hline & Std. Residual & -1.4 & .5 & \\
\hline \multirow[t]{4}{*}{ Anti-social } & Observed & & & \\
\hline & Expected & 2.0 & 16.0 & 18.0 \\
\hline & $\%$ & $.0 \%$ & $12.2 \%$ & $10.8 \%$ \\
\hline & Residual & -2.0 & 2.0 & \\
\hline \multirow[t]{3}{*}{ Total } & Observed & 20 & 148 & 167 \\
\hline & Expected & 20.0 & 148.0 & 167.0 \\
\hline & $\%$ & $100.0 \%$ & $100.0 \%$ & $100.0 \%$ \\
\hline
\end{tabular}

Table 16: Decision-making Outcome by Moral Imagination Group 


\section{Exploring Factors Impacting Moral Imagination}

The remaining hypotheses to be tested focused on other factors predicted to impact one's ability for moral imagination, specifically the abilities of discerning and developing. Given the exploratory nature of this study, and the fact that the measures I am using for moral imagination have not been tested elsewhere, for the subsequent hypotheses it was determined that bi-variate correlations were the most appropriate statistics to use. Such tests will allow for the rejection (or not) of the remaining proposed hypotheses and help determine if the predicted relationships are tenable for future research (which will be discussed in chapter 5).

Hypothesis 4 predicted that higher levels of egocentrism would negatively impact a participant's ability for discerning the moral issues in a situation. To test this hypothesis, an egocentrism score was calculated for each respondent by reverse coding items in Jordan's (2005) egotism scale used to assess this construct. The average score was 31.56 (minimum $=13 ;$ maximum $=48 ; \mathrm{SD}=6.76$ ) with higher scores signifying higher levels of egocentrism. A bi-variate correlation revealed that there was indeed a significant negative relationship between a participant's egocentrism and overall discerning score, $(r=-0.331, p=0.000)$, meaning that, as predicted in $\mathrm{H} 4$, the higher a person's level of egocentrism, the lower their overall discerning score.

Hypothesis 5 predicted that higher levels of dogmatism would negatively impact a participant's ability for discerning the moral issues in a situation. As detailed in Chapter 3, dogmatism was measured using Schulze's (1962) shortened version (10 items) of the Rokeach Dogmatism Scale. After reverse coding the needed items, a dogmatism score 
was calculated for each respondent, with higher scores indicating higher levels of dogmatism. The average score was $31.66($ minimum $=17$; maximum $=49 ; \mathrm{SD}=6.512)$. Another bi-variate correlation was run, revealing that there was also a significant negative relationship between a participant's dogmatism and overall discerning score, $(r$ $=-0.211, p=0.006)$, meaning that, as predicted in H5, the higher a person's level of dogmatism, the lower their overall discerning score.

Hypothesis 6 predicted that higher levels of relativism would negatively impact a participant's ability for discerning the moral issues in a situation. Moral relativism and idealism (analyzed below) were both measured using the Ethics Position Questionnaire (EPQ) developed by Forsyth (1980). Adding the appropriate items together, separate scores were calculated for moral relativism and moral idealism. The average score for relativism was $56.86($ minimum $=24 ;$ maximum $=82 ; \mathrm{SD}=11.722)$. A third bi-variate correlation was run, revealing that as $\mathrm{H} 5$ predicted, there was also a significant negative relationship between a participant's level of relativism and overall discerning score, $(r=$ 0.198, $p=0.011$ ), meaning that the higher a person's level of relativism, the lower their overall discerning score.

Hypothesis 7 predicted that higher levels of idealism would positively impact a participant's ability for discerning the moral issues in a situation. Based on the EPQ, the average score for idealism was $47.30($ minimum $=10 ;$ maximum $=82 ; \mathrm{SD}=11.963)$. The bi-variate correlation run between these two variables did reveal a significant relationship, $(r=-0.187, p=0.017)$, but not in the direction predicted by $\mathrm{H} 7$. While it was hypothesized that the higher a person's level of idealism the higher their overall 
discerning score would be, the correlation revealed that the relationship was negative, not positive.

Hypothesis 8 predicted that higher levels of dogmatism would negatively impact a participant's ability for determining a range of alternatives to a situation. A bi-variate correlation showed that there was a significant negative relationship between a participant's dogmatism and overall developing score, $(r=-0.172, p=0.026)$, meaning that, as predicted in H8, the higher a person's level of dogmatism, the lower their overall developing score.

Hypothesis 9 predicted that higher levels of relativism would positively impact a respondent's ability for determining a range of alternatives to a situation. A bi-variate correlation showed that there was a significant relationship between a participant's relativism score and their overall developing score, $(r=-0.172, p=0.028)$, but not in the direction predicted. Unlike predicted in H9, the higher a person's level of relativism the lower their overall developing score.

The remaining four hypotheses explored the relationship of empathy to discerning and developing, as well as to other factors explored above. Empathy was measured using the perspective-taking subscale from Davis’s $(1980,1983)$ Interpersonal Reactivity Index, which measures both cognitive and affective components of empathy. After reverse scoring the appropriate items, a composite empathy score was created for each respondent, such that a higher sore indicated a higher level of empathy. The average score was $26.60($ minimum $=10 ;$ maximum $=35 ; \mathrm{SD}=4.650)$. Hypothesis 10 predicted that higher levels of empathy would positively impact a participant's ability for discerning the moral aspects of a situation. A bi-variate correlation did not indicate a 
significant relationship between these two scores, $(r=0.019, p=0.806)$. Based on this finding, $\mathrm{H} 10$ is not supported.

Hypothesis 11 predicted that higher levels of empathy would also positively impact a participant's ability for determining a range of possible alternatives for a situation. As was the case with $\mathrm{H} 10$, a bi-variate correlation did not indicate a significant relationship between these two scores, $(r=0.094, p=0.211)$. Based on this finding, H11 is not supported.

Hypothesis 12 predicted that there would be a negative relationship between a participant's level of empathy and their level of egotism. A bi-variate correlation did not indicate a significant relationship between these two scores, $(r=0.090, p=0.247)$. Based on this finding, H12 is not supported.

Finally, hypothesis 13 predicted that there would be a negative relationship between a participant's level of empathy and their level of dogmatism. While a bi-variate correlation did suggest that the direction of the hypothesized relationship was correct, it did not indicate a significant relationship between these two scores, $(r=0.090, p=$ 0.251). Based on this finding, H13 is not supported.

\subsection{Post-hoc Exploratory Analysis}

Again, the aim of this research was to better understand who are the individuals that are creating mutually beneficial solutions when faced with a business dilemma. Thus, in addition to the a priori hypothesis testing conducted above, a number of posthoc exploratory analyses were also run to further explore the variables that might help predict who is creating mutual benefit in organizational decision-making. 
Using the demographic variables ${ }^{21}$ of gender, age, membership in Net Impact, and organizational experience as variables along which an individual's type of decisionmaking outcomes may differ, a series of analyses were run to explore what individual characteristics may help predict who is more likely to create mutually beneficial decisions. Additional analyses were also run to further explore other factors that may also impact an individual's demonstrated moral imagination ability.

\section{Impact of Gender on Decision-Making and Moral Imagination}

To explore how gender may be related to the type of decision-making outcome observed, a cross-tabulation was run to explore the relationship between these two categorical variables. Summarized in Table 17, the observed and expected counts for each cell were very similar, with men and women also demonstrating relatively equal distributions across the four possible decision-making outcomes. A non-significant Chisquare test on these results supported retaining the null hypothesis, which would suggested that there is no significant relationship between gender and type of decisions making outcome $\left(x^{2}(3 \mathrm{df})=1.333, \mathrm{p}<0.721\right)$.

\footnotetext{
${ }^{21}$ Given the lack of racial diversity in the sample (78\% Caucasian), this demographic variable was not used in post-hoc analysis. Future research with a larger, more diverse sample could explore this factor.
} 


\begin{tabular}{|c|c|c|c|c|}
\hline \multicolumn{2}{|c|}{ Type of Decision-Making Outcome } & \multicolumn{3}{|c|}{ Gender } \\
\hline & & Female & Male & Total \\
\hline Mutually beneficial & $\begin{array}{l}\text { Count } \\
\text { Expected Count } \\
\% \\
\text { Residual }\end{array}$ & $\begin{array}{r}29 \\
31.8 \\
32.6 \% \\
-2.8\end{array}$ & $\begin{array}{r}31 \\
28.2 \\
39.2 \% \\
2.8\end{array}$ & $\begin{array}{r}60 \\
60.0 \\
35.7 \%\end{array}$ \\
\hline Self-sacrificing & $\begin{array}{l}\text { Count } \\
\text { Expected Count } \\
\% \\
\text { Residual }\end{array}$ & $\begin{array}{r}4 \\
3.2 \\
4.5 \% \\
.8\end{array}$ & $\begin{array}{r}2 \\
2.8 \\
2.5 \% \\
-.8\end{array}$ & $\begin{array}{r}6 \\
6.0 \\
3.6 \%\end{array}$ \\
\hline Self-interested & $\begin{array}{l}\text { Count } \\
\text { Expected Count } \\
\% \\
\text { Residual }\end{array}$ & $\begin{array}{r}47 \\
44.5 \\
52.8 \% \\
2.5\end{array}$ & $\begin{array}{r}37 \\
39.5 \\
46.8 \% \\
-2.5\end{array}$ & $\begin{array}{r}84 \\
84.0 \\
50.0 \%\end{array}$ \\
\hline Anti-social & $\begin{array}{l}\text { Count } \\
\text { Expected Count } \\
\% \\
\text { Residual }\end{array}$ & $\begin{array}{r}9 \\
9.5 \\
10.1 \% \\
-.5 \\
\end{array}$ & $\begin{array}{r}9 \\
8.5 \\
11.4 \% \\
.5 \\
\end{array}$ & $\begin{array}{r}18 \\
18.0 \\
10.7 \%\end{array}$ \\
\hline Total & $\begin{array}{l}\text { Count } \\
\text { Expected Count } \\
\%\end{array}$ & $\begin{array}{r}89 \\
89.0 \\
100.0 \%\end{array}$ & $\begin{array}{r}79 \\
79.0 \\
100.0 \%\end{array}$ & $\begin{array}{r}168 \\
168.0 \\
100.0 \%\end{array}$ \\
\hline
\end{tabular}

Table 17: Gender by Type of Decision-Making Outcome

Looking at the relationship between gender and moral imagination, first one-way ANOVAs were run to examine the possible impact of gender on the two components of moral imagination, discerning, and developing. Gender was not found to have a significant impact on either demonstrations of discerning moral issues $(F(1,174)=$ $0.407 ; p=0.524)$ or developing a range of alternatives for a situation $(F(1,174)=0.119$; $p=0.731)$. As further detailed in Table 18, it was clear that the means for these two abilities across the genders were very similar. Even looking at the subcomponents that 
comprise both of these abilities, further ANOVAs showed that there were no significant differences across the genders for issue awareness $(F(1,174)=0.088 ; p=0.766)$, impact awareness $(F(1,174)=2.283 ; p=0.094)$, fluency $(F(1,174)=0.456 ; p=0.500)$, or flexibility $(F(1,174)=0.126 ; p=0.724)$.

\begin{tabular}{|l|l|r|r|r|r|r|r|}
\hline & & & \multicolumn{1}{c|}{$\begin{array}{c}\text { Std. } \\
\text { Nean }\end{array}$} & Deviation & Std. Error & Minimum & Maximum \\
\hline Discerning & Female & 94 & 2.1330 & 1.23823 & .12771 & .00 & 6.00 \\
average & Male & 81 & 2.2531 & 1.24530 & .13837 & .00 & 4.50 \\
& Total & 175 & 2.1886 & 1.23939 & .09369 & .00 & 6.00 \\
\hline Developing & Female & 94 & 3.9096 & 1.39885 & .14428 & .50 & 6.00 \\
average & Male & 81 & 3.8395 & 1.26942 & .14105 & 1.00 & 6.00 \\
& Total & 175 & 3.8771 & 1.33715 & .10108 & .50 & 6.00 \\
\hline
\end{tabular}

Table 18: Mean Discerning and Developing Scores by Gender

Next, to look at gender by overall moral imagination group, a cross tabulation was run between these two variables. As illustrated in Table 19 the observed and expected counts for each cell were very close, and looking across the genders there was a very similar distribution across the morally imaginative groups. For the women, $10.8 \%$ were in the morally imaginative group, and with the men, $11.1 \%$ were found to be in the morally imaginative group. Another non-significant Chi-square test suggested that there was no significant relationship between gender and overall moral imagination group $\left(x^{2}\right.$ $(1 \mathrm{df})=0.006, \mathrm{p}<0.94)$ 


\begin{tabular}{|c|c|c|c|c|}
\hline \multicolumn{2}{|c|}{ Moral Imagination Group } & \multicolumn{3}{|c|}{ Gender } \\
\hline & & Female & Male & Total \\
\hline Morally Imaginative & $\begin{array}{l}\text { Count } \\
\text { Expected Count } \\
\% \\
\text { Residual } \\
\text { Std. Residual }\end{array}$ & $\begin{array}{r}10 \\
10.2 \\
10.8 \% \\
-.2 \\
.0\end{array}$ & $\begin{array}{r}9 \\
8.8 \\
11.1 \% \\
.2 \\
.1\end{array}$ & $\begin{array}{r}19 \\
19.0 \\
10.9 \%\end{array}$ \\
\hline $\begin{array}{l}\text { Non-Morally } \\
\text { Imaginative }\end{array}$ & $\begin{array}{l}\text { Count } \\
\text { Expected Count } \\
\% \\
\text { Residual } \\
\text { Std. Residual } \\
\end{array}$ & $\begin{array}{r}83 \\
82.8 \\
89.2 \% \\
.2 \\
.0\end{array}$ & $\begin{array}{r}72 \\
72.2 \\
88.9 \% \\
-.2 \\
.0 \\
\end{array}$ & $\begin{array}{r}155 \\
155.0 \\
89.1 \%\end{array}$ \\
\hline Total & $\begin{array}{l}\text { Count } \\
\text { Expected Count } \\
\%\end{array}$ & $\begin{array}{r}93 \\
93.0 \\
100.0 \%\end{array}$ & $\begin{array}{r}81 \\
81.0 \\
100.0 \%\end{array}$ & $\begin{array}{r}174 \\
174.0 \\
100.0 \%\end{array}$ \\
\hline
\end{tabular}

Table 19: Gender by Moral Imagination Group

\section{Impact of Age on Decision-Making and Moral Imagination}

Next, to explore how age may be related to the type of decision-making outcome observed, a cross-tabulation was run to explore the relationship between these two variables (age was collected as a categorical variable). Summarized in Table 20, the observed and expected counts for each cell were very similar, with the various age groups also demonstrating relatively equal distributions across the four possible decision-making outcomes. A non-significant Chi-square test on these results supported retaining the null hypothesis, which would suggest that there is no significant relationship between age and type of decision making outcome $\left(x^{2}(21 \mathrm{df})=2.09, \mathrm{p}<0.465\right)$. 


\begin{tabular}{|c|c|c|c|c|c|c|}
\hline & \multirow{2}{*}{ Age Group } & \multicolumn{5}{|c|}{ Type of Decision Making Outcome } \\
\hline & & $\begin{array}{c}\text { Self } \\
\text { sacrificing }\end{array}$ & Anti-social & $\begin{array}{c}\text { Self- } \\
\text { interested }\end{array}$ & $\begin{array}{l}\text { Mutually } \\
\text { Beneficial }\end{array}$ & Total \\
\hline \multirow[t]{4}{*}{$18-20$} & Count & 0 & 1 & 3 & 3 & 7 \\
\hline & Expected Count & .2 & .8 & 3.5 & 2.5 & 7.0 \\
\hline & $\%$ & $.0 \%$ & $5.6 \%$ & $3.6 \%$ & $5.0 \%$ & $4.2 \%$ \\
\hline & Residual & -.2 & .2 & -.5 & .5 & \\
\hline \multirow[t]{4}{*}{$21-24$} & Count & 0 & 2 & 14 & 5 & 21 \\
\hline & Expected Count & .8 & 2.2 & 10.5 & 7.5 & 21.0 \\
\hline & $\%$ & $.0 \%$ & $11.1 \%$ & $16.7 \%$ & $8.3 \%$ & $12.5 \%$ \\
\hline & Residual & -.8 & -.2 & 3.5 & -2.5 & \\
\hline \multirow[t]{4}{*}{$25-29$} & Count & 0 & 5 & 20 & 16 & 41 \\
\hline & Expected Count & 1.5 & 4.4 & 20.5 & 14.6 & 41.0 \\
\hline & $\%$ & $.0 \%$ & $27.8 \%$ & $23.8 \%$ & $26.7 \%$ & $24.4 \%$ \\
\hline & Residual & -1.5 & .6 & -.5 & 1.4 & \\
\hline \multirow[t]{4}{*}{$30-34$} & Count & 1 & 2 & 17 & 8 & 28 \\
\hline & Expected Count & 1.0 & 3.0 & 14.0 & 10.0 & 28.0 \\
\hline & $\%$ & $16.7 \%$ & $11.1 \%$ & $20.2 \%$ & $13.3 \%$ & $16.7 \%$ \\
\hline & Residual & .0 & -1.0 & 3.0 & -2.0 & \\
\hline \multirow[t]{4}{*}{$35-39$} & Count & 2 & 2 & 10 & 9 & 23 \\
\hline & Expected Count & .8 & 2.5 & 11.5 & 8.2 & 23.0 \\
\hline & $\%$ & $33.3 \%$ & $11.1 \%$ & $11.9 \%$ & $15.0 \%$ & $13.7 \%$ \\
\hline & Residual & 1.2 & -.5 & -1.5 & .8 & \\
\hline \multirow[t]{2}{*}{$40-44$} & Count & 1 & 3 & 8 & 1 & 13 \\
\hline & Expected Count & .5 & 1.4 & 6.5 & 4.6 & 13.0 \\
\hline
\end{tabular}




\begin{tabular}{|c|c|c|c|c|c|c|}
\hline & $\%$ & $16.7 \%$ & $16.7 \%$ & $9.5 \%$ & $1.7 \%$ & $7.7 \%$ \\
\hline & Residual & .5 & 1.6 & 1.5 & -3.6 & \\
\hline \multirow[t]{4}{*}{$45-49$} & Count & 1 & 0 & 6 & 7 & 14 \\
\hline & Expected Count & .5 & 1.5 & 7.0 & 5.0 & 14.0 \\
\hline & $\%$ & $16.7 \%$ & $.0 \%$ & $7.1 \%$ & $11.7 \%$ & $8.3 \%$ \\
\hline & Residual & .5 & -1.5 & -1.0 & 2.0 & \\
\hline \multirow{4}{*}{$\begin{array}{l}50 \text { and } \\
\text { older }\end{array}$} & Count & 1 & 3 & 6 & 11 & 21 \\
\hline & Expected Count & .8 & 2.2 & 10.5 & 7.5 & 21.0 \\
\hline & $\%$ & $16.7 \%$ & $16.7 \%$ & $7.1 \%$ & $18.3 \%$ & $12.5 \%$ \\
\hline & Residual & .2 & .8 & -4.5 & 3.5 & \\
\hline Total & Count & 6 & 18 & 84 & 60 & 168 \\
\hline
\end{tabular}

Table 20: Age Group by type of Decision-Making Outcome

To explore the relationship between age and moral imagination, first one-way ANOVAs were run to examine the possible impact of age on the two components of moral imagination, discerning, and developing. Age was not found to have a significant impact on either demonstrations of discerning moral issues $(F(7,174)=1.677 ; p=0.118)$ or developing a range of alternatives for a situation $(F(7,174)=1.526 ; p=0.162)$. As further detailed in Table 21, it was clear that the means for these two abilities across the age groups were very similar. 


\begin{tabular}{|c|c|c|c|c|c|c|c|}
\hline $\begin{array}{l}\text { Moral Imagination } \\
\text { Component }\end{array}$ & $\begin{array}{l}\text { Age } \\
\text { Group }\end{array}$ & $\mathbf{N}$ & Mean & $\begin{array}{c}\text { Std. } \\
\text { Deviation }\end{array}$ & $\begin{array}{l}\text { Std. } \\
\text { Error }\end{array}$ & Min & Max \\
\hline \multirow[t]{9}{*}{ Discerning average } & $18-20$ & 8 & 1.1875 & .92341 & .32647 & .00 & 3.00 \\
\hline & $21-24$ & 21 & 2.0000 & 1.36931 & .29881 & .00 & 4.50 \\
\hline & $25-29$ & 42 & 2.2381 & 1.27947 & .19743 & .00 & 4.50 \\
\hline & $30-34$ & 29 & 2.5862 & 1.22525 & .22752 & .50 & 6.00 \\
\hline & $35-39$ & 27 & 2.3704 & 1.07946 & .20774 & .00 & 4.00 \\
\hline & $40-44$ & 13 & 2.0769 & 1.23905 & .34365 & .00 & 4.00 \\
\hline & $45-49$ & 14 & 2.3571 & 1.15073 & .30755 & 1.00 & 4.00 \\
\hline & $\begin{array}{l}50 \text { and } \\
\text { older }\end{array}$ & 21 & 1.8333 & 1.24833 & .27241 & .00 & 3.50 \\
\hline & Total & 175 & 2.1886 & 1.23939 & .09369 & .00 & 6.00 \\
\hline \multirow[t]{9}{*}{ Developing average } & $18-20$ & 8 & 3.1250 & 1.62019 & .57282 & .50 & 5.50 \\
\hline & $21-24$ & 21 & 3.7381 & 1.30018 & .28372 & 1.50 & 5.50 \\
\hline & $25-29$ & 42 & 4.2500 & 1.28429 & .19817 & 1.00 & 6.00 \\
\hline & $30-34$ & 29 & 4.1897 & 1.16046 & .21549 & 2.00 & 6.00 \\
\hline & $35-39$ & 27 & 3.8333 & 1.51277 & .29113 & 1.00 & 6.00 \\
\hline & $40-44$ & 13 & 3.6154 & 1.12090 & .31088 & 2.00 & 5.50 \\
\hline & $45-49$ & 14 & 3.7143 & 1.17202 & .31324 & 2.00 & 6.00 \\
\hline & $\begin{array}{l}50 \text { and } \\
\text { older }\end{array}$ & 21 & 3.4524 & 1.45692 & .31793 & 1.00 & 6.00 \\
\hline & Total & 175 & 3.8771 & 1.33715 & .10108 & .50 & 6.00 \\
\hline
\end{tabular}

Table 21: Mean Discerning and Developing Scores by Age Group

Then, to look at age by overall moral imagination group, a cross tabulation was run between these two variables. Similar to gender, as illustrated in Table 22, the observed and expected counts for each cell were very close, and looking across the age groups there was a very similar distribution across the morally imaginative groups. Based on these results, another non-significant Chi-square test suggested that there was 
no significant relationship between gender and overall moral imagination group $\left(x^{2}(7 \mathrm{df})\right.$ $=8.302, \mathrm{p}<0.307)$.

\begin{tabular}{|c|c|c|c|c|}
\hline & \multirow{2}{*}{ Age Group } & \multicolumn{3}{|c|}{ Moral Imagination Group } \\
\hline & & $\begin{array}{c}\text { Morally } \\
\text { Imaginative }\end{array}$ & $\begin{array}{l}\text { Non-Morally } \\
\text { Imaginative }\end{array}$ & Total \\
\hline \multirow[t]{4}{*}{$18-20$} & Count & 0 & 8 & 8 \\
\hline & Expected Count & .9 & 7.1 & 8.0 \\
\hline & $\%$ of MI Group & $.0 \%$ & $5.2 \%$ & $4.6 \%$ \\
\hline & Residual & -.9 & .9 & \\
\hline \multirow[t]{4}{*}{$21-24$} & Count & 4 & 17 & 21 \\
\hline & Expected Count & 2.3 & 18.7 & 21.0 \\
\hline & $\%$ of MI Group & $21.1 \%$ & $11.0 \%$ & $12.1 \%$ \\
\hline & Residual & 1.7 & -1.7 & \\
\hline \multirow[t]{4}{*}{$25-29$} & Count & 6 & 36 & 42 \\
\hline & Expected Count & 4.6 & 37.4 & 42.0 \\
\hline & $\%$ of MI Group & $31.6 \%$ & $23.2 \%$ & $24.1 \%$ \\
\hline & Residual & 1.4 & -1.4 & \\
\hline \multirow[t]{4}{*}{$30-34$} & Count & 5 & 24 & 29 \\
\hline & Expected Count & 3.2 & 25.8 & 29.0 \\
\hline & $\%$ of MI Group & $26.3 \%$ & $15.5 \%$ & $16.7 \%$ \\
\hline & Residual & 1.8 & -1.8 & \\
\hline \multirow[t]{4}{*}{$35-39$} & Count & 1 & 25 & 26 \\
\hline & Expected Count & 2.8 & 23.2 & 26.0 \\
\hline & $\%$ of MI Group & $5.3 \%$ & $16.1 \%$ & $14.9 \%$ \\
\hline & Residual & -1.8 & 1.8 & \\
\hline \multirow[t]{4}{*}{$40-44$} & Count & 1 & 12 & 13 \\
\hline & Expected Count & 1.4 & 11.6 & 13.0 \\
\hline & $\%$ of MI Group & $5.3 \%$ & $7.7 \%$ & $7.5 \%$ \\
\hline & Residual & -.4 & .4 & \\
\hline $45-49$ & Count & 2 & 12 & 14 \\
\hline
\end{tabular}




\begin{tabular}{|c|c|c|c|c|}
\hline & $\begin{array}{l}\text { Expected Count } \\
\% \text { of MI Group } \\
\text { Residual }\end{array}$ & $\begin{array}{r}1.5 \\
10.5 \% \\
.5\end{array}$ & $\begin{array}{r}12.5 \\
7.7 \% \\
-.5\end{array}$ & $\begin{array}{r}14.0 \\
8.0 \%\end{array}$ \\
\hline \multirow[t]{4}{*}{50 and older } & Count & 0 & 21 & 21 \\
\hline & Expected Count & 2.3 & 18.7 & 21.0 \\
\hline & $\%$ of MI Group & $.0 \%$ & $13.5 \%$ & $12.1 \%$ \\
\hline & Residual & -2.3 & 2.3 & \\
\hline \multirow[t]{3}{*}{ Total } & Count & 19 & 155 & 174 \\
\hline & Expected Count & 19.0 & 155.0 & 174.0 \\
\hline & $\%$ of MI Group & $100.0 \%$ & $100.0 \%$ & $100.0 \%$ \\
\hline
\end{tabular}

Table 22: Moral Imagination Group by Age Group

Impact of Years Experience on Decision-Making Outcome and Moral Imagination

To investigate how years of work experience may be related to type of decisionmaking outcome, an ANOVA was run between these two variables (as work experience was captured as a continuous variable). As summarized in Table 23 those who made self-sacrificing decisions were found to have the highest mean years of work experience (21.33 years), and those with self-interested outcomes had the least (12.01 years). The results of the ANOVA, however, were non-significant, $(F(3,165)=1.697 ; p=0.170)$, suggesting that years of work experience is not significantly related to type of decisionmaking outcome. 


\begin{tabular}{|l|r|r|r|r|r|r|}
\hline $\begin{array}{l}\text { Type of Decision- } \\
\text { Making Outcome }\end{array}$ & N & $\begin{array}{r}\text { Mean Years } \\
\text { of Work Exp. }\end{array}$ & $\begin{array}{c}\text { Std. } \\
\text { Deviation }\end{array}$ & Std. Error & Min & Max \\
\hline Mutually beneficial & 58 & 14.91 & 13.123 & 1.723 & 0 & 54 \\
\hline Self-sacrificing & 6 & 21.33 & 13.411 & 5.475 & 8 & 46 \\
\hline Self-interested & 84 & 12.01 & 10.105 & 1.102 & 0 & 41 \\
\hline Anti-social & 18 & 13.17 & 11.367 & 2.679 & 0 & 38 \\
\hline Total & 166 & 13.49 & 11.562 & .897 & 0 & 54 \\
\hline
\end{tabular}

Table 23: Mean years of work experience by type of decision-making outcome

Looking at how years of work experience may impact an individual's ability for moral imagination, an ANOVA was run between overall moral imagination group and years of work experience. This test revealed a significant relationship between these two variables $(F(1,171)=4.820 ; p=0.029)$. As summarized in Table 24 , the morally imaginative group had, on average, less years work experience ( 8.08 years) compared to the non-morally imaginative group who had 14.08 years on average.

\begin{tabular}{|l|r|r|r|r|r|r|}
\hline $\begin{array}{l}\text { Moral Imagination } \\
\text { Group }\end{array}$ & $\mathbf{N}$ & $\begin{array}{r}\text { Mean Years } \\
\text { Work Exp. }\end{array}$ & $\begin{array}{c}\text { Std. } \\
\text { Deviation }\end{array}$ & Std. Error & Min & \multicolumn{1}{c|}{ Max } \\
\hline $\begin{array}{l}\text { Morally Imaginative } \\
\text { Non-Morally }\end{array}$ & 19 & 8.08 & 7.223 & 1.657 & 0 & 24 \\
Imaginative & 153 & 14.08 & 11.632 & .940 & 0 & 54 \\
Total & 172 & 13.42 & 11.372 & .867 & 0 & 54 \\
\hline
\end{tabular}

Table 24: Years of Work Experience by Moral Imagination Group 
Exploring the impact of years of work experience on demonstration of moral imagination further, bi-variate correlations were run between years of work experience, discerning scores and developing scores. Summarized in 25 , developing was the only component significantly correlated with years of work experience, and it was a negative relationship indicating the greater the number of years one has worked, the lower their developing score $(r=-0.159, p=0.037)$.

\begin{tabular}{|l|r|r|r|}
\hline & $\begin{array}{c}\text { Discerning } \\
\text { Average }\end{array}$ & $\begin{array}{c}\text { Developing } \\
\text { average }\end{array}$ & $\begin{array}{c}\text { Yrs. Work } \\
\text { Experience }\end{array}$ \\
\hline Discerning Average & 1.000 & $.481^{* *}$ & -.090 \\
\hline Developing Average & & 1.000 & $-.159^{*}$ \\
\hline Yrs. Work Experience & & & 1.000 \\
\hline **. Correlation is significant at the 0.01 level (2-tailed). \\
*. Correlation is significant at the 0.05 level (2-tailed). \\
\hline
\end{tabular}

Table 25: Correlations for Discerning, Developing and Yrs. Work Exp.

Impact of Net Impact Membership on Decision-Making Outcome and Moral Imagination

The final post-hoc exploration involved looking at the possible impact of Net Impact membership on type of decision-making outcome and demonstrated moral imagination. As mentioned before, Net Impact members are committed to addressing social issues with their business practices. Because of this, it was suspected that Net Impact members may have a bias toward creating mutually beneficial solutions to a situation, given their presumed heightened awareness of moral and strategic issues within the business world.

To explore how Net Impact may be related to the type of decision-making outcome observed, a cross-tabulation was run to explore the relationship between these two categorical variables. Summarized in Table 26, the observed and expected counts for 
each cell were very similar, with Net Impact and Non-Net Impact members demonstrating relatively equal distributions across the four possible decision-making outcomes. For example, $38.1 \%$ of the Net Impact members generated mutually beneficial decision-making outcomes and $35.2 \%$ of the non-Net Impact members did as well. A non-significant Chi-square test on these results supported retaining the null hypothesis, which would suggested Net Impact membership did not have a significant influence on the type of decisions making outcome $\left(x^{2}(3 \mathrm{df})=0.403, \mathrm{p}<0.940\right)$.

\begin{tabular}{|c|c|c|c|c|}
\hline \multirow{2}{*}{\multicolumn{2}{|c|}{ Type of Decision-making Outcome }} & \multicolumn{3}{|c|}{ Member of Net Impact } \\
\hline & & Yes & No & Total \\
\hline Mutually beneficial & $\begin{array}{l}\text { Count } \\
\text { Expected Count } \\
\% \\
\text { Residual }\end{array}$ & $\begin{array}{r}16 \\
15.1 \\
38.1 \% \\
.9 \\
\end{array}$ & $\begin{array}{r}43 \\
43.9 \\
35.2 \% \\
-.9 \\
\end{array}$ & $\begin{array}{r}59 \\
59.0 \\
36.0 \%\end{array}$ \\
\hline Self-sacrificing & $\begin{array}{l}\text { Count } \\
\text { Expected Count } \\
\% \\
\text { Residual }\end{array}$ & $\begin{array}{r}2 \\
1.5 \\
4.8 \% \\
.5 \\
\end{array}$ & $\begin{array}{r}4 \\
4.5 \\
3.3 \% \\
-.5 \\
\end{array}$ & $\begin{array}{r}6 \\
6.0 \\
3.7 \%\end{array}$ \\
\hline Self-interested & $\begin{array}{l}\text { Count } \\
\text { Expected Count } \\
\% \\
\text { Residual }\end{array}$ & $\begin{array}{r}20 \\
20.7 \\
47.6 \% \\
-.7 \\
\end{array}$ & $\begin{array}{r}61 \\
60.3 \\
50.0 \% \\
.7 \\
\end{array}$ & $\begin{array}{r}81 \\
81.0 \\
49.4 \%\end{array}$ \\
\hline Anti-social & $\begin{array}{l}\text { Count } \\
\text { Expected Count } \\
\% \\
\text { Residual }\end{array}$ & $\begin{array}{r}4 \\
4.6 \\
9.5 \% \\
-.6 \\
\end{array}$ & $\begin{array}{r}14 \\
13.4 \\
11.5 \% \\
.6\end{array}$ & $\begin{array}{r}18 \\
18.0 \\
11.0 \%\end{array}$ \\
\hline Total & Count & 42 & 122 & 164 \\
\hline
\end{tabular}

Table 26: Net Impact Member ship by Type of Decision-Making Outcome 
In examining how Net Impact may be related to the demonstration of moral imagination, a cross-tabulation was run to first explore the relationship between Net Impact membership and overall moral imagination group. Similar to the findings for type of decision-making outcome, the observed and expected counts for each cell were very similar, with Net Impact and Non-Net Impact members demonstrating relatively equal distributions across the moral imagination and non-moral imagination groups (see Table 27). For example, $15.2 \%$ of the Net Impact members were found to be morally imaginative, while $9.8 \%$ of non-members were; $84.8 \%$ of Net Impact members were in the non-morally imaginative group, compared to $90.2 \%$ of the non-members who were. A non-significant Chi-square test on these results supported retaining the null hypothesis, which would suggest that Net Impact membership did not have a significant influence on demonstration of overall moral imagination $\left(x^{2}(1 \mathrm{df})=1.001, \mathrm{p}<0.317\right)$.

\begin{tabular}{|l|l|r|r|r|}
\hline \multicolumn{2}{|l|}{ Moral Imagination Group } & \multicolumn{3}{|c|}{ Member of Net Impact } \\
\cline { 3 - 5 } \multicolumn{2}{l|}{ Morally Imaginative } & Yes & \multicolumn{1}{c|}{ No } & \multicolumn{1}{c|}{ Total } \\
\hline & Expected Count & 7 & 12 & 19 \\
& $\%$ & 5.2 & 13.8 & 19.0 \\
& Residual & $15.2 \%$ & $9.8 \%$ & $11.2 \%$ \\
\hline Non-Morally & Count & 1.8 & -1.8 & \\
\hline Imaginative & Expected Count & 39 & 111 & 150 \\
& $\%$ & 40.8 & 109.2 & 150.0 \\
& Residual & $84.8 \%$ & $90.2 \%$ & $88.8 \%$ \\
& Count & -1.8 & 1.8 & \\
\hline \multirow{2}{*}{ Total } & Expected Count & 46 & 123 & 169 \\
& $\%$ & 46.0 & 123.0 & 169.0 \\
& $\%$ & $100.0 \%$ & $100.0 \%$ & $100.0 \%$ \\
\hline
\end{tabular}

Table 27: Moral Imagination group by Net Impact Membership 
To explore the relationship between Net-Impact and the abilities that comprise moral imagination, one-way ANOVAs were run to examine the impact of Net Impact membership discerning and developing. Interestingly, Net Impact membership was found to have a significant impact on both demonstrations of discerning moral issues $(F(1,169)$ $=9.625 ; p=0.002)$ and developing a range of alternatives for a situation $(F(1,169)=$ 17.016; $p=0.000$ ). Further detailed in Table 28, the mean scores for both discerning and developing were higher for Net Impact members, thus suggesting that Net Impact members do demonstrate a greater ability for discerning the moral aspects of a situation and developing a greater range of alternatives compared to non-members. These findings, taken in concert with the finding regarding type of decision-making outcome, suggest that while Net Impact members are perhaps better at identifying the moral issues in a situation and coming up with a variety of possible solutions, their overall type of decision-making outcome was not significantly more mutually beneficial than non-Net Impact members. As a caveat to this particular series of analysis, however, it is important to recognize that the group of Net Impact members was much smaller than non-Net Impact members, and thus additional research could explore confirming these findings with a larger sample size of Net-Impact members. I will return to this discussion of these issues in Chapter 5. 


\begin{tabular}{|l|l|r|r|r|r|r|r|}
\hline \multicolumn{2}{|l|}{$\begin{array}{l}\text { Averages by Net Impact } \\
\text { Membership }\end{array}$} & $\mathbf{N}$ & Mean & $\begin{array}{c}\text { Std. } \\
\text { Deviation }\end{array}$ & \multicolumn{1}{c|}{$\begin{array}{c}\text { Std. } \\
\text { Error }\end{array}$} & \multicolumn{1}{c|}{ Min } & \multicolumn{1}{c|}{ Max } \\
\hline $\begin{array}{l}\text { Discerning } \\
\text { average }\end{array}$ & $\begin{array}{l}\text { Net Impact } \\
\text { member } \\
\text { Non- } \\
\text { member }\end{array}$ & 46 & 2.6739 & 1.22119 & .18005 & .50 & 6.00 \\
& Total & 170 & 2.1971 & 1.25139 & .09598 & .00 & 6.00 \\
\hline $\begin{array}{l}\text { Neveloping } \\
\text { average }\end{array}$ & $\begin{array}{l}\text { Net Impact } \\
\text { member }\end{array}$ & 46 & 4.5543 & 1.04471 & .15403 & 2.00 & 6.00 \\
& $\begin{array}{l}\text { Non- } \\
\text { member }\end{array}$ & 124 & 3.6331 & 1.37354 & .12335 & .50 & 6.00 \\
\cline { 2 - 7 } & Total & 170 & 3.8824 & 1.35360 & .10382 & .50 & 6.00 \\
\hline
\end{tabular}

Table 28: Discerning and Developing Scores by Net Impact Membership 


\section{CHAPTER 5}

\section{DISCUSSION and CONCLUSIONS}

\section{Imagination is more important than knowledge \\ $\sim$ Albert Einstein \\ Our imagination is the only limit to what we can hope to have in the future. $\sim$ Charles F. Kettering}

This chapter discusses the results and implications of the study. First I discuss the outcomes and implications from the hypotheses testing, as well as the post-hoc explorations performed, followed by the limitations of the current study. I conclude the chapter with a call for further research on the topic of moral imagination and mutually beneficial decision-making in organizational contexts and propose possible directions for such research.

\subsection{Discussion and Findings of Results}

Working under the assumption that mutual benefit is the most desired outcome for organizational decision-making because it represents doing the most good for the most people, the current study aimed at exploring factors that may impact an individual's ability to make mutually beneficial decisions. Building specifically on the work of Werhane (1999, 1998), Johnson (1993), and others, I argued that one's ability to exercise their moral imagination, including discerning moral issues and developing alternatives to a situation, was a critical component in the process of mutually beneficial organizational decision-making. Through the hypotheses discussed in Chapter 2 and then tested in Chapter 4, I examined if individuals who exercise moral imagination during a decisionmaking process are more likely to generate mutually beneficial outcomes -outcomes that 
have benefit to both the company and also to wider society - than individuals who do not exercise moral imagination.

\section{Hypotheses Findings}

Overall, findings supported the argument that individuals who exercised moral imagination during the decision-making process, including the ability for discerning moral issues and developing a range of possible outcomes, were indeed more likely to generate a mutually beneficial outcome for a situation compared to those who did not exercise moral imagination. The first hypothesis specifically looked at whether an individual's ability to discern moral aspects of a situation was related to their ability to create mutually beneficial solutions for that situation. As expected, results indicated that individuals who generated mutually beneficial outcomes also demonstrated the highest level $($ mean $=2.62, \mathrm{SD}=1.34)$ of discerning ethical issues compared to those who generated other types of decision-making outcomes. These findings lend support to the body of work done by a variety of scholars (Butterfield, Trevino, and Weaver, 2000; Jones, 1991; Rest 1979; 1986), which suggests that ethical decision-making begins with (or is at least impacted by) an individual's ability to recognize moral issues in a situation.

In looking at the discerning scores for the other types of decision-making outcomes, we see that those who generated self-sacrificing outcomes had the second highest discerning average $($ mean $=2.25, \mathrm{SD}=1.54)$. This finding is interesting but not surprising, as this group, like the mutual beneficial group, demonstrated higher altruistic tendencies in their decision-making outcomes. Thus, it makes sense that those who discern more moral issues in a situation compared are also those who make decisions that 
benefit others, to those who do not recognize moral issues. Also not surprising was the fact that those who made decisions that did not help others or themselves (i.e. antisocial/self-destructive) had the lowest demonstration of discerning (mean $=$ $1.31, \mathrm{SD}=0.89)$. This suggests that perhaps these individual's ability to recognize moral issues is so underdeveloped that they do not only see how outcomes impact others, they also do not fully recognize how they impact themselves either.

The second hypothesis looked at the relationship between the other proposed component of moral imagination, that is an individual's ability to develop a range of possible solutions for a situation, and their ability to create mutually beneficial solutions for that situation. In partial support of the hypothesis, the results did lend support the assumption that people who generated mutually beneficial solution also demonstrated a greater ability for developing a range of possible solutions for the situation. As mentioned in Chapter 4, individuals who generated mutually beneficial outcomes actually had the second highest developing average (mean $=4.13, \mathrm{SD}=1.35$ ), with the selfsacrificing group demonstrating the highest level of developing (mean $=4.67, \mathrm{SD}=$ 0.88). While these findings may be skewed given the relatively low number of individuals in the self-sacrificing group, it does raise an interesting question regarding the relationship between one's demonstration of creativity during the decision-making process and their ultimate type of decision-making outcome. Just because an individual is capable of generating a number of possible outcomes does not guarantee that their ultimate decision as to which of those outcomes to ultimately pursue is a mutually beneficial one. These findings suggest that those who generate the most alternatives actually end up creating self-sacrificing outcomes. 
What is interesting, and again perhaps not surprising, about these findings is that those in the anti-social group demonstrated the lowest ability for creating alternatives $($ mean $=2.83, \mathrm{SD}=1.21)$, followed by those in the self-interested group who had the second lowest developing average $($ mean $=3.82, \mathrm{SD}=1.29)$. Without the ability to see multiple possibilities for action within a situation, therefore, may lead to an individual making a decision that is not helpful to others, or ultimately even to themselves.

Such findings, taken in concert with the findings regarding the ability for discerning moral issues, suggest that the pro-social and anti-social ${ }^{22}$ axis along which decision-making outcomes vary is a particularly relevant one. Overall, individuals who generated outcomes that benefited others (which is represented by the top two quadrants in Figure 1 from Chapter 1) in some way were the same individuals who demonstrated higher levels of discerning and developing in the decision-making process.

The third hypotheses aimed at looking at the decision-making outcomes that occurred when an individual demonstrated both a high level for discerning moral issues and a high level of determining possible outcomes for the situation, which theoretically constituted a demonstration of moral imagination. As hypothesized it was found that individuals who simultaneously demonstrated these two abilities were found to be more likely to generate mutual beneficial decision-making outcomes compared to individuals who did not demonstrate these two abilities. A significant Chi-square test supported the argument that moral imagination and type of decision-making outcome were in fact related, with an overwhelming majority of those individuals who were categorized as demonstrating moral imagination $(68.4 \%)$ were also found to generate mutually

\footnotetext{
${ }^{22}$ Anti-social in this context is referring to decision-making outcomes that do not provide benefit to wider society; those outcomes that are represented by the bottom two quadrants depicted in Figure 1, Chapter1.
} 
beneficial outcomes, compared to only $(31.8 \%)$ of those who were categorized as being non-morally imaginative. The majority $(52.7 \%)$ of the non-morally imaginative group (i.e. those who did not demonstrate either a high level of discerning or developing) generated outcomes that were deemed to be "self-interested," compared to the $26.3 \%$ of the morally imaginative group who did. Noted in Chapter 4, it is also interesting that no one in the morally imaginative group generated responses that were considered antisocial/self-destructive, whereas $12.2 \%$ of those in the non-morally imaginative group were also found to arrive at such outcomes. Perhaps moral imagination acts as a buffer against such potentially negative outcomes. In summary, demonstrating moral imagination was linked more frequently with overall positive outcomes along both the self-interest axis and altruism axis. These findings suggest that moral imagination does have, at least in part, impact decision-making outcomes and typically results in mutually beneficial outcomes for both business and wider society.

The remaining hypotheses explored how other factors, such as moral development characteristics and empathy, may impact one's ability for demonstrating moral imagination. Based on the theoretical overview given in Chapter 2, it was hypothesized that one's ability to demonstrate discernment of the moral issues in a situation would be negatively impacted by their level of egotism, dogmatism, and relativism. Each of these hypotheses were supported, suggesting that an individual's ability to recognize moral issues in a situation is potentially impaired if they are highly egotistical, dogmatic, or morally relative. The hypothesis that idealism positively impacted one's ability for discerning moral issues was not supported, however. 
Similarly, it was hypothesized that one's ability to develop a range of possibilities for a situation would be negatively impacted by their level of dogmatism, but positively impacted by their level of relativism. Findings did support the idea that higher levels of dogmatism do impair the demonstration of developing a rage of solutions for a situation. Contrary to what was hypothesized however, findings suggested that higher levels of relativism actually result in lower demonstration of the ability to develop multiple possibilities.

The final remaining hypotheses explored the relationship between empathy and a number of variables. Empathy was hypothesized to have a positive impact on both discerning and developing. While the relationship found between these variables was positive, neither relationship was found to be significant, thus raising the question as to the impact empathy has on one's demonstration of moral imagination. Empathy was also hypothesized to have a negative relationship with both egocentrism and dogmatism, but again results did not find a significant relationship between these variables. One possible explanation as to why the findings were not significant could be linked back to the self-report measure used to assess empathy. This possibility will be discussed further below in relation to the limitations of the study.

\section{Post-hoc Findings}

In addition to the hypothesis testing, a variety of post-hoc tests raise interesting findings regarding the impact of gender, age, work experience and Net Impact membership on moral imagination and decision-making outcomes. First, looking at gender, it is perhaps heartening to see that there were no significant differences seen 
across the genders regarding demonstration of the moral imagination abilities of discerning, developing, nor in the type of decision-making outcomes given. Because there is not a developed body of literature on mutually beneficial decision-making, this study does provide one of the first empirical investigations to support the argument that both men and women are equally capable and likely to generate mutually beneficial outcomes to business situations.

Theoretically, there has been disagreement over the relationship between gender and moral awareness - or ability to discern moral issues. For example, theorists such as Gilligan (1977) argue that because men and women are socialized differently, women are "more prone to base their moral judgments on obligations to care for and avoid hurting others," where others such as Rest (1986) argue that there is no difference across the genders. Prior research has also produced mixed findings regarding gender and its relationship to moral awareness and ethical decision-making, with studies finding no difference between the genders (i.e. Butterfield, et al, 2000) and others finding a difference (i.e. Richmond, 2001). The results of this current study lend support to the argument that there is no significant difference in the recognition of moral issues across the genders.

Similar to moral awareness, the creativity literature paints an unclear picture regarding the relationship between divergent thinking and gender. As Baer (2005) states, in a review of over 80 studies, the results of studies that compare men and women's scores on divergent thinking tests have resulted in mixed results, with half reporting no difference, and the rest disagreeing on the direction of impact gender has. Results from this study would support the argument that men and women are equally capable of 
generating a range of alternatives to a situation, and thus have no demonstrated difference in divergent thinking.

Next, looking at the impact of age on moral imagination and type of decisionmaking outcome, no significant differences were found across the age groups either. Again, such results are perhaps hopeful, suggesting that individuals at any age can demonstrate the ability to discern moral issues, develop a range of alternatives, and arrive at mutually beneficial decisions. While there have been prior studies which would suggest that age does impact moral awareness and creativity, much of the research that would suggest there might be age-related differences for these abilities has looked at children and adolescents in comparison to adults. Given that the youngest participant in this study was 18 , with the majority being over 25 , it is possible that differences that may exist in comparison to younger groups was not picked up in the current sample. As I will discuss regarding possibilities for future research, it would be interesting to look at moral imagination and mutually beneficial decision-making among teenagers and even young children to see how these abilities change and evolve over the course of one's life.

I do want to note, however, that while the differences across the age groups proved to not be significant, the pattern of differences observed was interesting. For both discerning and developing scores, there was a possible crescendo-decrescendo pattern seen looking from youngest to oldest. In other words, younger respondents (i.e. 18-24 years) tended to have lower discerning and developing scores, with the 'middle-aged' group (i.e. 25 - 39 years) showed the highest scores for these abilities, and then older respondents (i.e. 40 and older) then showing lower scores. Such patterns raise the interesting questions regarding the nature of moral imagination. Is it an ability that builds, 
reaches a peak and then declines with age and experience? Or perhaps these differences reflect generational differences that exist between the current age cohorts that are in fact stable. As I will suggest below, further research is needed to explore the evolution of moral imagination throughout one's life.

Years of work experience was the next variable examined for possible impacts on moral imagination and type of decision-making outcome. There were no significant differences found across type of decision-making outcome, although it is interesting to note that the self-sacrificing group had the highest mean years of work experience $(21.33$ years). This reflected 6 more years of work experience, on average, than those who gave mutually beneficial outcomes, who had the second highest mean years of work experience (14.91 years). Again, given the small number of individuals in the selfsacrificing group, these findings could be skewed and further investigation is needed to explore the impact of work experience on type of decision-making outcome.

Next, looking at the tendency to demonstrate moral imagination, there was a significant difference found for work experience. Those in the morally imaginative group had an average of 8.08 years of work experience, compared to the non-morally imaginative group, which had 14.08 years of experience on average. Looking at moral imagination even further, it was also found that the component of moral imagination that may be driving this finding was the difference in demonstrated developing abilities that were seen in relationship to years or work experience. The significant negative correlation between developing scores and years of work experience suggests that individuals with the most work experience also had the lowest developing scores. This finding is particularly interesting taken together with the above findings regarding age. 
Both the trends toward lower developing scores (and lower discerning scores, although this relationship was not significant) indicates that as one gains more experiences, particularly work experience, their ability to see and generate alternatives for a situation become more limited. Such findings support other research that has also found a negative relationship between professional experience and moral awareness. For example, Jordan (2005) proposes, people with more experience in business may actually become "entrenched" or "fixated on examining issues from (their) particular perspective" and thus unable to recognize moral issues, or other alternatives for the situation (p. 39). In other words, experience may actually lead to a myopic focus on what one has done in the past, rather than looking at every situation as a new opportunity to recognize the unique issues and potential outcomes therein.

However, it could also be argued that individuals with more work experience are not prisoners of their past experience, but sages thereof. Perhaps as one gains more work experience they have a better idea of what outcomes are feasible and will be accepted, so they self-censor their imaginations and limit their development of possibilities. While this efficiency could prove useful in many cases (especially when time is critical), there could still be instances when the idea that seems crazy and thus gets censored out, may prove to be the best idea going forward. Regardless of the reason for the lower developing scores, it does raise interesting questions about what organizations can do to help offset this tendency and help even the most veteran business practitioner approach each situation with an appreciative eye that is able to see a range of great possibilities.

The final demographic variable that was explored was Net Impact membership. As noted earlier, it was assumed that membership in this organization would possibly 
skew an individual's results, with Net Impact members demonstrating higher levels of moral imagination as well as higher tendencies for generating mutually beneficial outcomes. Net Impact members did not show a significant difference in the type of decision-making outcome they created, nor in their demonstration of overall moral imagination. They did, however, demonstrate significantly higher scores on the individual abilities for discerning and developing compared with non-Net Impact members. These findings suggest that Net Impact members do have a greater tendency for both recognizing moral aspects in a situation and creating a range of possible outcomes, but overall, their final decision-making outcome does not differ from nonmembers. That is, they are not more likely to arrive at a mutually beneficial solution than anyone else. These findings further support the argument that it is therefore not discerning or developing in isolation, as shown by the Net Impact members, but that it is these two abilities acting together, which was not shown to be any different in NetImpact members, that leads one to create mutually beneficial outcomes. The implications of this finding are discussed further below with regard to overall implications for management education.

\subsection{Limitations}

With any study there are limitations. The current study, in its attempt to explore previously untested measures, is not without drawbacks. First, the current sample poses specific limitations both in terms of its size and composition. While the sample size was large enough to conduct these initial exploratory analyses, future studies of these constructs should be applied to even larger samples to test the reliability of current 
findings. Also, future studies may want to expand the sample beyond MBAs to help make results more generalizable across populations. It is necessary to explore if the current findings hold true when applied to non-business populations, including individuals with other types of professional training (i.e. educational fields, health care fields, legal fields, etc.). For example, do people in other fields have the same distribution of decision-making outcomes as seen in the MBA-trained population? While there has been research that would validate the current finding that MBAs have a tendency to generate self-interested decision-making outcomes ${ }^{23}$ (i.e. Aspen Institute, 2002), it is necessary to see if this pattern is mirrored in other populations as well. Also, overall, $11 \%$ of the MBA population demonstrated discerning and developing skills high enough to be considered "morally imaginative". Perhaps those in other professions have a greater tendency to be in the morally imaginative group and/or a greater tendency to create mutually beneficial outcomes or self-sacrificing outcomes, or anti-social outcomes.

Another limitation that must be acknowledged involves the measures used. As referred to in Chapter 3, many of the measures were self-report scales. It has been argued that such measures may "threaten the validity of research conducted in business settings and thus hinder the development of theories of organizational behavior" (Donaldson and Grant-Vallone, 2002, p. 245). The weaknesses presented by self-report measures may be particularly relevant for the measures of empathy and creativity (i.e. divergent thinking) used in the current study. These abilities may be more accurately assessed with instruments that are not self-report. Empathy, for example may be better reflected by observational data, peer-reports, interviews, or other qualitative measures where the

${ }^{23}$ Within the current MBA sample, $48 \%$ were found to create self-interested outcomes. The Aspen (2002) study suggests that during their MBA experience, students shift from having a greater appreciation for moral issues to a more narrow focus on strategic issues specifically. 
demonstration of empathetic behaviors can be captured rather than an individual's selfperception, which may be skewed (positively or negatively). Similarly, if participants had inaccurate self-perceptions, they may have over (or under) estimated their creative abilities. Future tests to explore the validity of the moral imagination measure may consider using alternative creativity measures for testing criterion related validity, such as more performance-based creativity measures like the classic Wallach and Kogan (1965) test that requires participants to demonstrate their divergent thinking on a number of exercises where responses are coded for originality, fluency, flexibility and elaboration.

Not all the measures were self-report, however. The measures for moral imagination (specifically discerning and developing), type of decision-making outcome, and moral awareness were all vignette-based, open-ended responses. As Morrison et al state:

Vignettes are only as good as the associated assumptions made... Vignettes assume that respondents will give the same answers for the vignette as if the situation actually applied to them (Martin and Polivka, 1995). Furthermore, vignette usage assumes that respondents will understand circumstances that may be outside their experience or knowledge (2004, p. 320).

While such assumptions were made in this research, it could be argued that vignettes still pose an artificial measure of the cognitive process being investigated. Other measures such as participant observations, in depth interviewing, and longitudinal studies may provided even clearer understanding of the decision-making process that individuals use when faced with a potentially challenging ethical situation.

Other limitations with the moral imagination and decision-making measures include their newness and thus untested validation. While the criterion-related validity checks were aimed at providing the beginning of validity testing for the new measures, 
further testing and development of the instruments is needed. From examining the content of the vignettes used, the number of vignettes used, the coding method applied, to the way that scores were calculated, are all subject to further exploration to see if other approaches would lead to even more accurate assessments of the abilities in question. For example, even using different calculations of the "high" and "low" scores on the discerning and developing measures could be open to other configurations if the coding rubric evolves (as the rubric scores were used as theoretical cutoffs for the groups). Scores could also be determined by creating percentile cutoffs from the observed scores. Any such reconfiguration of the coding rubric or scoring process, however, has the possibility of altering subsequent findings.

\subsection{Implications for Practice, Education and Future Research}

Despite the limitations of the current study, this investigation raises many interesting implications for business practice, education, and research. If we assume that mutually beneficial decision-making is the preferred outcome for business practitioners, the current findings suggest that creating a culture that fosters individuals' ability to discern moral issues and develop a range of alternatives will help promote such outcomes. Specifically thinking about nurturing individuals' ability to discern moral issues in the business context, the words stated by Amitai Etzioni over a decade ago still echo true today:

(We need to realize that) there is a moral dimension in all business decisions. When planning a corporate takeover, which substance to use for a product, whether to hire temps or full-time workers, or where to invest, all reflect values and hence moral considerations. It is not enough to change people; we must change the structure. Within the corporate structure it is important to have special 
divisions dedicated to the implementation of ethics such as internal audit committees (1991, p. 335).

Indeed, integrating the awareness of and valuation for moral awareness and divergent thinking into daily business practices will potentially require the alteration of current business structures. For example, incorporating the evaluation of these abilities into performance appraisals may help begin to shift employees' awareness toward the importance of developing and demonstrating these skills. Developing trainings, and other programs such as mentoring or coaching that specifically focus on cultivating moral imagination, may also help strengthen an employee's ultimate ability to create mutually beneficial decisions.

For business education, the findings have implications at both the curricular level and philosophical levels. Working under the assumption that we can cultivate the abilities for discerning moral issues and developing a range of alternatives through practice and reflection, pedagogy needs to be developed that most effectively helps students build and reinforce these skills. This could range from designing experiential learning activities to using case studies that promote discerning and developing abilities. Creating and sharing best practices across programs will also begin to move business education programs toward becoming institutions that help their students cultivate moral imagination in their decision-making processes.

Even deeper than curriculum changes, however, business education programs may also need to fundamentally reevaluate their philosophical approach if the idea of mutual benefit is to take root in organizational decision-making. Unfortunately, the idea of creating mutual benefit through business actions is not yet an integrated reality in most business programs. This fact is reflected in the recent scrutiny given to business schools 
as socializing agents in the wake of recent corporate scandals. Many academics

themselves have begun to question if students are unduly learning to promote self-interest over the interest of wider society (i.e Emiliani, 2004; Grey, 2004; Mitroff and Swanson, 2004; Giacalone, 2004; Waddock, 2003; Bennis and O’Toole, 2005; Adler, 2002;

Ghoshal, 2005; Gioia, 2002). These critiques build upon research that indicates management students actually decline in their moral awareness skills over the course of their education and become ever more focused on the strategic interests of the business over the interests of other stakeholder groups (Conry and Nelson, 1989; Aspen Institute, 2002). Reflecting on such findings, Giacalone poses the following thoughtful challenge to management education to move its aims beyond a narrow focus on self-interest, and toward creating and promoting mutual benefit:

What are the transcendent, aspirational goals of business education? There are none. Whether society is improved as it gets richer or whether the individual is enriched at all has long been assessed in quantitative or financial terms, and not transcendent ways. We teach students a simple pay-off matrix: Increase the company's wealth and improve the chances of increasing your own affluence and status. In our lesson plans, there is no selflessness, no objective for the nonfinancial, collective improvement of our world, and no generative aspiration to leave behind a better world for those who follow. We are, at best, silent about transcendent aspirations and, at worst, participants in the shallow goal of increasing material wealth without a sense of long-term social benefit. It is not that we are teaching faulty ethics per se, but that we are not socializing students to assess their working assumptions of what goals are worthy of professional aspiration. (2004, p. 416)

If we are to foster moral imagination and mutually beneficial decision-making, we must continue to explore what these constructs look like, what factors impact these abilities (both at the personal and organizational level), and how to develop and maintain them. The current research represents an important first step toward this understanding. Future research is needed to further explore the nature of moral imagination, including 
specifically looking at how discerning and developing may interact with each other. For instance, while the current study lumped together all individuals who were not morally imaginative (i.e. were low on discerning or developing or both), we can further tease out differences in the "non-morally imaginative" groups. For example, just as we can create a typology of decision-making outcomes, then conceptualizing discerning and developing also as two separate abilities which individuals can be high or low on will actually produce another typology, illustrated in Table 29.

\section{DISCERNING ABILITY}

\begin{tabular}{|c|c|c|}
\hline & Lower & Higher \\
\hline DEVELOPING & $\begin{array}{c}\text { Aware, but } \\
\text { Unimaginative }\end{array}$ & $\begin{array}{l}\text { Morally } \\
\text { Imaginative }\end{array}$ \\
\hline Lower & $\begin{array}{l}\text { Unaware and } \\
\text { Unimaginative }\end{array}$ & $\begin{array}{l}\text { Imaginative, but } \\
\text { Unaware }\end{array}$ \\
\hline
\end{tabular}

Table 29: An Expanded Framework for Moral Imagination

Using such a framework opens the door for further theorizing and empirical investigation regarding how each "type" relates to the different types of decision-making outcomes. Are unaware and unimaginative individuals the most likely to generate antisocial/self-destructive outcomes? What kind of outcomes do the other "types" most often generate? What will help move people into the upper right quadrant of "morally imaginative"? In addition to exploring these questions, other research is also needed to better understand how discerning and developing skills evolve over the course of one's life, how different experiences (both personally and professional) impact these abilities, and how situational factors (i.e. ethical climate, time constraints, etc.) also impact moral imagination and mutually beneficial decision-making. Furthermore, research is needed to 
examine how mutually beneficial decisions are ultimately enacted once they are reached. As referred to previously, just because an individual can cognitively arrive at a mutually beneficial outcome does not guarantee that their idea is translated into successful action. The factors, both individually and contextually, that support the enactment of the mutually beneficial decision is yet another area of inquiry ripe for exploration. For example: What facilitates or prevents an individual from committing to, building consensus for, and implementing a mutually beneficial decision?

Adding such questions will help expand the current conceptual model of moral imagination and mutually beneficial decision-making (see Figure 3). From longitudinal research, to in-depth qualitative interviews, to additional empirical-based research, a variety of inquires are needed, each informing the other, if the nature of these constructs will be fully realized.

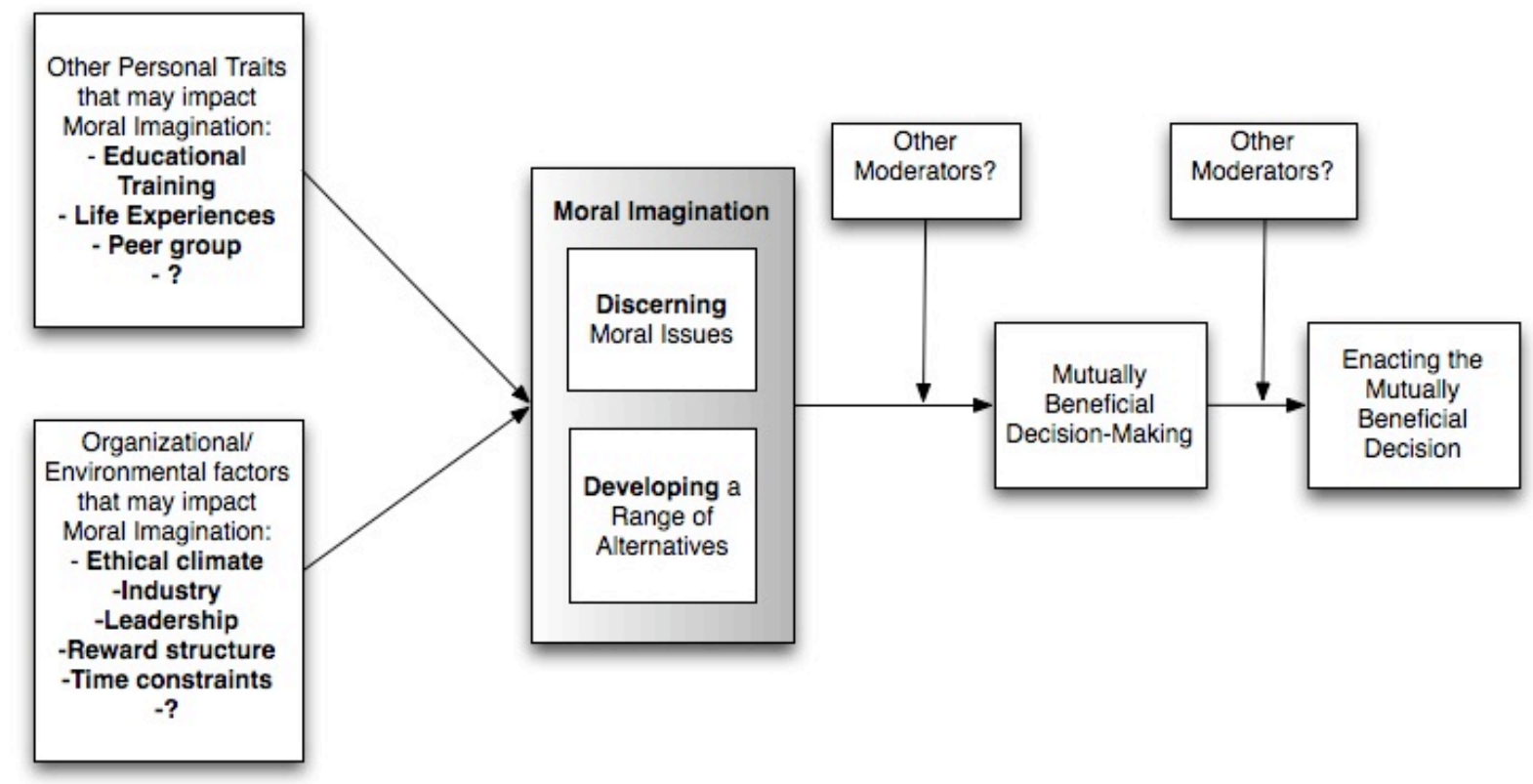

Figure 3: Expanded Conceptual Model 
Although the current study focused on the individual-level of analysis, further theory building and supporting research can also begin to apply the concepts of moral imagination and mutually beneficial decision-making to groups and organizations as a whole. First, looking at groups and teams, even more questions emerge, including: How does team collaboration impact the demonstration of moral imagination? Do collaborative processes lead to greater demonstrations of discernment and development? To more mutually beneficial outcomes? How does team composition (homogenous, heterogeneous, small, large, etc.) impact their ability generate mutually beneficial outcomes? Do groups that represent multiple stakeholders lead to an increase in moral imagination because awareness and creativity are heightened? Future research is needed to begin to answer such questions. The current measure for moral imagination could be expanded to capture if individuals would choose to make a decision alone or collaboratively to see if those with the predilection to collaborate are the same people who most often demonstrate moral imagination. Additionally, future experiments could be designed to compare teams' decision-making outcomes to individuals, looking for differences along discerning, developing, overall moral imagination and type of decisionmaking outcome.

In addition to looking at the group level of analysis, research also is needed to explore moral imagination and its impact on decision-making at the organizational level. How do organizations as a whole cultivate and demonstrate moral imagination? How does an organizational culture foster or impair its ability to generate mutually beneficial decisions? Additionally, the relationship between the individual level and organizational level needs to be explored through questions such as: How do individual decisions lead 
to entire organizational strategies moving toward mutual benefit? Can a business demonstrate mutual benefit only when its top leaders demonstrate moral imagination, or despite when top leaders do not demonstrate it?

Furthermore, we can also begin to unpack what it even means for businesses to act in a mutually beneficial manner. Some have already begun to theorize a more nuanced view of mutual benefit, suggesting that even this construct can be further differentiated. For example, building on the work of Jackson and Nelson (2004), Bright, Fry and Cooperrider (2006), describe three different modes of business activities that may constitute mutually beneficial organizational outcomes, illustrated in Figure 4. In the first mode, organizations are acting with minimal compliance to externally imposed regulations. In the second mode, they go above the minimum and actively look for innovative ways to minimize the negative impact of their company on the environment and even try to leave the world better than they found it. Those organizations who reach the third mode of mutual benefit (which would represent the upper most right area of Quadrant IV) are those who are "game changing" players working to revolutionize industries (or create new ones) by using their business activity to not only reap increased profits, but also deeply benefit society. Companies in this mode have been able to answer the provoking call posed by organizational thought-leader, Peter Drucker, who claimed that "every single pressing social and global issues of our time is a business opportunity." 


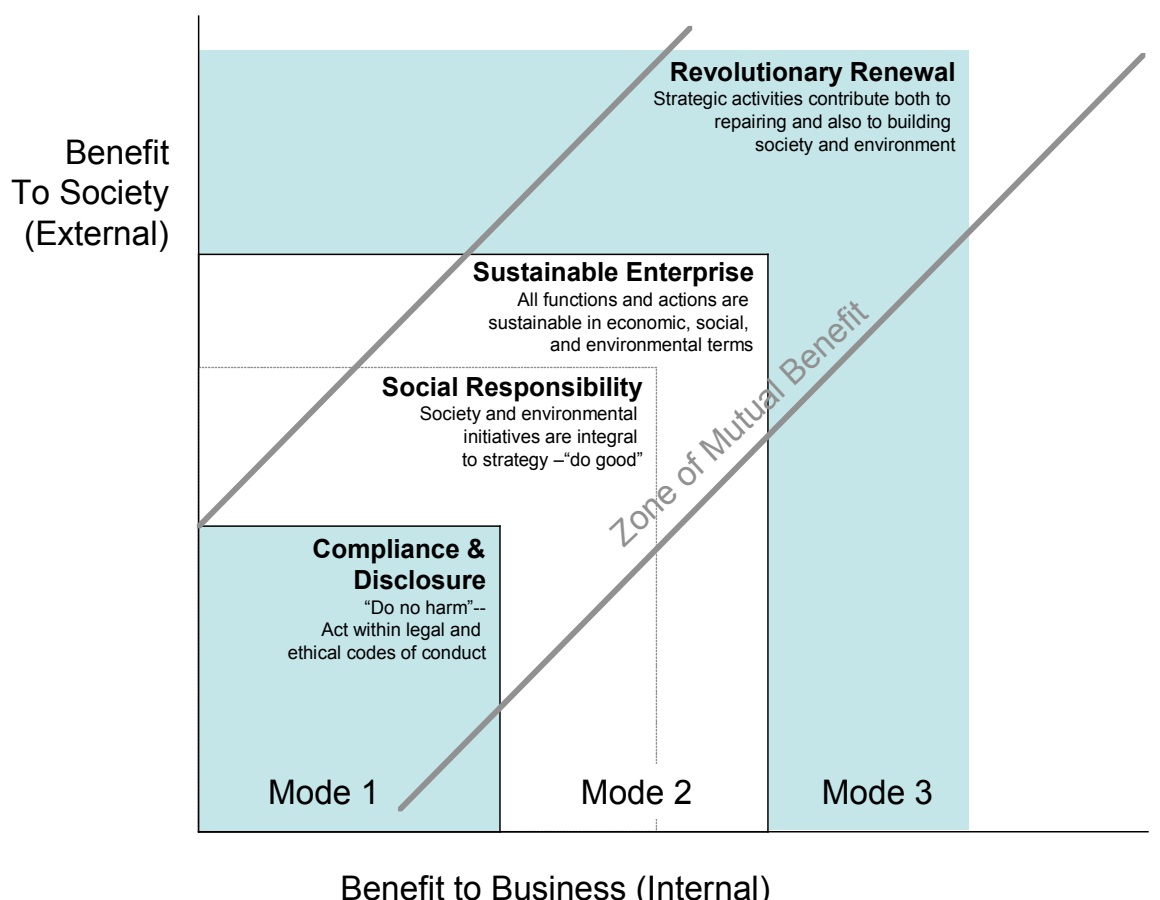

Figure 4: Dimensions and Degrees of Mutual Benefit

From Bright et al (2006), modeled after Jackson and Nelson, 2002

As any future research unfolds, Johnson (1993) claims that "one thing is clear - if we take moral imagination seriously, we are going to have to do some radical rethinking of our culturally inherited notion of morality. We are going to have to take as our principle task, not the formulation of moral laws, but the cultivation of moral imagination," (p. xii). These words ring true whether applied to practice, education, or research.

\section{Concluding Thoughts}

The current study lends support to the postulation that moral awareness combined with a productive imagination are seemingly two important elements in the expression of moral imagination. Findings also suggest that moral imagination is indeed a critical key 
to the understanding of how individuals generate mutually beneficial outcomes. Based on these outcomes, if we want to answer society's growing call for the creation mutual benefit, then we must each learn to open our eyes to the world around us, appreciating the moral aspects that appear, as well as the potentially endless possibilities that exist, for each situation. Moral imagination gives hope that our decisions can help bring about benefit to ourselves, as well as all those around us. Anything we can imagine is possible and the stakes of our decisions, especially in the business arena, are becoming ever greater in the face of ongoing erosion of our social and environmental fabric. It is time for us to begin putting our moral imagination to work to create not only the world we want to live in, but also the world we want to leave to future generations. My favorite poet, Brian Andreas, captures this sentiment ever so eloquently:

In my dream, the angel shrugged \& said, if we fail this time, it will be a failure of imagination \& then she placed the world gently in the palm of my hand. 
APPENDIX A: Survey Instrument

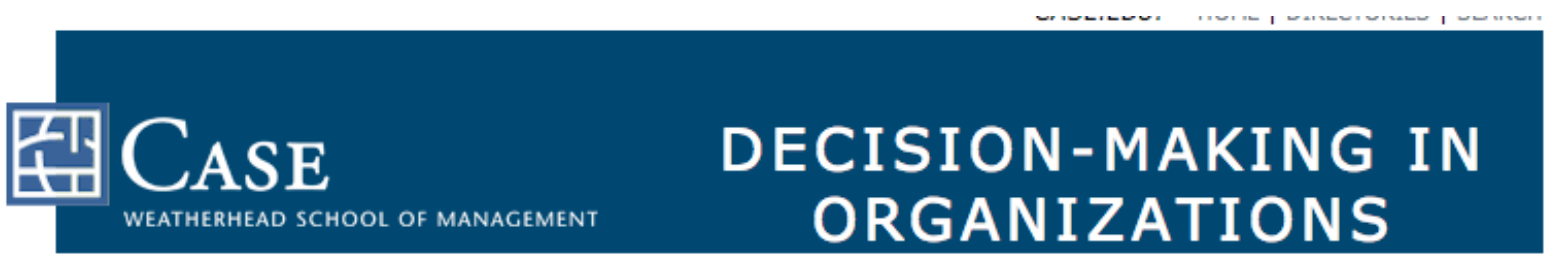

Decision-Making in Organizations

Thank you for your interest in the study! We appreciate your participation and candid responses.

Background Information on the Study and Consent to Participate

The purpose of this study is to learn more about how individuals make decisions in various business situations. The information you provide will be used to inform the researcher's dissertation.

Your participation is voluntary and the total time required to participate is approximately $\mathbf{3 0}$ minutes. Although there is no direct compensation for participating, upon completion of the survey, you will be asked to enter your name in a drawing to win an iPod shuffle the researcher will be raffling off at random at the end of the project.

Your responses will be kept completely confidential. No one in your organization or university will ever have access to your individual responses or have the ability to trace your individual responses. If you are a student, neither participation nor lack of participation, nor the type of data entered can affect your grade in any way in any of the classes you are enrolled.

The researchers conducting this study are Dr. Ronald Fry and Lindsey Godwin. You can have questions addressed by contacting them at Ing2@case.edu.

Feel free to print and retain this page for your records so that you may contact us if you have any questions.

I have read the above and I would like to participate in the survey:

Yes $\square$ No 


\section{SECTION 1: Demographic Information}

Please answer the following questions about yourself.

2) What is your gender?

$\square$ Male $\square$ Female

3) What is your age? (Select One)
$18-20$
$21-24$
$25-29$
$30-34$
$35-39$
$40-44$
$45-49$
50 or older

4) To which ethnic group(s) to you most identify? (Mark all that apply)

5) What is your educational status?

$\square$ Part-Time MBA student currently

$\square$ Full-Time MBA student currently

$\square$ Executive Education student currently

$\square$ Undergraduate student currently

$\square$ Not currently a student (skip to question \#9)

Other (please specify)

6) What school do you currently attend?

7) How long have you been in your current program?

$\square$ less than 6 months

$\square 6$ months - 1 year

1 year -2 years

2 years -3 years

$\square$ years -4 years

$\square$ more than 4 years

8) What is your concentration(s) or major?

9) Are you a member of Net Impact? (yes or no)

10) How many years of work experience do you have?

11) Which of the following describes your present employment status?

$\square$ Employed full-time (35 hours or more per week)

Employed part-time (less then 35 hours per week)

$\square$ Not Employed (Please skip to question 13 on next page) 
12) What type of organization do you work for?

Public sector (e.g. government)

$\square$ Private sector (e.g. most businesses and individuals)

$\square$ Not-for-profit sector

Other (please specify):

\section{SECTION 2: Decision-Making Scenarios}

Please read the following 3 scenarios and answer the questions below each.

\section{Scenario \#1}

You are the CEO of Apple-a-Day, Inc., the leading U.S. manufacturer of healthy foods. This morning your Vice President of Production tells you she just received reports from two separate county health departments who are investigating the possible link between acute food poisoning of a child and an unpasteurized apple product produced by your company.

Every few months you receive reports like these which, to date, have always turned out to be related to another cause and not traceable to your products. You listen with concern, however, knowing that your company's brand has been built on being the highest quality of non-pasteurized foods in the U.S. Your workers take pride in their products and your company has the highest quality standards in the industry for picking, processing, canning and shipping fresh products. Even with the precautions your company takes, you know that contamination could occur any step along the process, from the handling of the fruit at its source to transporting or processing the fruit in your plants, to shipping it to the stores.

During your conversation, you learn that there have just been three more cases reported in other states similar to the first two. Although these are also not conclusive yet in making a link to the illnesses and your product, you are concerned. If there is a problem you want to resolve it, however you are also weary of any bad press that will tarnish your company's reputation and you do not want to cause false panic. Your VP asks you what you want to do.

\section{3) Please answer the following:}

A) Briefly, list as many ways as you can think of to take action on this situation (please separate your responses with a comma).

B) Briefly list the underlying issues that you think are important to consider when deciding on which of the above actions to take in this situation (please separate your responses with a comma).

C) Of the possible actions you generated, indicate which you think is best and briefly explain WHY this choice/option is better than the others you thought of.

D) Briefly list who you think will be impacted by your decision and how they will be impacted. 


\section{Scenario \#2}

You are the CEO of Hearty Harvest, a large-scale agricultural machine manufacturer. Your company has a long history in the business and has a strong reputation for being a good place to work. Employee turnover is very low (it is typical for people to work for the company for 20 years or longer) and morale is very high in part, you believe, thanks to the generous pension and retirement package your company offers. Though not required by law or written into employee contracts, your company promises retirees that they and their spouses will continue to get full health care benefits, in the form of "feefor-service" coverage. Unfortunately, because of a new accounting law, the government is requiring that Hearty Harvest record, and be made liable, for all employee health care costs, present and future in the same way you do for pensions. As such, you must now account for these benefits when they are earned not when they are paid out, as previously done. You accountants estimate this will be approximately 1.8 billion dollars, and that accounting for all the benefits (including current and retired employees) will push the company near bankruptcy. However, you know that cutting or reducing the benefits for retirees will have a significant impact on the employee relations. The Board of Directors is meeting to discuss what can and should be done in this situation.

\section{4) Please answer the following:}

A) Briefly, list as many ways as you can think of to take action on this situation (please separate your responses with a comma).

B) Briefly list the underlying issues that you think are important to consider when deciding on which of the above actions to take in this situation (please separate your responses with a comma).

C) Of the possible actions you generated, indicate which you think is best and briefly explain WHY this choice/option is better than the others you thought of.

D) Briefly list who you think will be impacted by your decision and how they will be impacted.

\section{Scenario \#3}

Although Mathias Labs is one of the leading drug manufacturers in the world, they have not produced any new or extremely profitable drugs for humans in the last ten years. Instead the company has relied on non-human medications like FarmMed (a top seller among veterinarians for treating parasitic infection in cows, sheep, dogs and cats, making it a very profitable drug for the company) to account for the company's $\$ 2$ billion in annual revenues. Unfortunately, the patents on many of their drugs, including FarmMed, is coming to an end, meaning that generic (cheaper) versions will soon be on the market, potentially impacting your revenues. As such, the company has decided to contribute $\$ 1$ billion over the next five years to research for the development of new drugs. On average, it takes 12 years and \$200 million to bring a drug from the laboratory to the market. Recently, chemists doing research for Mathias Labs discovered that the same basic chemical structure of Farmmed was effective in killing a parasitic worm that has been shown to cause Amazon River Blindness (ARB) in humans. This parasite causes severe itching and eventually total blindness in people that it infects. The disease is not found in the U.S., but severely effects poor populations in South America where over 350,000 people are blind due to ARB, more than a million others suffer various stages of the disease and children grow up expecting to 
become blind. Upon news of this discovery, the company has created a committee to decide what the best course of action is to take regarding further research and development of Farmmed for humans. Mathias Labs knows that what it produces and distributes over the next five years will greatly impact its competitive stance in the industry. Given that Farmmed has never been tested on humans, the company must decide if it wants to invest in development of the drug for human consumption. The company also realizes that the population in most need of the drug may never be able to afford the drug. Even if the company does develop it, if it shows negative side effects in humans, it could result in millions of dollars in lawsuits and could hurt the sales of the animal form of the drug. You are a member of Mathias Labs and have been asked to join the committee deliberating on this situation. In preparation for your meeting with the committee, you decide to make a list of the factors that you think should be given the most consideration by the committee when it is making its decision.

15) Please list the top 3 to 5 issues that you would bring up when deciding on what course of action to take. In one sentence, also indicate why this issue is important. Do not indicate what you think the company should do, but rather only the issues that are important to consider when making this decision. Please list one issue at a time.

Issue 1:

Issue 2:

Issue 3:

Issue 4:

Issue 5:

16) Now, rank the responses you generated above in order from 1 to 5 (or 3, or 4), making " 1 " the issue that you would encourage the committee to give the most weight to on its final decision and " 5 " the issue that you would give the least weight to.

\begin{tabular}{|l|l|}
\hline Issue \# & Weighted Rank \\
\hline Issue 1 & \\
\hline Issue 2 & \\
\hline Issue 3 & \\
\hline Issue 4 & \\
\hline Issue 5 & \\
\hline
\end{tabular}

\section{SECTION 3: Personal Opinions}

In this section, you will be asked to respond to a variety of statements according to how much you agree or disagree with them. Please be as honest as possible.

17) Please indicate to what extent you agree with the following statements:

$\begin{array}{lllllllll}1 & 2 & 3 & 4 & 5 & 6 & 7 & 8\end{array}$

Strongly Agree Disagree Strongly

When deciding what to do, one should consider his or her own wants before the wants of others. 
Other people's needs and wants come before mine when making decisions.

If I look out for my own needs first, others seem to do quite well, nevertheless.

People spend to much time worrying about what other people think and feel instead of concentrating on their own thoughts and feelings.

The truth is that people will do best when they consider their own desires before the desires of others.

Although some people don't like to admit it, life is ultimately about "looking out for \#1," that is, oneself.

I have to admit that I like to be the center of attention.

\section{8) Please indicate to what extent you agree with the following statements:}

$\begin{array}{ccccccccc}1 & 2 & 3 & 4 & 5 & 6 & 7 & 8 & 9 \\ \text { Completely disagree } & & & & & & & \text { Completely Agree }\end{array}$

People should make certain that their actions never intentionally harm another, even to a small degree.

Risks to another should never be tolerated, irrespective of how small the risks might be.

The existence of potential harm to others is always wrong, irrespective of the benefits to be gained.

One should never psychologically or physically harm another person.

One should not perform an action which might in any way threaten the dignity and welfare of another individual.

If an action could harm an innocent other, then it should not be done.

Deciding whether or not to perform an act by balancing the positive consequences of the act against the negative consequences of the act is immoral.

The dignity and welfare of people should be the most important concern in any society.

It is never necessary to sacrifice the welfare of others.

Moral actions are those which closely match ideals of the most "perfect" action.

There are no ethical principles that are so important that they should be a part of any code of ethics.

What is ethical varies from one situation and society to another.

Moral standards should be seen as being individualistic; what one person considers to be moral may be judged to be immoral by another person.

Different types of moralities cannot be compared as to rightness.

Questions of what is ethical for everyone can never be resolved since what is moral or immoral is up to the individual.

Moral standards are simply personal rules that indicate how a person should behave, and are not to be applied in making judgments of others.

Ethical considerations in interpersonal relations are so complex that individuals should be allowed to formulate their own individual codes.

Rigidly codifying an ethical position that prevents certain types of actions could stand in the way of better human relations and adjustment.

No rule concerning lying can be formulated; whether a lie is permissible or not permissible totally depends on the situation.

Whether a lie is judged to be moral or immoral depends upon the circumstances surrounding the actions. 
19) Please indicate to what extent you agree with the following statements:

$\begin{array}{llll}1 & 2 & 3 & 4\end{array}$

Strongly Agree

Disagree Strongly

My own personal beliefs seem to be more right than others.

I am open to hear others opinions and let them at least try to change my mind.

Nobody should have beliefs or opinions so strong that they are not willing to

change them.

I consider someone to be ignorant when they do not share my opinion or belief.

Even with evidence against my belief or opinion, I still do not change my mind.

In a debate, I do not bother to consider the validity of the other side.

I accept that many or at least some of my beliefs and/or opinions may be wrong.

I often disassociate from people who disagree with me.

I feel I am flexible towards the beliefs or opinions of everyone else.

My beliefs and opinions will never be changed.

20) The following statements inquire about your thoughts and feelings in a variety of situations. For each item, indicate how well it describes you. Answer as honestly as you can.

$\begin{array}{lllcc}1 & 2 & 3 & 4 & 5 \\ \text { DOES NOT } & & & & \text { DESCRIBES } \\ \text { DESCRIBE ME } & & & & \text { ME VERY WELL }\end{array}$

I sometimes find it difficult to see things from the "other guy's" point of view. I try to look at everybody's side of a disagreement before I make a decision. I sometimes try to understand my friends better by imagining how things look from their perspective.

If I'm sure I'm right about something, I don't waste much time listening to other people's arguments.

I believe that there are two sides to every question and try to look at them both. When I'm upset at someone, I usually try to "put myself in his shoes" for a while. Before criticizing somebody, I try to imagine how I would feel if I were in their place.

21) Listed below are a number of statements concerning personal attitudes and traits. Read each item and decide whether the statement pertains to you personally and mark Yes or No.

Have there been occasions when you took advantage of someone?

Have you sometimes taken unfair advantage of another person?

Are you always willing to admit when you make a mistake?

Are you quick to admit making a mistake?

Do you sometimes try to get even rather than forgive and forget?

Do you sometimes feel resentful when you don't get you own way?

Are you always courteous, even to people who are disagreeable?

Are you always a good listener, no matter to whom you are talking? 


\section{2) Please indicate to what extent you agree with the following statements:}

2

4

5

Strongly Agree

Disagree Strongly

I have often been able to come up with a new idea myself based on an idea from someone else.

New ideas seldom work out

Most people never really open their minds to all the possible options or alternatives when considering solutions to a problem.

I am often too embarrassed to suggest my wild ideas.

I really enjoy the challenge of finding a different way to solve a problem

Some people really surprise me with their new ideas.

Most innovations occur because of needs or problems

When I get a new idea, I get really excited.

All people have creative ideas from time to time.

Crazy sounding ideas can really come to something

Listening to other people's ideas is a waste of time.

The more problems I have, the more opportunities I have

Only smart, knowledgeable people have good ideas. 
APPENDIX B: Coding Rubric for Moral Awareness Measure

From Jordan (2005)

Rating Scale:

$\begin{array}{ccccccc}1 & 2 & 3 & 4 & 5 & 6 & 7 \\ \text { Not at All } & & & & & & \text { Almost Entirely }\end{array}$

1. How much does this response incorporate issues that directly affect the financial profitability of the corporation involved?

2. How much does this response incorporate issues that directly affect the viability, longevity, or competitive stance of the corporation involved?

3. How much does this response incorporate issues that directly affect the legal culpability of the corporation involved?

4. How much does this response incorporate issues that directly affect the industry image or public reputation

5. How much does this response incorporate issues that directly affect the well-being (financial, physical, or emotional) of the human beings in powerful positions (not including the executives making the decision) who are affected by this decision's outcome. By powerful positions, I mean those who hold direct power over the corporation's fiscal stability (e.g. shareholders, investors, etc.)

6. How much does this response incorporate issues that directly affect the well-being (financial, physical, or emotional) of the human beings in non-powerful positions (not including the executives making the decision) who are affected by this decision's outcome. By non-powerful positions, I mean those who do not hold direct power over the corporation's fiscal stability (e.g. non-managerial employees, community residents, etc.).

7. How much does this response incorporate issues that directly affect the well-being and/or prosperity of the community and/or society affected by this decision's outcome?

8. How much does this response explicitly address the ethical or moral responsibility of the corporation involved? 


\section{REFERENCES}

ABC News .2006. Enron Verdict: Ken Lay Guilty on All Counts. Article by Gina Sunseri and Sylvie Rottman. Retrieved March 1, 2008 from: http://abcnews.go.com/Business/LegalCenter/story?id=2003728\&page=1

Adler, P. S. 2002. Corporate Scandals: It's Time for Reflection in Business Schools. Academy of Management Executive, 16(3): 148-149.

Adolphson, D. 2004. A New Perspective on Ethics, Ecology and Economics. Journal of Business Ethics, 54(3): 203-216.

Alligood, M. R. 1991. Testing Rogers' theory of accelerating change. The relationships among creativity, actualization, and empathy in persons 18 to 92 years of age. Western Journal of Nursing Research, 13, 84-96.

Alker, H. A., \& Poppen, P. J. 1973. Personality and ideology in university students. Journal of Personality, 41, 652-67

Arnold, D., \& Hartman, L. 2003. Moral Imagination and the Future of Sweatshops. Business and Society Review, 108(4): 425-461.

Aspen Institute: Business and Society Program. 2002. Where will They Lead? MBA students attitudes about business and society.

Aspen Institute: Business and Society Program. 2006. Teaching Innovation Program. http://www.aspeninstitute.org/site/c.huLWJeMRKpH/b.612443/k.8512/Teaching_ Innovation_Program.htm

Baer, J. 2005. Gender and creativity. Paper presented at the Annual Meeting of the American Psychological Association, Washington, DC

Bandura, A. 1977. Social Learning Theory. Englewood Cliffs, New Jersey: Prentice-Hall.

Bandura, A. 1986. Social Foundations of Thought and Action. Englewood Cliffs, New Jersey, Prentice-Hall.

Basadur, M. and Hausdorf, P. 1996. Measuring Divergent Thinking Attitudes Related to Creative Problem Solving and Innovation Management. Creativity Research Journal. 9:1, 21-32.

Basadur, M. S., Graen, G. B., and Scandura, T. A. 1986. Training effects on attitudes toward divergent thinking among manufacturing engineers. Journal of Applied Psychology, 7I.612-617.

Basadur, M. S., Graen, G. B., \& Green, G. B. 1982. Training in creative problem 
solving: Effects on ideation and problem finding in an applied research organization. Organizational Behavior and Human Performance, 30,41-70.

Bennis, W.G. and J. O'Toole, 2005. How Business Schools Lost Their Way. Harvard Business Review (May): 96-104.

Besemer, S. and O'Quin, K. 1993. Assessing Creative Products: Progress and potentials. In S.G. Isaken, M.C. Murdock, R.L. Firestein and D.J. Treffinger (Eds.), The emergence of a discipline: Nuturing and developing creativity. (p. 331-349). Norwood, NJ: Ablex.

Black, J. 1980. The Influence of Dogmatism on Ethical Behavior of Journalistic Gatekeepers. Paper presented at the Annual Meeting of the Association for Education in Journalism (63rd, Boston, MA, August 9-13)

Bowman, J. T., and Reeves, T. G. 1987. Moral development and empathy in counseling. Counselor Education and Supervision, 26(4): 293-298.

Bright, D.S., Fry, R.E., and Cooperrider, D.L. (2006). Transformative innovations for the mutual benefit of business society, and environment. BAWB Interactive Working Paper Series 1(1):17-31. http://worldbenefit.case.edu/research/paperseries/?p=21.

Business as Agent of World Benefit (BAWB) Summit. 2005. The Future of Management Education at the Intersection of Business and Society: Designing the School within the School for Business as an Agent of World Benefit http://worldbenefit.case.edu/center/summit_2005.cfm

Business as Agent of World Benefit (BAWB) Global Forum. 2006. http://www.bawbglobalforum.org/

Butterfield, K. D., L. K. Trevino, and G.R. Weaver. 2000. Moral Awareness in Business Organizations: Influences of issue-related and social context factors. Human Relations 53(7): 982-1018.

Cameron, K. S. 2003. Organizational Virtuousness and Performance. San Francisco: Berrett Koehler.

Cameron, K. S., \& Quinn, R. E. 1999. Diagnosing and Changing Organizational Culture. Reading: Addison-Wesley.

Carroll, A. 1978. Linking business ethics to behavior in organizations. SAM Advanced Management Journal, 43, 4-11.

Carroll, A. 1999. Corporate Social Responsibility: Evolution of a Definitional Construct. Business \& Society, 38(3): 268-295. 
Cattell, R. B. (1971). Abilities: Their structure, growth, and action. Boston: Houghton Mifflin.

CBS News. 2002. Poll: Little Faith in Big Biz. New York. Retrieved March 1, 2008: http://www.cbsnews.com/stories/2002/07/10/opinion/polls/main514732.shtml

Center for Corporate Citizenship at Boston College. 2005. The state of corporate citizenship in the U.S.: Business perspectives in 2005. Working Paper Series

Charan, R., \& Colvin, G. 1999. Why CEOs Fail, Fortune, Vol. June 21: 69.

Cohen, J., L. Pant, et al. 2004. An Examination of Differences in Ethical DecisionMaking Between Canadian Business Students and Accounting Professionals. Journal of Business Ethics 30(4): 319-336.

Conry, E. J. and D. R. Nelson: 1989, 'Business Law and Moral Growth', American Business Law Journal 27, 1-39.

Crowne, D.P. and Marlowe, D. 1960. A new scale of social desirability independent of psychopathology. Journal of Consulting Psychology, 24, 349-354.

Davis, M. 1980. A multidimensional approach to individual differences in empathy. Catalog of Selected Documents in Psychology, I0(4), 1-17.

Davis, M. 1983. Measuring individual differences in empathy: Evidence for a multidimensional approach. Journal of Personality and Social Psychology, 44(1), 113-126.

Davis, M., M. Andersen, et al. 2001. Measuring ethical ideology in business ethics: A critical analysis of the ethics position questionnaire. Journal of Business Ethics 32(1): 35-54.

Donaldson, S.I., and Grant-Vallone, E. J. 2002. Understanding self-report bias in organizational behavior research. Journal of Business and Psychology, 17(2), 245-262.

Drumwright, M., \& Murphy, P. 2004. How Advertising Practitioners View Ethics. Journal of Advertising, 33(2): 7-24.

Duan. C, and Hill. C. E. 1996. The current state of empathy research, journal of Counseling Psychology, 43; 261-274.

Emiliani, M. L. 2004. Is Management Education Beneficial to Society? Management Decision, 42(3/4): 481-498.

Encarta Encyclopedia. 1999. Microsoft Software.

Essex, E. 2005. The Corporate Journey Towards Environmental and Social 
Responsibility: Contradictions, Activism and Intuitive Vision. Case Western Reserve University.

Estes, R. 1996. Tyranny of the Bottom Line: Why Corporations Make Good

People Do Bad Thing. San Francisco, Berrett-Koehler Publishers.

Etzioni, A. 1991. Reflections on Teaching Business Ethics. Business Ethics Quarterly, 1(4): 355-365.

Fiske, S. T. and S. E. Taylor. 1991. Social Cognition. New York, Random House

Foder, E. M., \& Greenier, K. D. 1995. The power motive, self-affect, and creativity. Journal of Research in Personality, 29: 242-252.

Forsyth, D. R.: 1980, ‘A taxonomy of ethical ideologies', Journal of Personality and Social Psychology 39(1), 175-184.

Forsyth, D. R.: 1992, 'Judging the morality of business practices: The influence of personal moral philosophies', Journal of Business Ethics 11, 461-470. Administrative Science Quarterly 23, 224-253.

Freeman, R. Edward (1984). Strategic Management: A Stakeholder Approach. Boston: Pitman.

Freeman, R. E. 1994. The politics of stakeholder theory. Business Ethics Quarerly. 4(4) $409-421$

Fredickson, B. 1998. What Good are Positive Emotions? Review of General Psychology, 2(3): 300-319.

Friedman, M. 1970. The Social Responsibility of Business is to Increase Profits. The New York Times Magazine (September), pp.32-33.

Gerber, E.R., Wellens, T.R., and Keeley, C. 1996. Who Lives Here: The Use of Vignettes in Household Roster Research, Proceedings of the Section on Survey Research Methods, American Statistical Association, Alexandria, VA, p. 962-967.

Ghoshal, S. 2005. Bad Management Theories are Destroying Good Management Practices. Academy of Management Learning and Education, 4(1): 75-91.

Giacalone, R. A. 2004. A Transcendent Business Education for the 21st Century. Academy of Management Learning and Education, 3(4): 415-420.

Guilford, J. P. (1950). Creativity. American Psychologist, 5,444-454. 
Gilligan, C. 1982. In a different voice: psychological theory and women's development. Cambridge, MA: Harvard University Press.

Gioia, D. A. 2002. Business Education's Role in the Crisis of Corporate Confidence. Academy of Management Executive, 16(3): 142-144.

Grey, C. 2004. Reinventing Business Schools: The Contribution of Critical Management Education. Academy of Management Learning and Education, 3(2): 178-186.

Gruber HE. 1993. Creativity in the moral domain: ought implies can implies create. Creativity Research Journal. 6:3-16 Jakab PL. 1999.

Halpin, G., Halpin, G., \& Torrance, E. P. 1974. Relationships between creative thinking abilities and a measure of the creative personality. Educational and Psychological Measurement, 34: 75-82.

Hart, Stuart. 2005. Capitalism at the crossroads. Wharton School Publishing Co., Philadelphia, Pennsylvania

Hart, S., \& Milstein, M. 2003. Creating Sustainable Value. Academy of Management Executive, 17(2): 56--69.

Hart, S., \& Sharma, S. 2004. Engaging fringe stakeholder for competitive imagination. Academy of Management Executive, 18(1).

Hinman, L. 2005. Moral Imagination: What it is, and why you need it in business, law, and life.

Hogan, R. 1969. Development of an empathy scale. Journal of Consulting and Clinical Psychology, 33, 307-316.

Huck, S. W. 2004. Reading statistics and research. 4th Edition. New York, NY: Allyn \& Bacon.

Isen, A. M. 1987. Positive affect, cognitive processes and social behavior. Advances in Experiemental Social Psychology, 20: 203-253.

Isen, A. M., Daubman, K. A., \& Nowicki, G. P. 1987. Positive affect facilitates creative problem solving. Journal of Personality and Social Psychology, 52: 1122-1131.

Jackson, I., \& Nelson, J. 2004. Profits with Principles. New York: Currency-Doubleday.

Jacobs, J. 1991. Moral Imagination, Objectivity and Practical Wisdom. International Philosophical Quarterly, 31(23-37). 
Johnson, M. 1993a. Imagination in Moral Judgment. Philosophy and phenomenological research, 46(265-280).

Johnson, M. 1993b. Moral Imagination: Implications of Cognitive Science for Ethics. Chicago: University of Chicago Press.

Jones, T. M. 1991. Ethical Decision making by individuals in organizations: An issuecontingent model. Academy of Management Review, 16: 366-395.

Jones J. 1989. Personality and epistemology: Cognitive social learning theory as a philosophy of science. Zygon, 24(1):23-38.

Jordan, J. 2005. Business Experience and Moral Awareness: When Less May Be More. Yale University

Kellerman, B. 2004. Bad Leadership: What it is, How it Happens, Why it Matters. Boston Harvard Business School Press.

Kerr, G., \& Gagliardi, C. 2004. Measuring creativity in research and practice: Arizona State University, Tempe, AZ.

Kohlberg, L. 1969. Stage and sequence: The cognitive-developmental approach to socialization. In D. A. Goslin (Ed.), Handbook of Socialization and Research: 347-480. Chicago: Rand McNally.

LaForge, P. (2004). Cultivating Moral Imagination through Mediation. Journal of Business Ethics. 51(1):15-29.

Larmore, C. 1981. Moral Judgment. Review of Metaphysics, 35: 275-296.

Laszlo, C. 2003. The Sustainable Company: How to Create Lasting Value through Social and Environmental Performance: Island Press.

Lee, L. C. 1971. The concomitant development of cognitive and moral modes of thought: a test of selected deductions from Piaget's theory. Genetic Psychology Monographs, 83, 93-146.

Lux, K. 1990. Adam Smith's Mistake. Shambhala.

Margolis, J. D., \& Walsh, J. P. 2001. People and Profits? The Search for a Link Between a Company's Social and Financial Performance. Mahwah, NJ: Lawrence Erlbaum Associates.

McConell, D. and J. LeCapiaine. 1985 The Effects of Group Creativity Training on Teachers' Empathy and Interactions with Students. Reading Improvement. 25(4), 269-275. 
Mehrabian, A. \& Epstein, N. 1972. A measure of emotional empathy. Journal of Personality, 40(4), 525-543

Minkes, A. L., Small, M. W., \& Chatterjee, S. R. 1999. Leadership and Business Ethics: Does It Matter? Implications for Management. Journal of Business Ethics, 20(4): 327-335.

Mischel, W. 1973. Towards a Cognitive, Social Learning Reconception of Personality. Psychological Review 80(252-83).

Mitroff, I., \& Swanson, D. 2004. An Open Letter to the Deans and the Faculties of American Business Schools: A Call for Action. Academy of Management News, 35(2): 6-8.

Morrison, R., K. Stettler, and A. Anderson. 2004. Using Vignettes in Cognitive Research on Establishment Surveys. Journal of Official Statistics. 20(2): 319-340.

Mott, P E. (1972). The characteristics of effective organizations. New York: Harper \& Row.

Mumford, M. and Gustafson, S. 1988. Creativity Syndrome: Integration, Application and Innovation. Psychological Bulletin, 103, 27-43.

Mumford, M. D., Marks, M. A., Connelly, M. S., Zaccaro, S. J., and Johnson, J. F. 1998. Domain-based scoring of divergent thinking tests: Validation evidence in an occupational sample. Creativity Research Journal, 11, 151-163.

Paine, L. S. 2003. Value Shift. New York: McGraw-Hill.

Park, H. 2005. The Role of Idealism and Relativism as Dispositional Characteristics in the Socially Responsible Decision-Making Process. Journal of Business Ethics 56(1): 81-98.

Parker, S. and C. Axtell. 2001. Seeing Another Viewpoint: Antecedents and Outcomes of Employee Perspective Taking. Academy of Management Journal. 44(6), p. 10851100.

Pasha, S. and Seid, J. 2006. Lay and Skilling's Day of Reckoning. CNN Money.com, retrieved March 2, 2008 from http://money.cnn.com/2006/05/25/news/newsmakers/enron_verdict/index.htm

Pask, E. 1997. Developing Moral Imagination and the Influence of Belief. Nursing Ethics, 4(3): 202-210. 
Paul, P. 2002. The Bottom Line - consumer attitudes towards big business, corporate scandals, American Demographics.

PBS. 2005. Bigger than Enron, Frontline.

Peirchy, L. 2001. The Impact of Personal Gains on Cognitive Dissonance for Business Ethics Judgments. Teaching Business Ethics, 5(1): 21-33.

Piaget, J. 1932. The Moral Judgment of the Child: Routlege and Kegan Paul.

Plucker, J. A., and Renzulli, J. S. (1999). Psychometric approaches to the study of human creativity. In R. J. Sternberg (Ed.), Handbook of creativity (pp. 35-61). Cambridge, England: Cambridge University Press.

Post, S. 2003. Unlimited Love. Randor, PA: Templeton Foundation Press.

Powers, C., and Vogel, D. 1980. Ethics in the Education of Business Managers. Hastingson-Hudson, NY: The Hastings Center.

Prahalad, C. K. 2004. The Fortune at the Bottom of the Pyramid: Eradicating Poverty Through Profits. Upper Saddle River: Wearton School Publishing.

Quinn, R. E., and Rohrbaugh, J. 1983. A Spatial model of effectiveness criteria: Towards a competing values approach to organizational analysis. Management Science, 29: 363-377.

Ray, J.J. 1984. The reliability of short social desirability scales. Journal of Social Psychology, 123, 133-134.

Reynolds, S. 2006. Moral Awareness and Ethical Predispositions: Investigating the Role of Individual Differences in the Recognition of Moral Issues. Journal of Applied Psychology 91(1): 233-243.

Rest, J.R. 1979. Defining Issues Test. Minnesota: University of Minnesota.

Rest, J. R. 1986. Moral development: Advances in research and theory. New York: Preager.

Rest, J.R. 1994. Background: Theory and research. In J. Rest \& D. Narvaez (Eds.), Moral development in the professions: Psychology and applied ethics. Hillsdale, NJ: Lawrence Erlbaum Associates.

Richmond, K. 2001. Ethical Reasoning, Machiavellian Behavior, and Gender: The Impact on Accounting Students' Ethical Decision Making. Virginia Polytechnic Institute and State University. Retrieved March 1, 2008, from http://scholar.lib.vt.edu/theses/available/etd-04252001- 
131758/unrestricted/richmond.pdf.prn.pdf

Rocha, H. and Ghoshal, S. 2006. Beyond Self-Interest Revisited. Journal of Management Studies, 43:3, p. 585-619.

Rubin, K.H. (1973). Egocentrism in childhood: A unitary construct? Child Development, $44,102-110$.

Runco, M. 2004. Creativity. Annual Review of Psychology. 55:657-87.

Schultze R. H. K. 1962. A Shortened Version of the Rokeach Dogmaitism Scale. Journal of Psychological Studies, Vol. 13, No. 2, 93-97.

Scratchley, L. and A. R. Hakstain. 2001. The Measurement and Prediction of Managerial Creativity. Creativity Research Journal 13(3\&4): 367-384.

Seabright, M., and Schminke, M. 2002. Immoral Imagination and Revenge in Organizations. Journal of Business Ethics, 28(1/2): 19-31.

Selman, R. L. 1971. The relation of role taking to the development of moral judgment in children. Child Development, 42, 79-91.

Shannon, J. R., and Berl, R. L. 1997. Are we teaching ethics in marketing? A survey of student attitudes and perceptions. Journal of Business Ethics, 16: 34-42.

Shaub, M. K., D. W. Finn, et al. 1993. The effects of auditor's ethical orientation on commitment and ethical sensitivity. Behavioral Research in Accounting, 5: 14569.

Shaub, M. (1989). An Empirical Examination of the Determinants of Auditors' Ethical Sensitivity. Unpublished doctoral dissertation. Texas Technological UniversityLubbock.

Singhapakdi, A. 2004. Important Factors Underlying Ethical Intentions of Students: Implications for Marketing Education. Journal of Marketing Education, 26(4): 261- 270.

Singhapakdi, A., K. Kraft, et al. 1995. The Perceived Importance of Ethics and Social Responsibility on Organizational Effectiveness, Journal of the Academy of Marketing Science, 23(Winter): 49-56.

Smith, A. 1776. An Inquiry into the Nature and Causes of the Wealth of Nations

Smith, A. W., Hill, \& Barber. 1989. Creativity in Individuals: A Conceptual Extension of Kirton's Adaptation-Innovation Inventory. Paper presented at the Best Paper Proceedings: Academy of Management, Washington, DC. 
Sparks, J. R. and S. D. Hunt: 1998, 'Marketing researcher ethical sensitivity: Conceptualization, measurement, and exploratory investigation', Journal of Marketing 62, 92-109.

Sternberg, R. J. 2002. Smart people are not stupid, but they sure can be foolish: The imbalance theory of foolishness. In R. J. Sternberg (Ed.), Why smart people can be so stupid: 232-242. New Haven: Yale University Press.

Sundaram, A. K., A. C. Inkpen. 2004. The corporate objective revisited. Organizational Science. 15(3) 350-363.

Torrance, E. P. Torrance Tests of Creative Thinking: Norms-technical manual. Princeton. New Jersey: Personnel Press/ Ginn, 1974.

Trevino, L. K., \& Brown, M. E. 2004. Managing to be ethical: Debunking five business ethics myths. Academy of Management Executive, 18: 69-77.

Unsworth, K. 2001. Unpacking Creativity. Academy of Management Review, 26(2): 289297.

Vidaver-Cohen, D. 1997. Moral imagination in organizational problem-solving: An institutional perspective. Business Ethics Quarterly, 7(4), 1-26.

Villegas de Posada, C. 2005 Some problems in use of the Moral Judgment Test. Psychological Reports, 96, 698-700.

Waddock, S. 2003. A Radical Agenda for Business in Society Education. Paper presented at the Academy of Management Annual Meeting, Seattle, Washington.

Wallach, M.A., Kogan, N., 1965. Modes of Thinking in Young Children: A Study of the Creativity and Intelligence Distinction. Holt, Rinehart and Winston, New York

Werhane, P. H. 1998. Moral Imagination and the Search for Ethical Decision-Making in Management. Business Ethics Quarterly, 1: 75-98.

Werhane, P. H. 1999. Moral Imagination and Management Decision-Making New York: Oxford University Press.

World-Inquiry. 2006. Innovation Bank. Case Weatherhead School of Management.

Yetmar, S., Eastman, K. K. 2000. Tax Practioner's Ethical Sensitivity: A Model and Empirical Examination. Journal of Business Ethics, 26(4), 271-288. 